\title{
PRELIMINARY INVESTIGATION OF THE POTENTIAL OF MESOPOROUS BIOACTIVE GLASSES TO TREAT HEMORRHAGE
}

\author{
by \\ Md Saidur Rahman \\ B.Sc. in Mechanical Engineering, Chittagong University of Engineering and Technology, \\ Bangladesh, 2009 \\ A thesis presented to Ryerson University \\ in partial fulfillment of the requirements for the degree of \\ Master of Applied Science \\ in the program of \\ Mechanical and Industrial Engineering
}

Toronto, Ontario, Canada, 2018

(C) Md Saidur Rahman, 2018 


\section{Author's declaration}

I hereby declare that I am the sole author of this thesis. This is a true copy of the thesis, including any required final revisions, as accepted by my examiners.

I authorize Ryerson University to lend this thesis to other institutions or individuals for the purpose of scholarly research.

I further authorize Ryerson University to reproduce this thesis by photocopying or by other

means, in total or in part, at the request of other institutions or individuals for the purpose of scholarly research.

I understand that my thesis may be made electronically available to the public. 


\section{Abstract
Preliminary investigation of the potential of mesoporous bioactive glasses to treat hemorrhage Md Saidur Rahman \\ Master of Applied Science, 2018 \\ Mechanical and Industrial Engineering Ryerson University}

Hemorrhage is the primary cause of death in both trauma and war. Commercially available hemostats cannot achieve hemostasis within two minutes of application and cannot inhibit bacterial infection, which are the properties of an ideal hemostatic agent. Organic hemostats are acidic in nature and can lead to inflammation. Inorganic hemostats can achieve hemostasis with fewer complications. Mesoporous bioactive glasses (MBGs) are inorganic agents that possess high surface area, pore volume and ordered channel structure. They have the potential to act as molecular sieves for platelets and other serum proteins to aggregate.

Calcination heating rate is a major processing parameter during the synthesis of MBGs. Any variation in calcination heating rate could alter the physical properties of MBGs, affecting their ability to facilitate clotting. A low heating rate is preferred because it can yield more ordered mesoporous channel structures.

A series of novel MBGs based on the glass composition (80-x) $\mathrm{SiO}_{2}-15 \mathrm{CaO}-5 \mathrm{P}_{2} \mathrm{O}_{5}-\mathrm{x} \mathrm{Ta}_{2} \mathrm{O}_{5}(\mathrm{~mol} \%)$ were synthetized using a $1^{\circ} \mathrm{C} /$ min calcination heating rate. The effect of $\mathrm{T}_{\mathrm{a}}$ incorporation on the glass structure was investigated. X-ray diffraction revealed that all glasses were completely amorphous. Fourier transform infrared spectroscopy showed that higher concentrations of $\mathrm{T}_{\mathrm{a}}(5$ and $10 \mathrm{~mol} \%)$ in the glass structure acted as a network modifier which disrupts the silica backbone and leads to discontinuities in porous channel structures, confirmed by transmission electron microscopy. Brunauer-Emmett-Teller (BET) theory quantified the effects of the discontinuities through surface area measurement. It was found that MBGs with 0 and $0.5 \mathrm{~mol} \%$ of $\mathrm{Ta}_{2} \mathrm{O}_{5}$ in the glass structure had 373.87 and $373.98 \mathrm{~m}^{2} / \mathrm{g}$ surface area respectively indicating that such low levels of Ta incorporation did not influence surface area. The addition of further Ta in the glass structure reduced surface area and produced more discontinuities in the channel structure. 1, 5 and $10 \mathrm{~mol} \% \mathrm{~T}_{\mathrm{a}}$ had approximately 5, 12 and 20\% reduced surface area compared to $0 \mathrm{~mol} \%$ $\mathrm{T}_{\mathrm{a}}$ in the glass structure. The whole blood coagulation study indicated that MBGs with lower concentrations of $\mathrm{T}_{\mathrm{a}}(0$ and $0.5 \mathrm{~mol} \%)$ could achieve $58 \%$ and $46 \%$ hemostatic efficiency, which decreased as tantalum content increased.

It is concluded that the application of a low heating rate during calcination, of the order of $1{ }^{\circ} \mathrm{C} / \mathrm{min}$, is more likely to result in mesoporous bioactive glasses with high surface area and pore volume than MBG samples processed at a higher heating rate. MBGs containing 0 and $0.5 \mathrm{~mol} \%$ Ta could be potential hemostatic agent. 


\section{Acknowledgements}

I owe my deepest gratitude to my supervisor Professor Dr. Mark Towler for his proper guidance and continuous support during my master's degree. His enthusiasm, motivation and immense knowledge helped me to achieve the goal of this research. I could not have ever imagined working with an excellent supervisor like Mark Towler and I was really fortunate.

I am fully indebted to my colleague Andrew Mendonca for his time, invaluable discussions, laboratory analysis and his sagacity on structural chemistry. Thanks Andrew.

I would like to thank the Canadian Institute of Health Research (CIHR) Project [appl. \# 366716. A novel approach to treating hemorrhage with mesoporous bioactive glasses] for the financial support during my masters. I would like to show my gratitude to the Mechanical and Industrial Engineering Department for early financial assistance of my stipend.

I am grateful to Dr. Adel Alhalawani for his advice and directions to write this thesis and critical discussions about different results.

I also would like to thank my committee chair Professor Dr. Ahmad Ghasempoor and committee members Professor Dr. Jacob Friedman, Professor Dr. Scott S.H. Tsai for their expertise, continuous support and insightful comments.

Finally, I must express my gratitude to my parents, my brother, sister and my wife who were always with me during the hard times, and especially to my sister, who always inspired me about graduate studies.

Thank you all. 


\section{Dedication}

This thesis is dedicated to my father Md. Mozibur Rahman, my mother Shahana Begum, my

brother Md. Monsur Rahman, my younger sister Faria Rahman Rosy and my wife Sayfullah Nandita. 


\section{Table of contents}

Author's declaration $\quad$ ii

Abstract iii

Acknowledgements

Dedication $\quad$ v

List of tables $\quad$ ix

List of figures $\quad x$

Nomenclature $\quad$ xiii

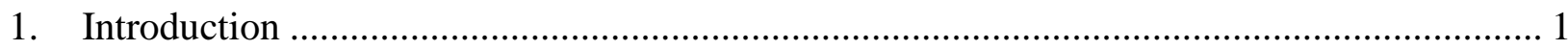

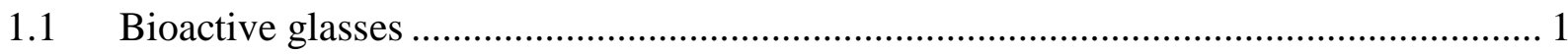

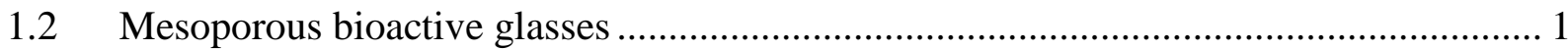

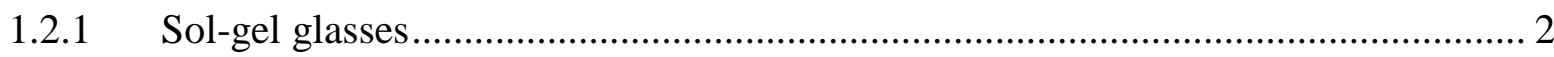

1.2.2 EISA (Evaporation induced self-assembly) .................................................... 3

1.3 Difference between melt quench and sol-gel glasses .............................................. 4

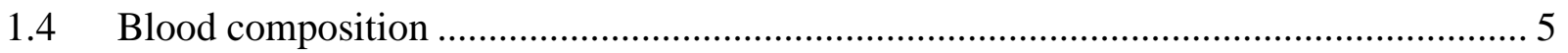

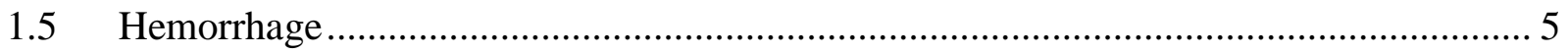

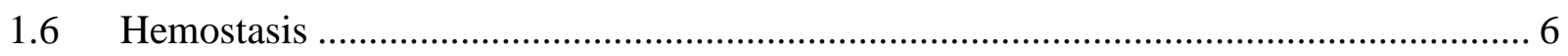

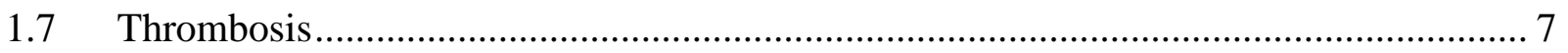

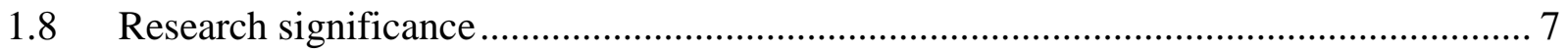

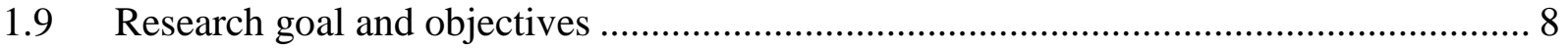

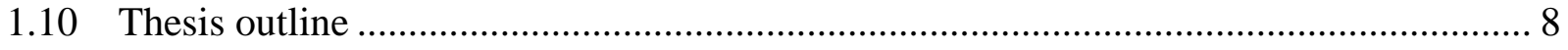

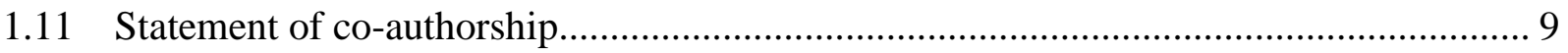

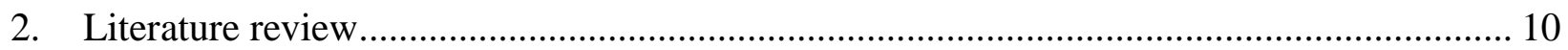

2.1 Parameters that control the physical structure of MBGs.......................................... 10

2.2 Commercial hemostatic agents............................................................................. 11

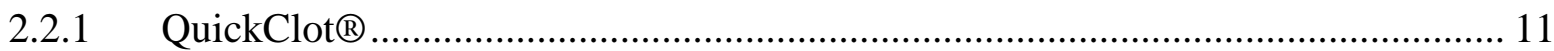

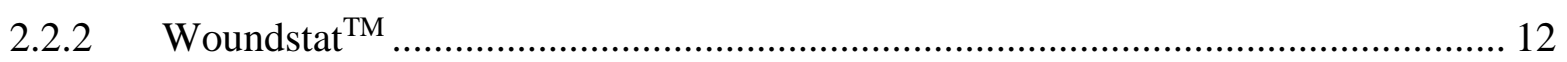

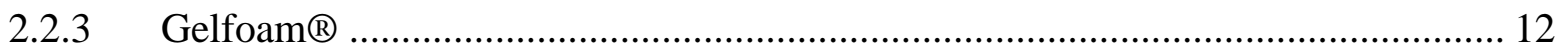

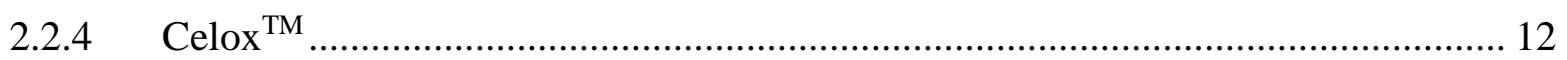

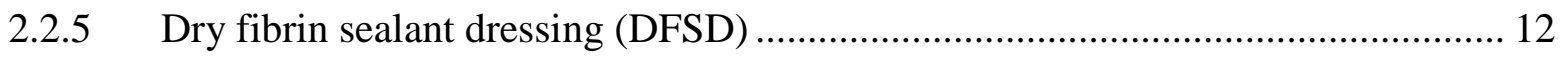

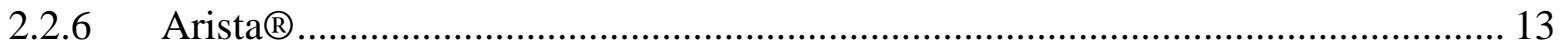

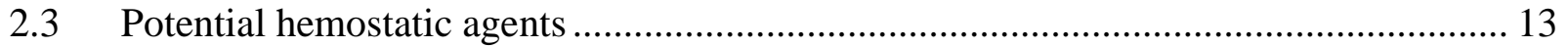

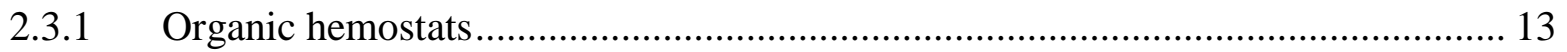




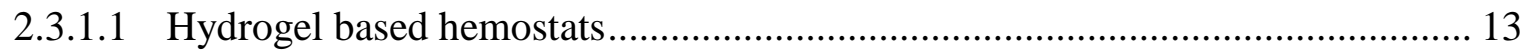

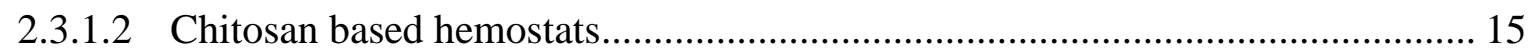

2.3.1.3 Micro and nano particles ........................................................................... 16

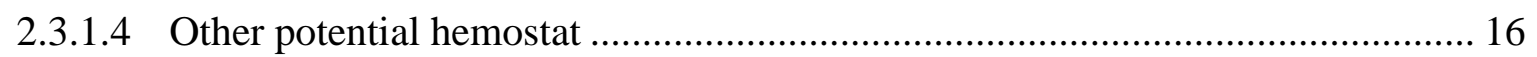

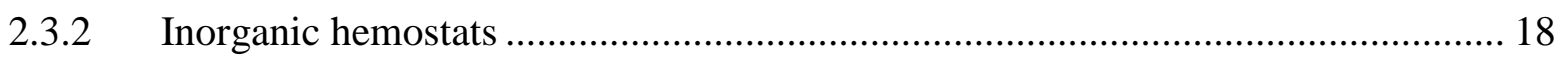

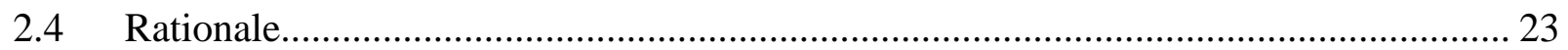

3. The Effect of Calcination Heating Rate on the Structure of Mesoporous Bioactive

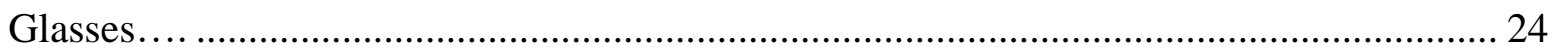

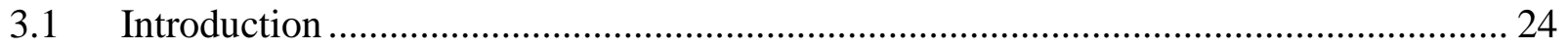

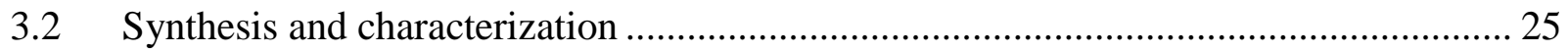

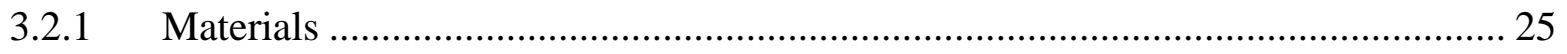

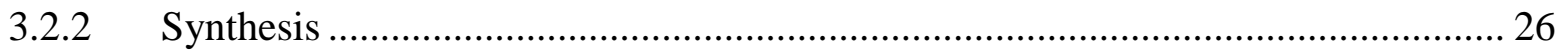

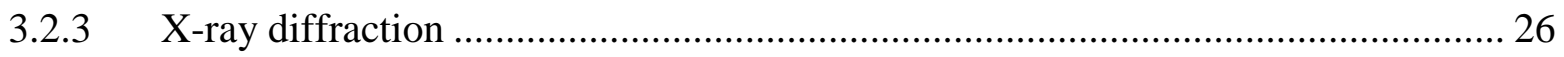

3.2.4 Energy dispersive X-ray spectroscopy (EDS) and X-ray photoelectron

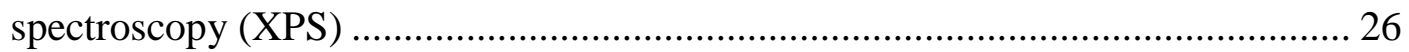

3.2.5 Fourier transform infrared (FT-IR) spectroscopy ………........................................ 27

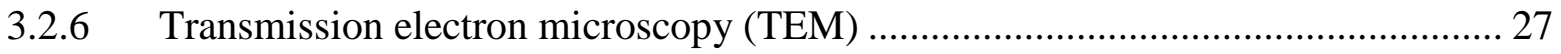

3.2.7 Brunauer-Emmett-Teller (BET) and Barrett-Joyner-Halenda (BJH) analysis ....... 27

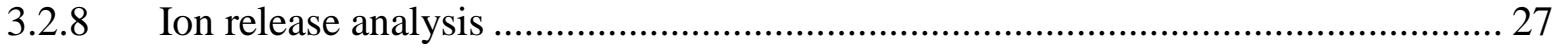

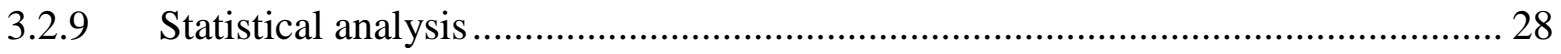

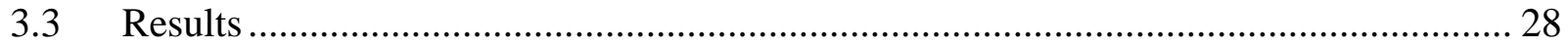

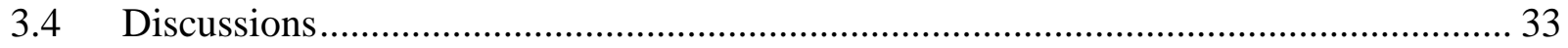

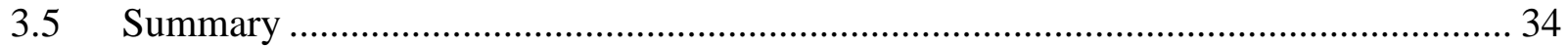

4. Tantalum Containing Mesoporous Bioactive Glasses as a Potential Hemostatic Agent. ..... 36

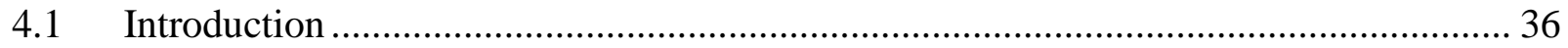

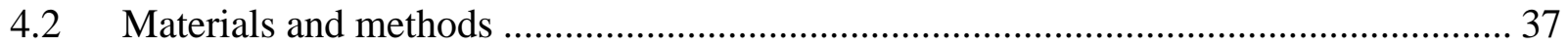

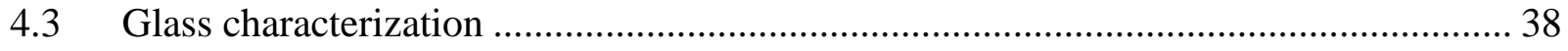

4.3.1 X-ray diffraction ……………………….................................................. 38

4.3.2 Scanning electron microscopy (SEM) and Energy dispersive X-ray spectroscopy

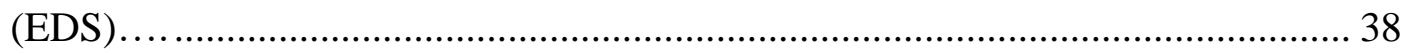

4.3.3 X-ray photoelectron spectroscopy (XPS) ………………………………........ 38

4.3.4 Fourier transform infrared (FT-IR) spectroscopy ……………………………...... 38

4.3.5 Transmission electron microscopy (TEM) ………………………………...... 39

4.3.6 Brunauer-Emmett-Teller (BET) and Barrett-Joyner-Halenda (BJH) analysis ....... 39 


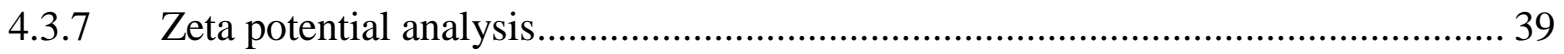

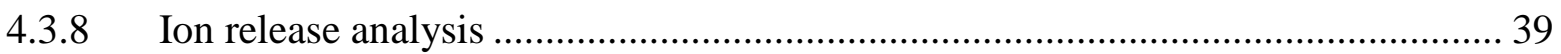

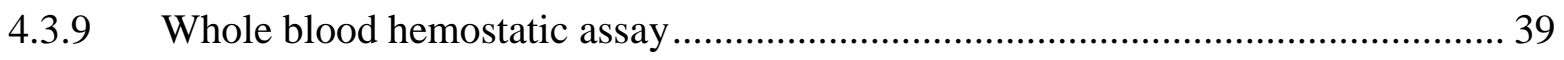

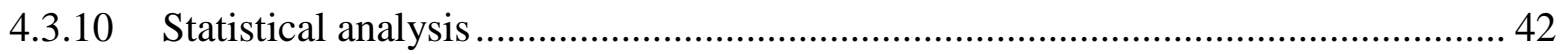

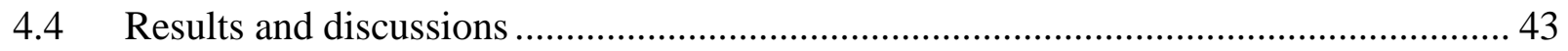

4.5 Limitations of thromboelastography ............................................................... 58

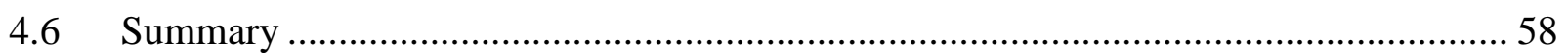

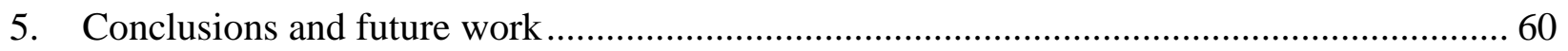

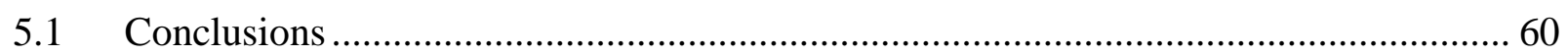

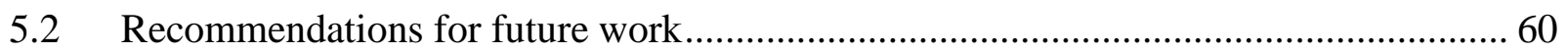

Appendix I.................................................................62

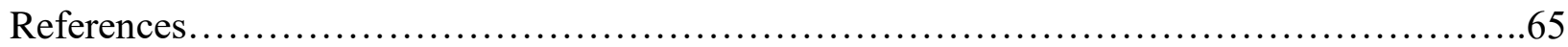




\section{List of tables}

Table 1.1: Distinctive features of ideal hemostatic agents................................................. 8

Table 2.1: Commercial and potential hemostats, their working principles and shortcomings .... 22

Table 3.1: Compositions for synthesized MBGs (mol\%) .................................................... 26

Table 3.2: Summary of compositions (wt.\%) obtained from EDS ....................................... 29

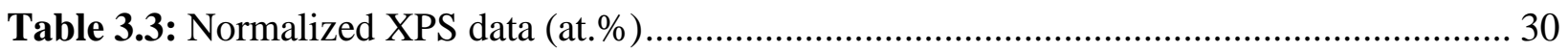

Table 3.4: Physical properties of L-MBG and H-MBG................................................... 32

Table 4.1: Compositions of synthesized synthesized MBGs (mol\%) ..................................... 38

Table 4.2: Amounts of precursors used to synthesize MBGs ................................................ 38

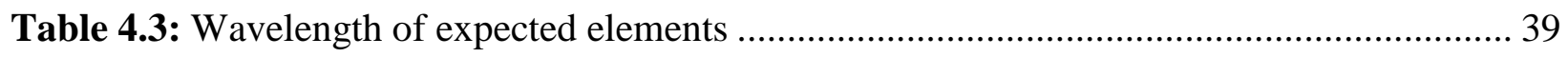

Table 4.4: Summary of compositions (wt.\%) obtained from EDS ...................................... 45

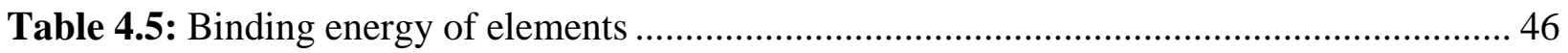

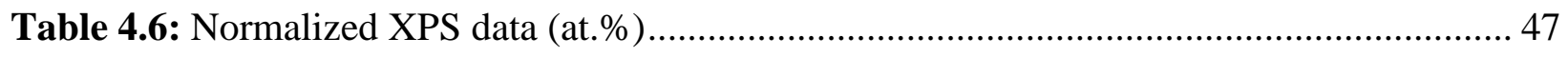

Table 4.7: Binding energy and concentration (at.\%) of oxygen in silica and Ca-P-Ta

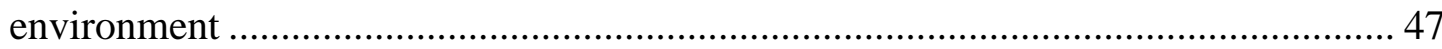

Table 4.8: Physical properties for MTa series glasses .................................................... 55

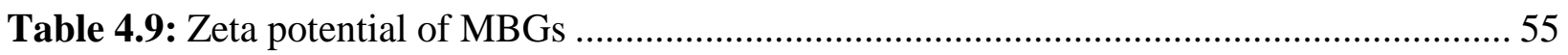

Table 4.10: R time performance of different powder samples with respect to no powder added 58 


\section{List of figures}

Figure 1.1: Representation of the a) structure (where $R$ is an alkyl group) and b) drug loading of

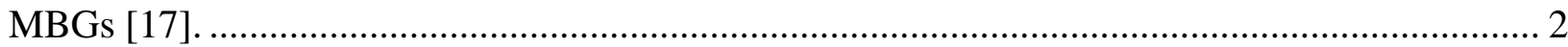

Figure 1.2: Chemical reactions during sol-gel process [18] .......................................... 3

Figure 1.3: Representation of EISA method [8] ........................................................... 4

Figure 1.4: a) Bridging oxygens are connected to Si atom, b) network modifiers break network

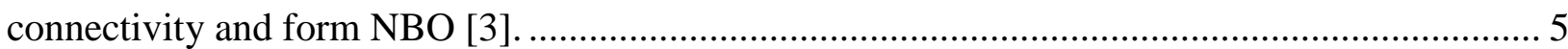

Figure 1.5: Intrinsic, extrinsic and common pathway during blood coagulation cascade [34].... 7

Figure 2.1: TEM images of MBGs with varying amount of $\mathrm{CaO}$ [41] .................................. 10

Figure 2.2: a) Representation of MBG atomic structure, b) Ca-P cluster in amorphous MBG

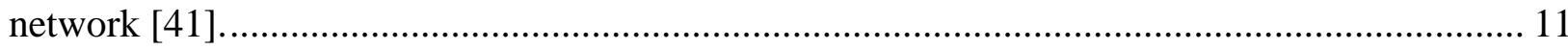

Figure 2.3: Cross section of MeTro hydrogel [58] ........................................................ 15

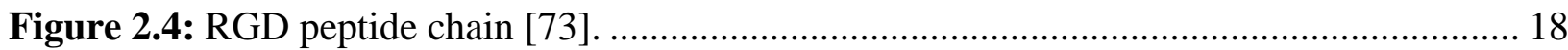

Figure 2.5: Schematic representation of synthetic platelets [70]..................................... 18

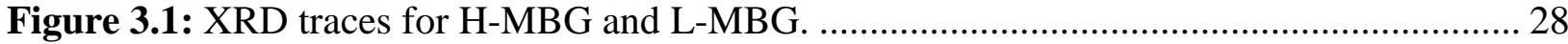

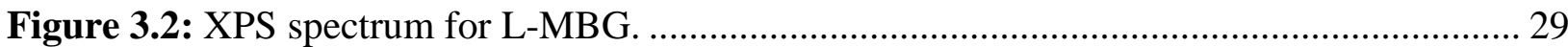

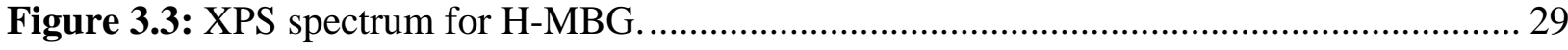

Figure 3.4: FT-IR spectra for L-MBG and H-MBG samples............................................ 30

Figure 3.5: TEM image of L-MBG at 30k magnification. ................................................. 31

Figure 3.6: TEM image of $\mathrm{H}-\mathrm{MBG}$ at $30 \mathrm{k}$ magnification. Arrow sign in the discontinuous

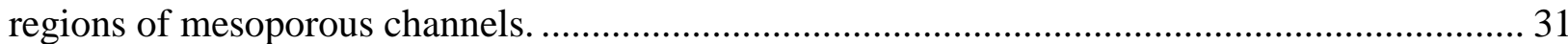

Figure 3.7: a) $\mathrm{SiO}_{4}{ }^{4-}$, b) $\mathrm{Ca}^{2+}$ and c) $\mathrm{PO}_{4}{ }^{3-}$ ion release from L-MBG and H-MBG samples. Error bar represents standard deviation from the mean $(n=9)$ * Represents statistical significance

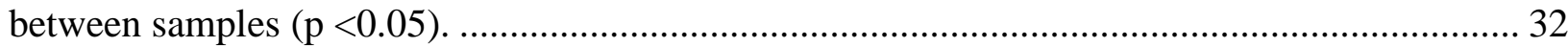

Figure 4.1: Schematic representation of thromboelastography [78]..................................... 40

Figure 4.2: Values of thromboelastograph that represent clot formation [78] ...................... 41

Figure 4.3: a) Anesthetized mouse, b) mouse dissection to lift abdominal skin..................... 42

Figure 4.4: Sequence of thromboelastography experiment [108] ........................................ 42

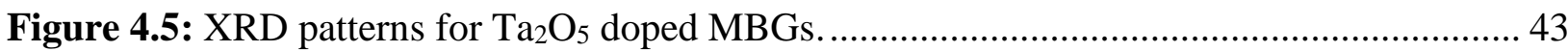


Figure 4.6: EDS spectra and SEM images for a) MTa-0, b) MTa-0.5, c) MTa-1, d) MTa-5 and e)

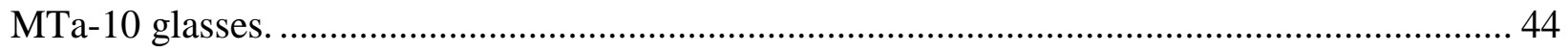

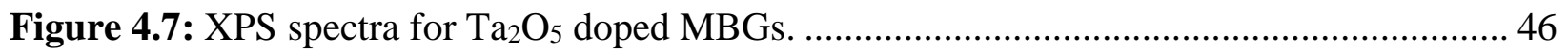

Figure 4.8: High resolution O1s spectra for a) MTa-0, b) MTa-0.5, c) MTa-1, d) MTa-5 and e)

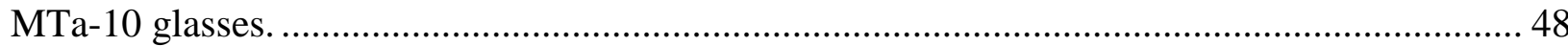

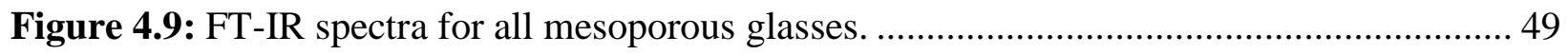

Figure 4.10: TEM images of a) MTa-0, b) MTa-0.5, c) MTa-1, d) MTa-5 and e) MTa-10

glasses. Arrow sign indicates discontinuity in the channel................................................... 50

Figure 4.11: Simplified representation of physical chemistry of MBGs................................ 51

Figure 4.12: Schematic representation of surface detected by gas adsorption method for

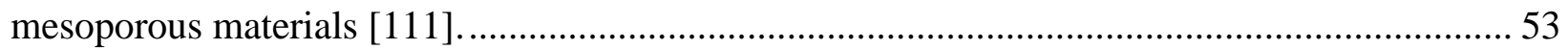

Figure 4.13: $\mathrm{N}_{2}$ gas molecules adsorption in the porous structure during different stages to

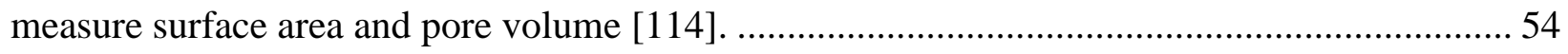

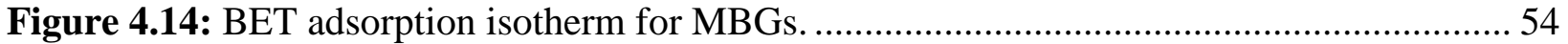

Figure 4.15: Ion release profiles for $\mathrm{Ta}_{2} \mathrm{O}_{5}$ doped MBGs: a) Silicon, b) Calcium, c) Phosphorus

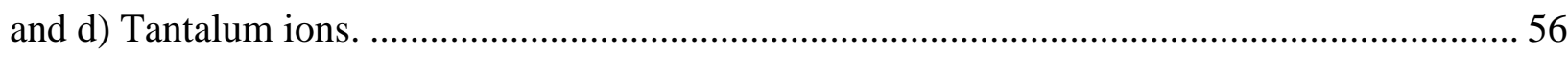




\section{Nomenclature}

\begin{tabular}{|c|c|}
\hline BG & Bioactive glasses \\
\hline $\mathrm{Na}$ & Sodium \\
\hline $\mathrm{Ca}$ & Calcium \\
\hline $\mathrm{Si}$ & Silicon \\
\hline $\mathrm{P}$ & Phosphorus \\
\hline NBO & Non-bridging oxygen \\
\hline HA & Hydroxyapatite \\
\hline $\mathrm{K}$ & Potassium \\
\hline $\mathrm{Mg}$ & Magnesium \\
\hline $\mathrm{Sr}$ & Strontium \\
\hline $\mathrm{Zn}$ & Zinc \\
\hline $\mathrm{B}$ & Boron \\
\hline $\mathrm{Cu}$ & Copper \\
\hline $\mathrm{Ti}$ & Titanium \\
\hline $\mathrm{MBG}$ & Mesoporous bioactive glasses \\
\hline TEOS & Tetraethyl orthosilicate \\
\hline EISA & Evaporation induced self-assembly \\
\hline $\mathrm{NC}$ & Network connectivity \\
\hline $\mathrm{RBC}$ & Red blood cell \\
\hline WBC & White blood cell \\
\hline $\mathrm{PPH}$ & Postpartum hemorrhage \\
\hline $\mathrm{Ta}$ & Tantalum \\
\hline CTAB & Cetyltrimethyl ammonium bromide \\
\hline $\mathrm{BO}$ & Bridging oxygen \\
\hline $2 \mathrm{D}$ & 2 dimensional \\
\hline SMP & Shape memory polymer \\
\hline PEG & Poly ethylene glycol \\
\hline $\mathrm{kDa}$ & Kilodalton \\
\hline
\end{tabular}




$\begin{array}{ll}\text { HNC } & \text { Hydrogel nanocomposite } \\ \text { DI } & \text { Deionized } \\ \text { MeTro } & \text { Methacrylated tropoelastin } \\ \text { UV } & \text { Ultraviolet } \\ \text { PT } & \text { Prothrombin time } \\ \text { aPTT } & \text { Activated partial thromboplastin time } \\ \text { PBS } & \text { Phosphate buffer saline } \\ \text { RGD } & \text { Arginine-glycine-aspartic acid } \\ \text { ORC } & \text { Oxidized regenerated cellulose } \\ \text { MTT } & \text { Methyl thiazol tetrazolium } \\ \text { TEG® } & \text { Thromboelastography } \\ \text { Ag } & \text { Silver } \\ \text { Ga } & \text { Gallium } \\ \text { SA } & \text { Surface area } \\ \text { PV } & \text { Pore volume } \\ \text { TEP } & \text { Triethyl phosphate } \\ \text { XRD } & \text { X-ray diffraction } \\ \text { EDS } & \text { Energy dispersive X-ray spectroscopy } \\ \text { XPS } & \text { X-ray photoelectron spectroscopy } \\ \text { FT-IR } & \text { Fourier transform infrared spectroscopy } \\ \text { TEM } & \text { Transmission electron microscopy } \\ \text { BET } & \text { Brunauer-Emmett-Teller } \\ \text { BJH } & \text { Barrett-Joyner-Halenda } \\ \text { ICP-OES } & \text { Inductively coupled plasma- optical emission spectroscopy } \\ \text { SEM } & \text { Scanning electron microscopy } \\ \text { IVC } & \text { Inferior vena cava } \\ \text { R } & \text { Initial clot formation time } \\ \text { K } & \text { Time taken by the clot to reach 20 mm clot strength } \\ \alpha & \text { Rate of clot formation } \\ \text { MA } & \text { Maximum clot strength } \\ & \end{array}$




\section{Introduction}

\subsection{Bioactive glasses}

Bioactive glasses (BGs) were discovered in the 1970s by Hench and co-researchers [1]. They synthesized a biodegradable glass containing sodium $(\mathrm{Na})$, calcium $(\mathrm{Ca})$, silicon $(\mathrm{Si})$ and phosphorus (P) [1]. Bioglass ${ }^{\circledR}$ (Novabone products, Alachua, FL, USA), composed of 46.1\% $\mathrm{SiO}_{2}, 24.4 \% \mathrm{Na}_{2} \mathrm{O}, 26.9 \% \mathrm{CaO}$, and $2.6 \% \mathrm{P}_{2} \mathrm{O}_{5}(\mathrm{~mol} \%)$, is one of the most common examples of bioactive glasses and is known by the formula, 45S5 [2]. Silica $\left(\mathrm{SiO}_{2}\right)$ is the network former and so the main backbone material for silicate glasses. Na is used to reduce the melting temperature of the glasses for synthesis. It is also a network modifier which disrupts the continuity of the glass network and forms non-bridging oxygens (NBO) [2]. NBO increases the dissolution rate of bioactive glasses in the surrounding environment [3]. Alkali cations such as $\mathrm{Ca}^{2+}$, potassium $\left(\mathrm{K}^{+}\right)$, magnesium $\left(\mathrm{Mg}^{2+}\right)$ are examples of network modifiers [4]. The release of $\mathrm{Ca}^{2+}$ and $\mathrm{PO}_{4}{ }^{3-}$ ions during degradation leads to the development of a hydroxyapatite (HA) layer at the glass surface which is chemically commensurate in content with bone. Bone cells can grow at the interfaces with an HA layer, resulting in an interfacial bond. Bioactive glasses degradation rate can be controlled by changing the glass composition [3]. Different ions can also be doped into silicate, borate and phosphate glasses which have particular targeted effects. Strontium (Sr) doping is used for bone healing; zinc $(\mathrm{Zn})$ is good for bone proliferation and has antibacterial properties; boron (B) assists in bone formation; copper $(\mathrm{Cu})$ can be used for angiogenesis; titanium (Ti) can increase compressive strength of implants and so on [5]. Bioactive glasses are also used to coat implants for improving bioactivity [6]. Gradual ion release from glass coated implants provide a strong bond between implant and bone [6]. These properties make bioactive glasses very promising for future biomedical applications.

\subsection{Mesoporous bioactive glasses}

Mesoporous materials were first synthesized in 1992 by Mobil Research and Development Corporation using a surface directing agent [7]. Surface directing agents are surfactants that control the order of the mesopore channel structure [8]. Mesoporous bioactive glasses (MBGs) possess highly ordered mesoporous channel structures (Figure 1.1a) and greater surface area compared to conventional bioactive glasses [9]. The higher surface area (> $\left.100 \mathrm{~m}^{2} / \mathrm{g}\right)$ and ordered channels of MBGs allows more effective release of doped ions and results in improved bioactivity compared 
to conventional BGs [2] [10]. MBGs also possess higher pore volume $\left(0.45 \mathrm{~cm}^{3} / \mathrm{g}\right)$ compared to BGs $\left(0.03 \mathrm{~cm}^{3} / \mathrm{g}\right)$ [11]; pore sizes range from 2 to $50 \mathrm{~nm}$ [12]. These properties make MBGs potential candidates for drug loading and delivery [12-14], bone grafting [14], implant coatings [15], dental [16] and tissue engineering applications [15] [16]. The morphology of MBG allows the adsorption of drug into the mesopores (Figure $1.1 \mathrm{~b}$ ) [17]. MBGs with surface area greater than $50 \mathrm{~m}^{2} / \mathrm{g}$ can also bond to bone and soft tissue within 24 hours in-vitro [1].

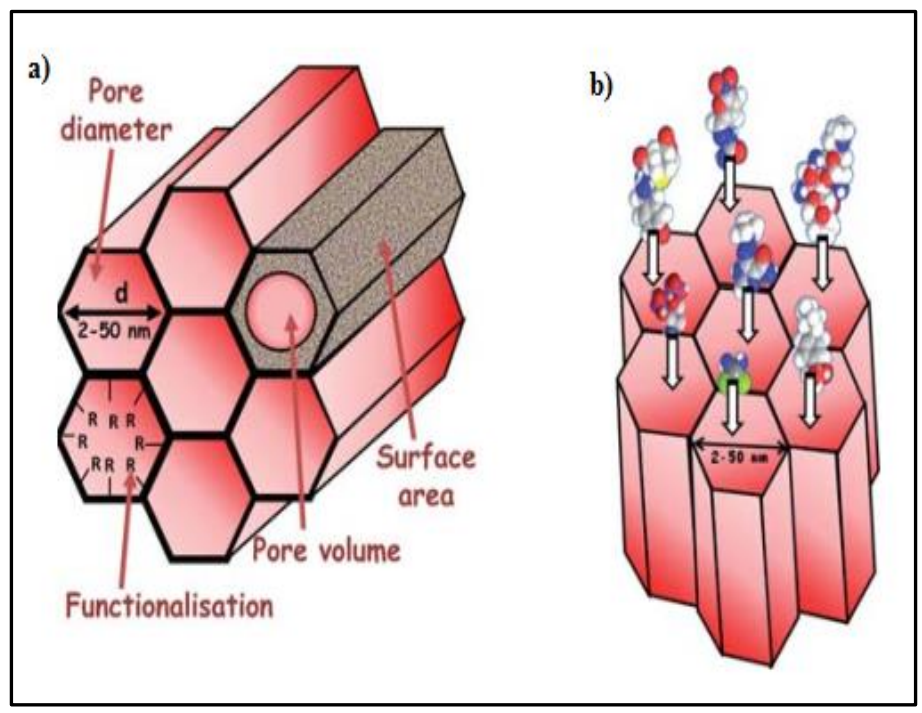

Figure 1.1: Representation of the a) structure (where $R$ is an alkyl group) and b) drug loading of MBGs [17].

\subsubsection{Sol-gel glasses}

The sol-gel process is the building block for the synthesis of MBGs. A stable suspension of colloidal particles (1 to $100 \mathrm{~nm}$ diameter) in a liquid are called sols and the three dimensional, polymeric, porous, rigid network is termed a gel [8] [18]. A gel is formed because of covalent bonding (Van der Waals forces, hydrogen bonding) between sol particles [8]. The hydrolysis (bond cleavage by the action of water) of organometallic precursors like TEOS (tetraethyl orthosilicate, $\left.\mathrm{Si}\left(\mathrm{OC}_{2} \mathrm{H}_{5}\right)_{4}\right)$ in an acidic condition leads to sols being created in solution. The following polycondensation reaction leads to the formation of a gel [19]. Figure 1.2 shows the hydrolysis and polycondensation reactions during the sol-gel process. 


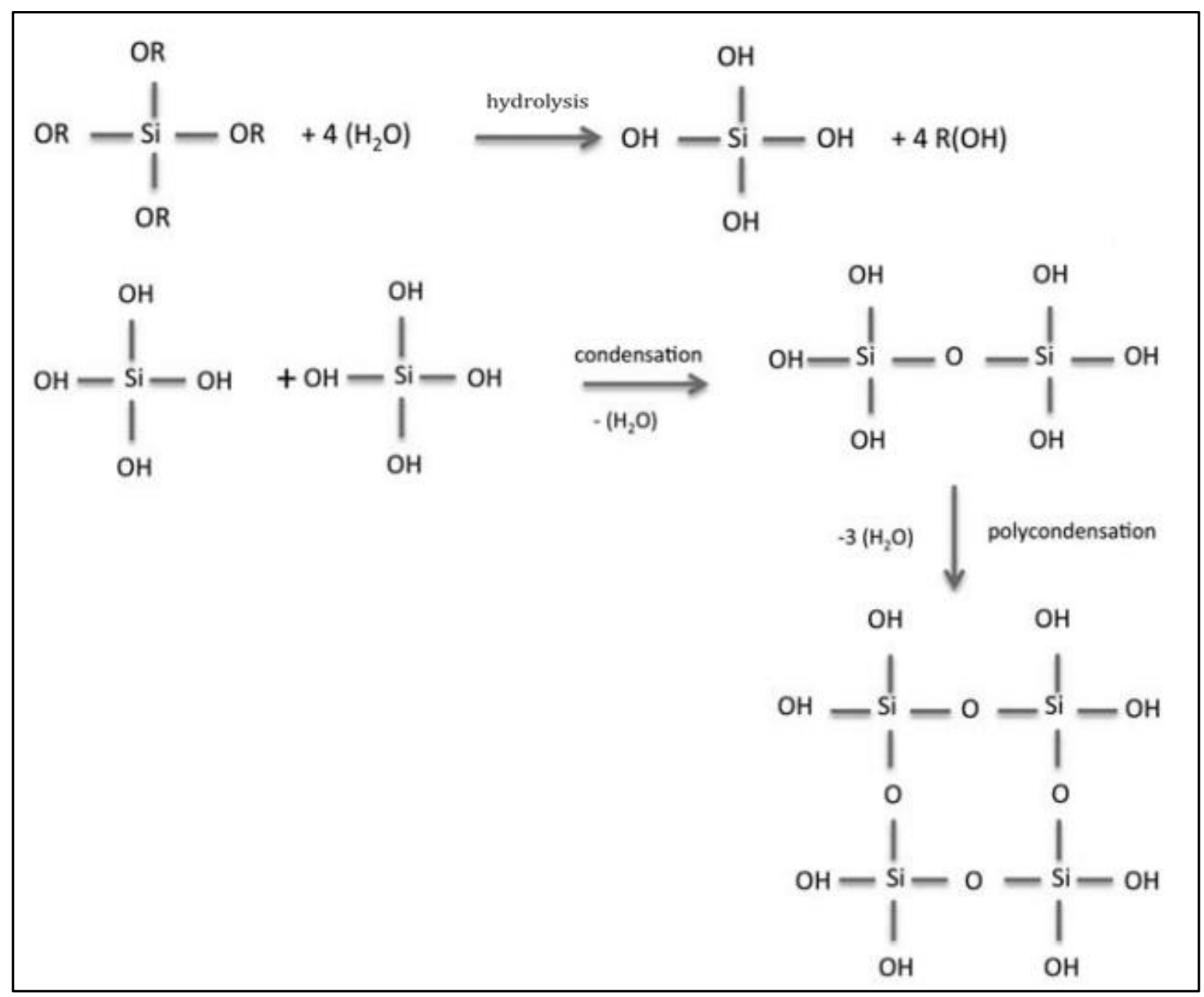

Figure 1.2: Chemical reactions during sol-gel process [18].

\subsubsection{EISA (Evaporation induced self-assembly)}

Surfactants or surface acting agents are amphiphilic molecules that contain a polar head group (hydrophilic) and a non-polar tail group (hydrophobic). Surfactant molecules aggregate in the aqueous solution and form micelles [8]. Micelles spontaneously self-assemble through electrostatic forces, Van der Waals forces (electrostatic attraction between molecules which depends on distance) and hydrogen bonding when concentrated; evaporation of the solvent increases the concentration of the depositing layer [20]. Micelle interaction with silicate precursors (TEOS) leads to the condensation of an ordered solid containing the surface structuring agent. Removing the surfactant by calcination causes the formation of the mesopores within the MBGs [8]. The whole EISA method is depicted in Figure 1.3. 


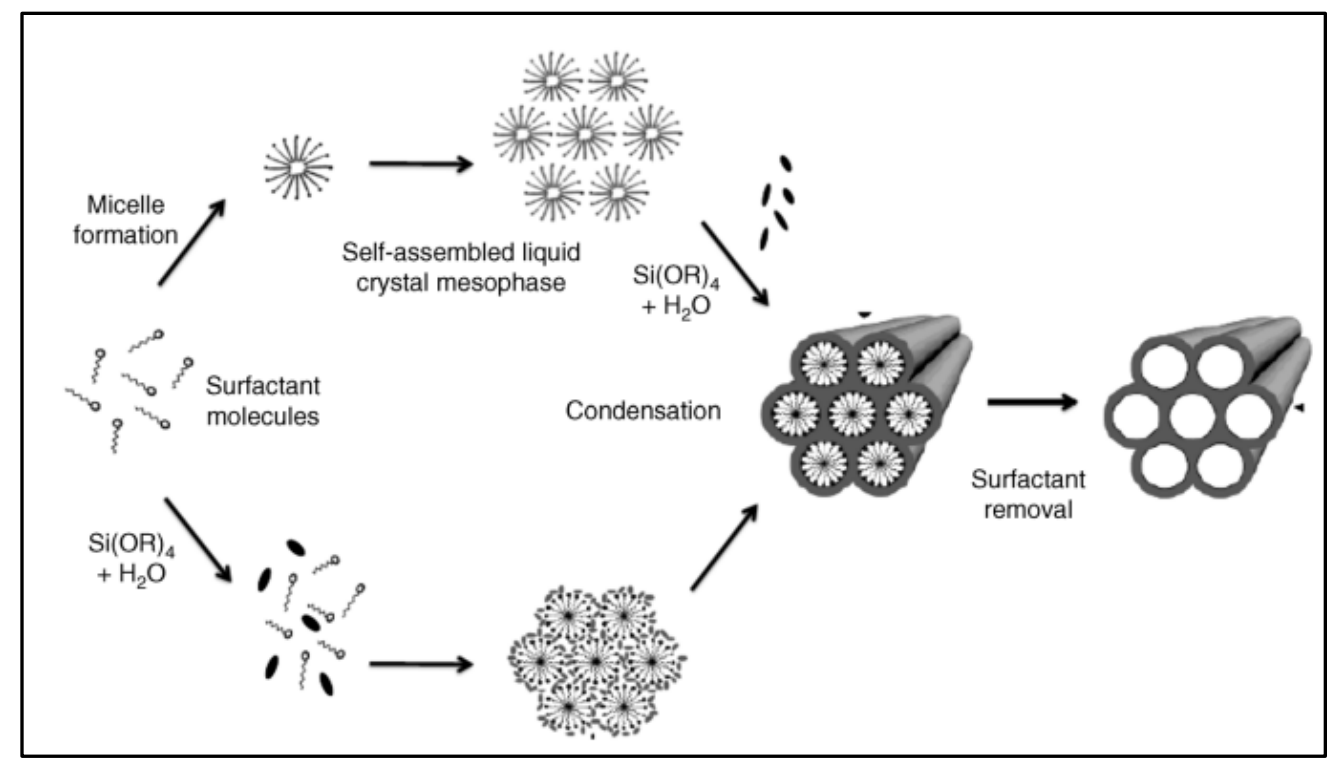

Figure 1.3: Representation of EISA method [8].

\subsection{Difference between melt quench and sol-gel glasses}

Bioactive glasses are conventionally synthesized using the melt quench method. For this method, appropriate amounts of oxide precursors are mixed and melted at high temperatures $\left(>1300^{\circ} \mathrm{C}\right)$ followed by a quenching step [18]. It is very difficult to synthesize nanoparticles employing such high temperatures [2]. A lower processing temperature is employed during the synthesis of sol-gel glasses [18], typically between $500-900^{\circ} \mathrm{C}$ [21]. This temperature range does not affect the silicate structure but does remove other organic residuals, such as nitrates and ethoxides, from the glass [21]. Higher purity and homogeneity can be maintained during the sol-gel process compared to melt quench glass firing [19]. Silica based BGs can contain some cations as network modifiers $\left(\mathrm{Na}^{+}, \mathrm{Ca}^{2+}\right.$ and $\left.\mathrm{K}^{+}\right)$[22]. These network modifiers disrupt the continuity of the glass network and form non-bridging silicon-oxygen bonds (Si-NBO) (Figure 1.4). The number of Si-NBOs directly influences the bioactivity of the glasses, with greater number of Si-NBO bonds leading to greater reactivity [22]. Network connectivity (NC) is an important parameter for melt quench glasses. NC can be defined as the number of bridging oxygen bonds to each Si atom (Figure 1.4) and is used to predict BGs surface reactivity and solubility [3]. NC $\geq 2.4$, greatly reduces the bioactivity (HA formation) of BGs [3]. This threshold limits $\mathrm{SiO}_{2}$ content to $60 \mathrm{~mol} \%$ in the melt quench BGs, to obtain sufficient bioactivity [3]. However, for sol-gel glasses it is possible to synthesize them with even $90 \mathrm{~mol} \% \mathrm{SiO}_{2}$ while maintaining their ability to form HA. During sol-gel glass synthesis, 
inherent nanoporosity is introduced into the glass structure. This porous structure leads to the higher surface area of sol-gel glasses (more than $\left.100 \mathrm{~m}^{2} / \mathrm{g}\right)$ compared to melt quench glasses ( 2 $\mathrm{m}^{2} / \mathrm{g}$ ) [3], and therefore accelerated apatite formation [1] [19]. On the other hand, melt quench glasses can exhibit superior mechanical properties compared to sol-gel glasses [16].

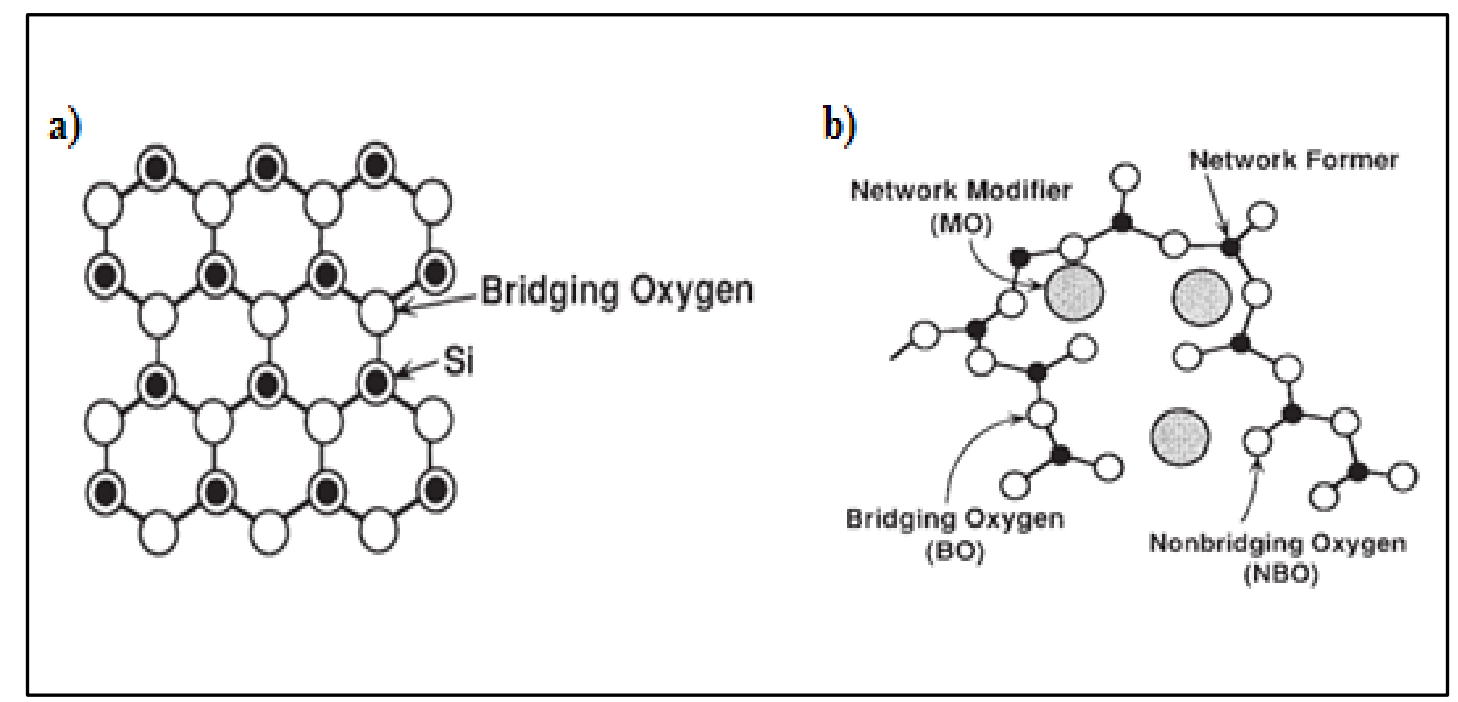

Figure 1.4: a) Bridging oxygens are connected to Si atom, b) network modifiers break network connectivity and form NBO [3].

\subsection{Blood composition}

Blood is a fluid connective tissue that is circulated around the body through vessels by the pumping action of the heart [23]. Blood carries oxygen which is needed for cellular metabolism, and also transports waste products away from the cells to remove from the body [24]. Blood is composed of red blood cells (RBCs), white blood cells (WBCs) and platelets. Plasma is the fluid portion of blood and makes up 55\% of total blood volume [24]. WBCs and platelets make up less than $1 \%$ and the balance is RBCs [25]. Plasma contains different proteins and other solutes such as nutrients, electrolytes, clotting factors and hormones [25].

\subsection{Hemorrhage}

Hemorrhage is the excessive discharge of blood from a ruptured vessel [26]. Hemorrhage is the leading cause of death in trauma and war, accounting for almost $50 \%$ of deaths on the battle field [27]. Excessive bleeding from limb wounds is attributable to more than half of the curable deaths in a combat zone [28]. In the battlefield, torso hemorrhage is responsible for around $80 \%$ of deaths [29]. Uncontrolled bleeding results in $33 \%$ of civilian deaths [30] and is the second leading cause 
of death in non-combative trauma patients [31]. Postpartum hemorrhage (PPH) is a major cause of maternal mortality and morbidity in Canada (increased 22\% from 2003 to 2010) and can lead to serious health complications like drop in blood volume, organ failure, coagulopathy and shock [32].

\subsection{Hemostasis}

Hemostasis is a process which stops bleeding through a blood vessel [26]. During tissue injury, host defence mechanisms maintain vascular system integrity [33]. After insult, there is an immediate occurrence of constriction of blood vessels which is called vasoconstriction. The constriction of small arteries reduces blood flow to the injured area. Collagen (the main structural protein) and von Willebrand factor (a blood glycoprotein), exposed in the vessel wall, cause platelets to adhere to them and become activated. Activated platelets release platelet granule content which induce more platelets at the injured site and enhance platelet activation. This process leads to primary hemostasis which forms an initial platelet plug. In secondary hemostasis, a stable platelet plug is formed. Secondary hemostasis occurs in the coagulation cascade which is a series of enzymatic reactions. The coagulation cascade is divided into two pathways: a) intrinsic pathway (contact activation) and b) extrinsic pathway (tissue factor). The intrinsic pathway is initiated with activation of factor XII (contact factor) when blood is in contact with an outer surface. The extrinsic pathway is activated by tissue factor and factor VII (from damaged blood vessel). Both pathways lead to a common pathway which activates factor $\mathrm{X}$ in the presence of calcium ions $\left(\mathrm{Ca}^{2+}\right)$. Activated factor Xa (lower case "a" to indicate an active form) with the presence of $\mathrm{Ca}^{2+}$ and co-factor Va, converts prothrombin to thrombin (an enzyme). Thrombin (with the help of $\mathrm{Ca}^{2+}$ ) alters soluble fibrinogen (glycoprotein that circulates in the blood) into insoluble fibrin (viscoelastic fibrous protein). Thrombin also activates factor XIII and then polymerizes fibrin to form a stable and strong fibrin plug [33] [34]. $\mathrm{Ca}^{2+}$ plays a pivotal role in the coagulation cascade [35]. The whole coagulation cascade is depicted in Figure 1.5. 


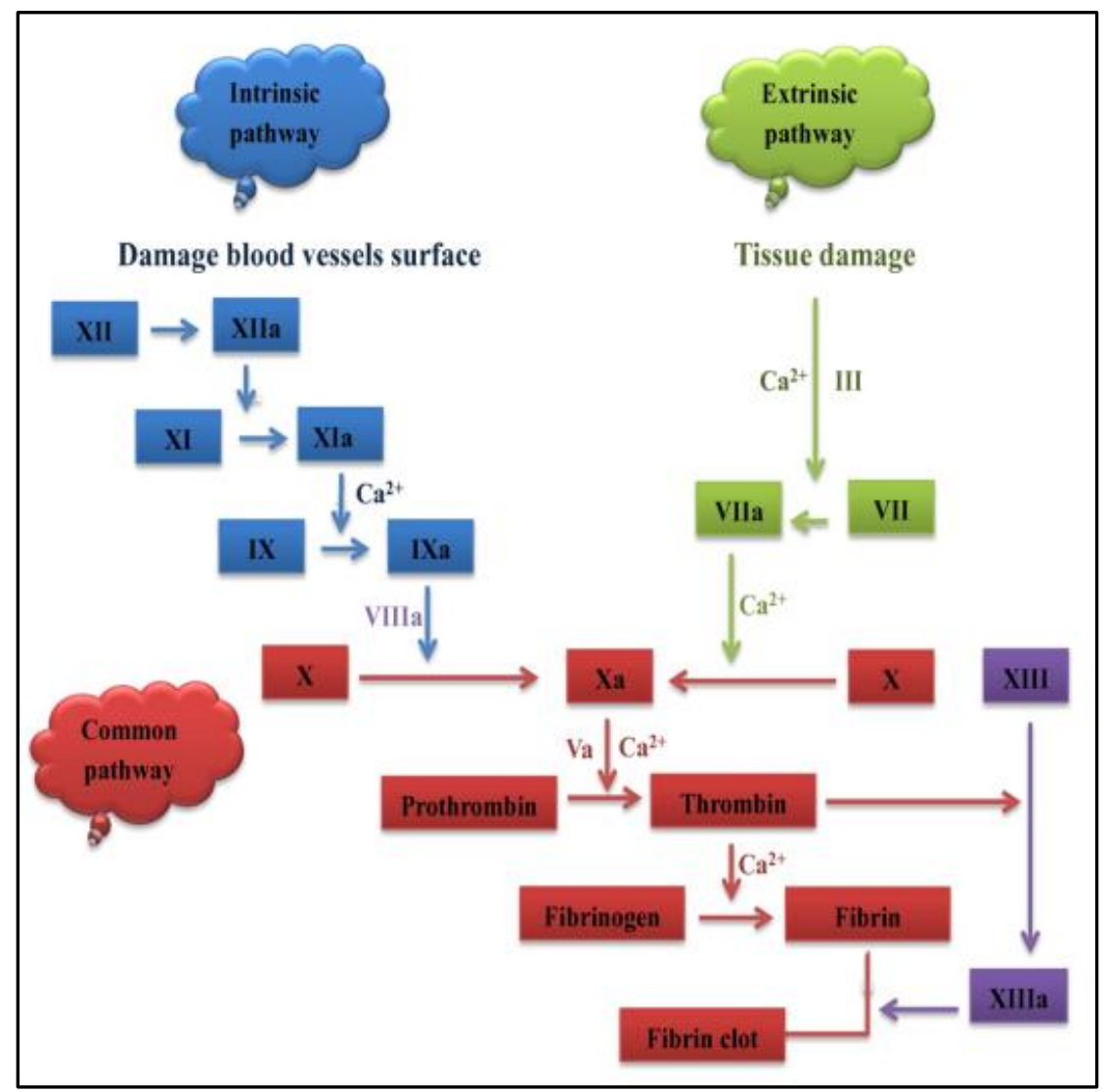

Figure 1.5: Intrinsic, extrinsic and common pathway during blood coagulation cascade [34].

\subsection{Thrombosis}

Thrombosis is the process of a blood clot formation inside of a healthy vessel [25]. During hemostasis, excessive formation of thrombin can cause thrombosis which can lead to stroke and deep vein complications [36].

\subsection{Research significance}

Post-operative hemorrhage is a common problem after any kind of surgical procedure; $36 \%$ of deaths at the scene of an injury are due to hemorrhage [37]. If excessive bleeding cannot be controlled it can be life threatening. Severe blood loss can lead to hypothermia, coagulopathy and multiple organ failure [28]. An ideal hemostat should have the following properties: it can achieve hemostasis within two minutes of application, it should be biodegradable and can inhibit bacterial infection, it could be applied to deep and irregular wounds, and will be both non-inflammatory and cost effective [28] [38]. Table 1.1 summarizes the properties of an ideal hemostatic agent. 
Table 1.1: Distinctive features of ideal hemostatic agents

\begin{tabular}{cc}
\hline Criteria & Function \\
\hline Hemostasis time & can stop serious vascular bleeding in less than two minutes \\
Bioactivity & non cytotoxic, bioabsorbable, no irritation and side effects \\
Antibacterial & can heal microbial infection \\
Wound conditions & can be applicable to any kind of wound \\
Cost & inexpensive \\
\hline
\end{tabular}

An ideal hemostatic agent remains a quest for military and civilian hemorrhage control. Rigorous research and innovation are required to develop an ideal hemostatic agent.

\subsection{Research goal and objectives}

This research will focus on the effect of heating rate on the physical properties of MBGs and then, utilizing that preferred heating rate, develop a series of mesoporous bioactive glasses which can be used as a potential hemostatic agent. The objectives of the research are:

- Synthesis of two batches of MBGs with varying heating rates $\left(1^{\circ} \mathrm{C} / \mathrm{min}\right.$ and $\left.20^{\circ} \mathrm{C} / \mathrm{min}\right)$ using the sol-gel process.

- Characterization of the physical and chemical structures of both glass batches.

- Synthesis of tantalum (Ta) containing MBGs

- Evaluate the effect of Ta incorporation into the physical structure and porosity of MBGs.

- Determine the effect of morphology on the ion release.

- Examine preliminary blood coagulation study

\subsection{Thesis outline}

After this introduction, chapter 2 provides a literature review related to the work. The objective is to provide insight on previous work done regarding the processing parameters of sol-gel glasses, commercial and potential hemostatic agents and their working principles, limitations, and reasons for choosing tantalum-containing MBGs. This will also lead to the rationale driving the current work and the holes in the literature that it fills. The effect of calcination heating rate on the structure of MBGs will be discussed in chapter 3. Chapter 4 will provide detail information about tantalum containing MBGs as potential hemostatic agents. Conclusions and future work will be described in chapter 5 . 


\subsection{Statement of co-authorship}

The following people and institutions contributed to the submission of papers undertaken as part of this thesis:

Md Saidur Rahman, Ryerson University = Candidate

Andrew Mendonca, Ryerson University = Author 1

Adel Alhalawani, Ryerson University = Author 2

Deanna Polintan, Ryerson University $=$ Author 3

Owen M. Clarkin, Dublin City University = Author 4

Mark R. Towler, Ryerson University = Author 5

Author details:

Paper 1, The Effect of Calcination Heating Rate on the Structure of Mesoporous Bioactive Glasses: Located in chapter 3.

Candidate was the primary author who collected the data and wrote the whole article. Authors 1, 2, 4 and 5 helped to outline the work, revising critically for submission. Author 3 helped during her summer internship for the synthesis of glasses.

Paper 2, Tantalum containing mesoporous bioactive glasses as a potential hemostatic agent: Located in chapter 4.

Candidate performed half of the lab work, collected data and analyzed the results. Author 1 was the primary author who wrote the entire article and data analysis. Author 4 conducted surface area measurements. Author 2 and 5 revised the article and prepared for submission. 


\section{Literature review}

\subsection{Parameters that control the physical structure of MBGs}

The literature shows that there are three main parameters which affect the morphology of sol-gel glasses: i) type of surface directing agent, ii) calcination temperature, and iii) glass composition. Common surfactants for MBG synthesis are: cetyltrimethyl ammonium bromide (CTAB), P 123 $\left(\mathrm{EO}_{20} \mathrm{PO}_{70} \mathrm{EO}_{20}\right.$, where $\mathrm{EO}$ is polyethylene oxide and $\mathrm{PO}$ is polypropylene oxide) and $\mathrm{F} 127$ (EO106PO70EO106) [39]. Calcination temperature can manipulate the sol-gel glasses' surface area and pore volume [40]. In regards to composition, $\mathrm{CaO}$ has considerable effect on the physical structure of MBGs. It was observed that by changing the concentration of $\mathrm{CaO}$ from $37 \mathrm{~mol} \%$ to $10 \mathrm{~mol} \%$ in a $\mathrm{SiO}_{2}-\mathrm{CaO}-\mathrm{P}_{2} \mathrm{O}_{5}$ ternary glass composition, mesoporous structure changed from $2 \mathrm{D}$ hexagonal to 3D cubic structure (Figure 2.1) [41].

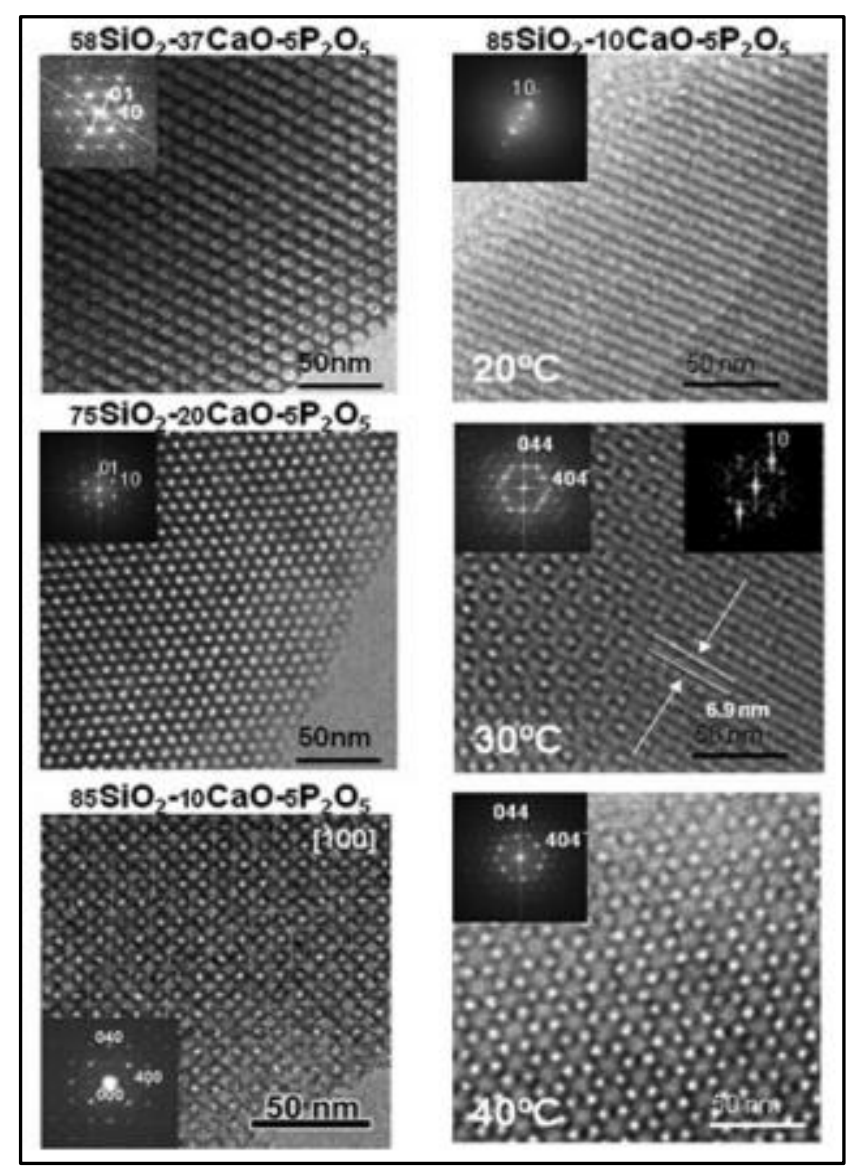

Figure 2.1: TEM images of MBGs with varying amount of $\mathrm{CaO}$ [41].

The presence of Ca-P cluster (calcium-phosphorus domain) in the amorphous $\mathrm{SiO}_{2}-\mathrm{CaO}-\mathrm{P}_{2} \mathrm{O}_{5}$ network, acts as a nucleation site which increases the crystallization kinetics of HA [41]. That is 
why MBGs are more bioactive than conventional melt quench glasses. Figure 2.2 shows the atomic structure and the presence of a Ca-P cluster in silica MBGs.

It is hypothesized that there is a fourth parameter, calcination heating rate, which can affect porous structure of MBGs. To the authors' knowledge, literature is lacking insight into the relationship between heating rate and MBG's physical and chemical properties.

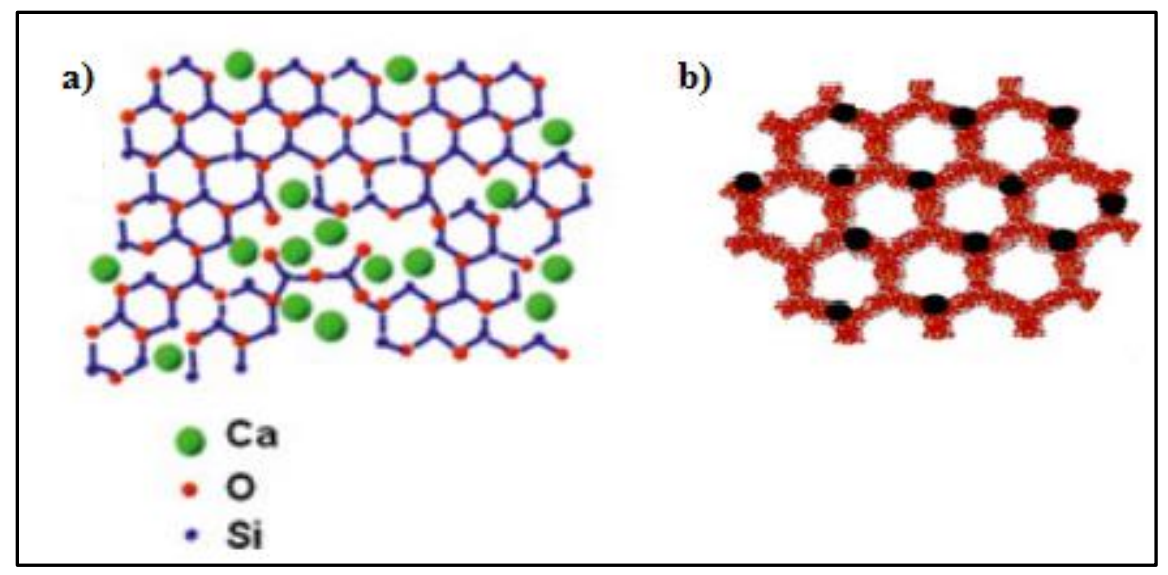

Figure 2.2: a) Representation of $M B G$ atomic structure, b) Ca-P cluster in amorphous $M B G$ network [41].

\subsection{Commercial hemostatic agents}

Hemostats are agents used to stop the bleeding from a damaged blood vessel. Commercially available hemostats work by two mechanisms: i) sealing the damaged blood vessels, and ii) concentrating clotting factors and initiating the intrinsic coagulation pathway [38]. They can be typically classified as inorganic and organic hemostats based on their compositions. The mechanism, efficacy and side effects of different inorganic and organic hemostats are described in the following section.

\subsubsection{QuickClot@}

QuickClot ${ }^{\circledR}$ (Z-Medica, Wallingford, CT, USA) is a zeolite (microporous aluminosilicate mineral) based granular powder hemostat. When zeolite is applied at the bleeding site, it absorbs water from the blood which concentrates platelets and other clotting factors. As a result, immediate hemostasis is achieved [42]. However, zeolite based hemostats incur an exothermic reaction at the wound site and cause tissue injury [38]. These zeolites were replaced with synthetic zeolite beads to mitigate the exothermic reaction, and the resultant product marketed as QuickClot ACS+ (advanced clotting sponge plus) [38]. QuickClot Combat Gauze (QCG) is made of rayon/polyester gauze where 
kaolin (hydrated aluminum silicate) is incorporated [43]. Kaolin activates coagulation factor XII and initiates intrinsic pathway of blood coagulation cascade [43]. When QCG is applied in a deep wound, kaolin particles can wash out from the gauze. These particles could enter into the cardiovascular system which could result in thrombosis [38]. During QCG application, firm manual pressure is required (25 psi) [43].

\subsubsection{Woundstat ${ }^{\mathrm{TM}}$}

WoundStat $^{\mathrm{TM}}$ (Trauma Cure, Inc., Bethesda, MD, USA) is a mineral based agent composed of granular clay smectite. WoundStat is highly water absorbent [44]. It is a highly effective hemostat compared to Quickclot ${ }^{\circledR}$ incurring the least amount of blood loss $(121 \mathrm{~mL}$ blood loss after applying Quickclot $\left.{ }^{\circledR}\right)$ [45]. However, computed tomography angiography of a pig model revealed that injured blood vessels treated with WoundStat exhibited large thrombus clots, resulting in the U.S army permanently suspending the use of WoundStat in 2009 [38].

\subsubsection{Gelfoam ${ }^{\circledR}$}

Gelfoam ${ }^{\circledR}$ (Pfizer Inc., NY, USA) is a hemostatic agent prepared from purified pork skin gelatin. It is water insoluble and porous. This agent provides a matrix at the bleeding site and initiates extrinsic pathway of blood coagulation cascade [44]. Gelfoam ${ }^{\circledR}$ is very effective in the event of minimal bleeding [46]. However, animal gelatin containing hemostats can cause serious allergic reactions and can lead to anaphylaxis [47].

\subsubsection{Celox $^{\mathrm{TM}}$}

Celox $^{\mathrm{TM}}$ (Medtrade, Crewe, UK) is a chitosan based hemostat. Chitosan is a linear polysaccharide synthesized from shrimp shells [48]. As chitosan particles are positively charged, they adhere to negatively charged surfaces (RBCs and platelets) due to mucoadhesive interfacial forces [49]. However, Celox ${ }^{\mathrm{TM}}$ hemostatic powder is very light in weight (could be washed away during excessive bleeding) and can cause an inflammatory reaction to people allergic to chitosan. [38].

\subsubsection{Dry fibrin sealant dressing (DFSD)}

DFSD consists of clotting proteins pooled from human plasma [50]. It provides fibrinogen to the injured site. DFSD is very effective compared to standard gauze for achieving hemostasis after ballistic injury [50]. However, because it is derived from human plasma, there are some safety concerns related to transmission of diseases like hepatitis and immunodeficiency syndromes [38]. 


\subsubsection{Arista ${ }^{\circledR}$}

Arista ${ }^{\circledR}$ (Bard, Warwick, RI, USA) is a sterile absorbable plant based microporous polysaccharide hemostatic powder which can notably reduce the hemostasis time [51]. Arista ${ }^{\circledR}$ can be used when conventional techniques to stop bleeding such as pressure, and ligature are ineffective. This topical hemostatic agent can be applied to any kind of wound. When Arista ${ }^{\circledR}$ is applied to a wound, it immediately dehydrates blood and forms a matrix. This matrix acts as a molecular sieve for platelets and other clotting factors to achieve hemostasis [44]. Using Arista ${ }^{\circ}$, hemostasis has been achieved within 165 seconds (mean time) during splenic surgery [52]. It has also been used during cardiothoracic surgery and achieved blood clotting within 93 minutes (whereas untreated control group took 107 minutes) [51].

It is recommended by the manufacturer that excess amounts of Arista® powder should be removed after achieving hemostasis [46]. During hemostasis, swelling of Arista ${ }^{\circledR}$ particles can lead to necrosis (death of cells) and is therefore not recommended for neurologic or ophthalmic surgery [44].

\subsection{Potential hemostatic agents}

Many research groups are working on new materials and methods to function as an ideal hemostat. In this section potential hemostatic agents are divided into two groups: i) organic and ii) inorganic hemostats.

\subsubsection{Organic hemostats}

\subsubsection{Hydrogel based hemostats}

Hydrogel coated SMP (shape memory polymer) composites could be potential hemostatic agents [53]. Hydrogel is a hydrophilic polymer capable of containing large amounts of water in its 3D network [54]. Shape memory polymer foam possess larger surface area because of porous morphology [55]. A hydrogel (PEG $10 \mathrm{kDa}, 5 \mathrm{wt}$ \% hydrogel) coated shape memory polymer foam (lowest cross-link density) that retains the advantages of each respective materials (i.e. large volume filling capabilities and rapid clotting of shape memory polymer with the swelling capacity of hydrogel), forms a composite for the treatment of traumatic hemorrhage [53]. Antibacterial ions can also be doped into the porous structure of the composite [56]. The mechanism of the composite is that, when it is applied to deep wounds, it will expand to fill the wound cavity and will stimulate rapid blood clotting [57]. Because of this mechanism, this composite could perform better than 
other hemostats for deep and irregular wounds. However, the removal of the composite from the wound after achieving hemostasis could lead to complications. This composite may not be suitable for intravenous application. No in-vivo test has been conducted on this material.

Superabsorbent hydrogel nanocomposites (HNCs) were studied as potent hemostats [58]. Three different types of nanocomposites were synthesized: i) $\mathrm{SiO}_{2}$, ii) clinoptilolite (natural zeolite) and iii) $\mathrm{Ca}^{2+}$-modified clinoptilolite [58]. Porosity plays a vital role for the swelling capability of HNCs. Swelling property was measured at 5, 10, 30, 60, 90, 120, 150 and 180 minutes time interval, in PBS (phosphate buffer saline) and DI (deionized) water. Average swelling recorded in PBS for the aforementioned time interval was $4000 \%$ (in size) and in DI water was $24000 \%$ (in size). The swelling property decreased in salt solution due to an uneven distribution of ions in the medium and the decrease of the polymer network. This nanocomposite material was applied in a surgically exposed femoral artery of a rat model where hemostasis was achieved rapidly [58]. The underlying hemostasis mechanism is the stimulation of intrinsic pathway of blood coagulation cascade (from the nanoparticles) and the fast swelling of the composite matrix provides physical barrier to form a hemostatic plug [58]. The fast swelling of nanoparticles can lead to compression necrosis of tissue [59], which could be a major concern about this potential hemostat.

An elastic hydrogel based surgical glue has been developed based on recombinant human tropoelastin (elastic skin protein that helps to retain shape) with methacrylic anhydride (polymer) [60]. The sealant was termed as methacrylated tropoelastin (MeTro) (Figure 2.3). During application, UV light is required $\left(6.9 \mathrm{~mW} / \mathrm{cm}^{2} ; 360\right.$ to $\left.480 \mathrm{~nm}\right)$ for photo-crosslinking of the polymer [61]. This synthesized product is a potential candidate for the sealing and repair of elastic tissue e.g. lung and cardiac tissues and blood vessels. In-vivo testing was performed on porcine lungs and sealed severe pulmonary air and blood leakage [60]. The best application of this surgical glue could be for soft tissues (such as lungs), without using any suture, but human trials are needed to show efficacy and lack of side effects. 


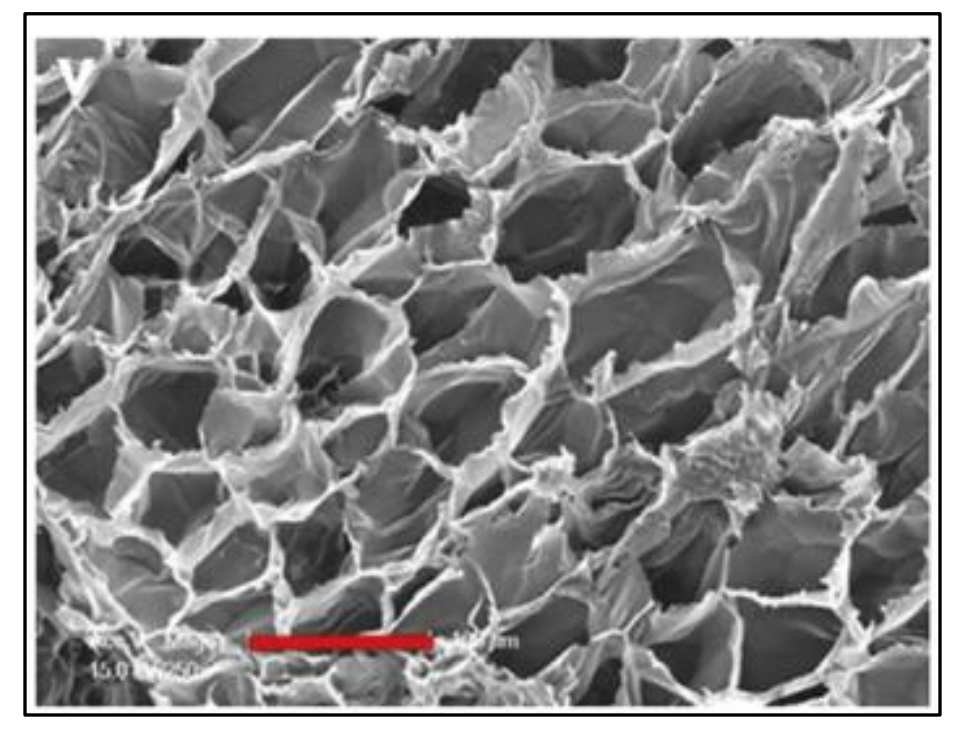

Figure 2.3: Cross section of MeTro hydrogel [61]

Batroxobin is a snake venom and can be used as a hemostat as it can catalyze fibrinogen to form soluble fibrin clots [62]. Nano-fibrous peptide hydrogels loaded with batroxobin enhanced blood clotting [63] and can initiate blood clotting time even in the presence of heparin (an anticoagulant used to prevent heart attack and deep vein thrombosis). The hydrogel provides the physical barrier for the bleeding and batroxobin initiates fibrin formation with entrapped erythrocytes (red blood cells) by fibrin fibers. In this way batroxobin can produce large amounts of blood clots [62] [63]. Cytotoxicity study was not conducted; the maximum safe concentration of batroxobin was not determined for application to animals and humans. Also, if the fibrin clot produced by batroxobin enters into the vein or artery, it can lead to thrombosis.

\subsubsection{Chitosan based hemostats}

Chitosan is a natural polysaccharide (derived from crab and shrimp shells) and diatoms are the largest group of single cellular microalgae [64]. Diatom silica (a 3 dimensional porous natural biomaterial developed by a single cell algae) coated with chitosan at different chitosan concentrations $(0.5,1,3,5 \mathrm{wt} \%)$ is a potential hemostatic agent [65]. Diatom silica was collected from diatomite frustule and diatom culture. During the whole blood clotting test, shorter clotting times were recorded for $1 \%$ chitosan coated diatom silica $(351 \pm 14.73$ seconds at $5 \mathrm{mg} / \mathrm{mL}$ concentration and $248 \pm 32.42$ seconds at $10 \mathrm{mg} / \mathrm{mL}$ concentration) [65]. Chitosan particles are positively charged [38]. This material can effectively absorb water from the blood (via porous diatom silica) and can induce RBC adsorption and aggregation (positively charged chitosan can 
bind negatively charged RBCs and platelets), along with activating the intrinsic pathway of blood coagulation cascade (due to negative surface charge of diatom silica) [65]. Chitosan coated diatom silica powder is very light so may not be suitable for excessive bleeding [66].

Cellulose based cylindrical shaped mini-sponge dressing could achieve immediate blood clotting for non-compressible hemorrhage [67]. These mini-sponges are coated with chitosan. They can expand within 20 seconds by absorbing blood from the wound, providing a physical barrier. Chitosan can bind RBCs and platelets [38], so that hemostasis can be achieved within 4 minutes [67]. This material is best suited for deep and wide exposed injury.

\subsubsection{Micro and nano particles}

Chicken feather keratin nanoparticles were investigated as a candidate for hemostasis [68]. Chicken feathers contain 90\% keratin [69]. The particle size of the keratin nanoparticles ranged from 50 to $200 \mathrm{~nm}$. During in-vitro blood coagulation assays, keratin nanoparticles showed faster blood clotting time compared to keratin extracts $(\mathrm{p}<0.05)$ [68]. In-vivo (rat tail amputation and liver scratch model) study showed that keratin nanoparticles took 60 seconds and keratin extracts took 100 seconds for blood coagulation in liver scratch model. In case of the tail amputation model, 100 seconds and 150 seconds were recorded for keratin nanoparticles and keratin extracts respectively [68]. Nanoparticles stimulate intrinsic pathway of blood coagulation cascade [70]. However, cytotoxicity and surface charge were not evaluated for keratin nanoparticles. CT angiography should be investigated for thrombus formation inside the blood vessel of animal models.

Kerlix ${ }^{\mathrm{TM}}$ gauze loaded with $\mathrm{CaCO}_{3}$ microparticles, human thrombin and tranexamic acid $\left(\mathrm{C}_{8} \mathrm{H}_{15} \mathrm{NO}_{2}\right)$ has been considered as a hemostat [71]. Tranexamic acid is an anti-fibrinolytic agent (fibrinolysis impedes blood clot). This material was used to stop turbinate (side wall of the nose) bleeding of sheep model and hemostasis was achieved after 5.09 minutes [71]. For plain gauze, hemostasis was achieved after 8.21 minutes [71]. As human thrombin is used in this material there is a possibility of transmission of diseases (hepatitis and immunodeficiency) [38].

\subsubsection{Other potential hemostat}

Phosphate coacervates (sodium polyphosphate) is a polymer rich viscoelastic material [72]. The mechanism of action for phosphate coacervate is based on platelet adhesion. There are two common blood clotting tests termed as prothrombin time (PT) and activated partial thromboplastin 
time (aPTT) [25]. PT indicates the time it takes to go through the extrinsic pathway and aPTT indicates the time it takes to go through the intrinsic pathway of the blood coagulation cascade. PT time is measured using PPP (platelet poor plasma) with the addition of PT agent (thromboplastin protein as tissue factor) and the mixture is kept in warm water at $37^{\circ} \mathrm{C}$. The test is timed until the plasma clots. In this study, $0.1 \mathrm{~mL}$ of coacervate sample was added with $200 \mu \mathrm{L}$ of $1 / 6$ diluted PT agent at $37^{\circ} \mathrm{C}$ in a water bath and maintained for 30 seconds [72]. PT time for PPP was found $13 \pm 1$ sec (from product certificate) and within this time period it is not possible to estimate coacervate formulations. That was the reason to dilute the PT agent to delay PT time. Then $100 \mu \mathrm{L}$ PPP was added and the timer started immediately. When the fibrin gel appeared, the timer paused immediately. An aPTT test is performed using PPP, addition of $\mathrm{Ca}^{2+}$ ions and aPTT reagent to initiate the intrinsic pathway. In this study, $0.1 \mathrm{~mL}$ of coacervate solution combined with $100 \mu \mathrm{L}$ of aPTT reagent (ellagic acid, $\mathrm{C}_{14} \mathrm{H}_{6} \mathrm{O}_{8}$ ) was incubated at $37^{\circ} \mathrm{C}$ in a water bath for 3 minutes. Then $100 \mu \mathrm{L} 0.02 \mathrm{M} \mathrm{CaCl}_{2}$ was added and aPTT time recorded [72]. It was noticed that polyphosphate coacervates induce extrinsic pathway (by reducing PT). However, this material has a negative effect on intrinsic pathway (increase aPTT) [72]. The intrinsic and extrinsic pathways both lead to the common pathway of the coagulation cascade (fibrin formation). Therefore, it can be said that this material has little effect on the common blood coagulation pathway which leads to the formation of stable fibrin clot.

Synthetic platelets based on arginine-glycine-aspartic acid (RGD), could stimulate activated platelets and can lead to hemostasis [73]. RGD is a peptide (short chain amino acid monomer) sequence accountable for cell adhesion to the extracellular matrix in humans. Figure 2.4 shows RGD peptide sequence. Synthetic platelets were fabricated by using poly (lactic-co-glycolic acid)poly-L-lysine (PLGA-PLL) block co-polymer cores conjugating with poly ethylene glycol (PEG) and RGD. The core diameter of platelets were measured $170 \mathrm{~nm}$ by scanning electron microscopy. These synthetic platelets bind activated platelets and increase platelet aggregation [74]. Figure 2.5 represents synthetic platelets. Concentration of synthetic platelets have considerable effect on invivo study and it was estimated $20 \mathrm{mg} / \mathrm{mL}$. It was observed that $10 \mathrm{mg} / \mathrm{mL}$ concentration has no effect on hemostasis time and $40 \mathrm{mg} / \mathrm{mL}$ concentration leads to cardiopulmonary complications. Synthetic platelets were supplied by injection to surgically exposed femoral artery of a rat model and hemostasis achieved after $131 \pm 11$ seconds [75]. More animal trials are required and improper concentration of synthetic platelets can lead to pulmonary problems. 


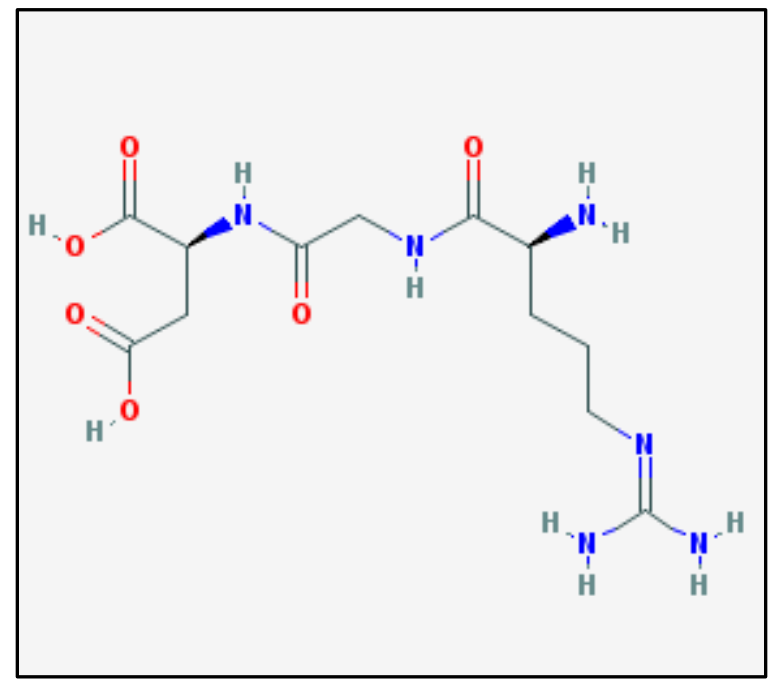

Figure 2.4: RGD peptide chain [76].

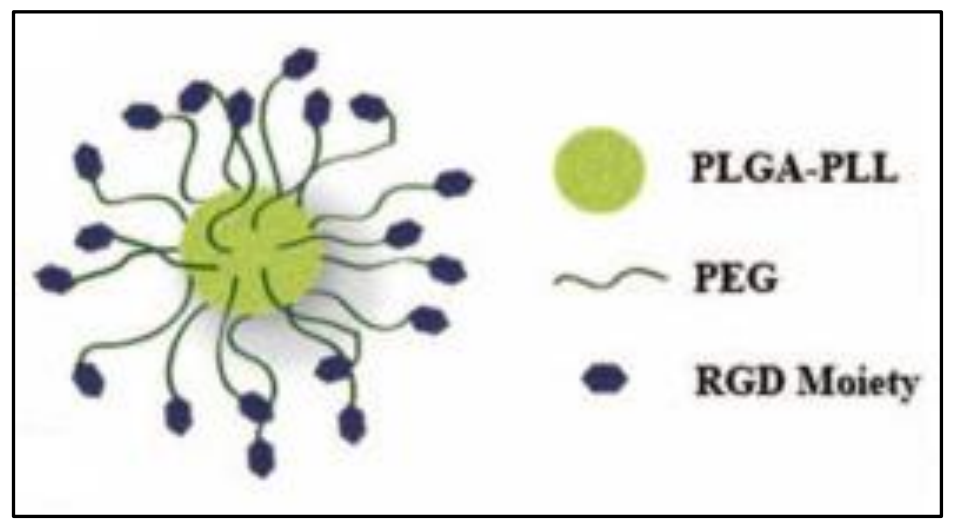

Figure 2.5: Schematic representation of synthetic platelets [73].

\subsubsection{Inorganic hemostats}

Novel oxidized regenerated cellulose (ORC) doped with sodium ( $\mathrm{Na}$ ) and potassium (K) ions could be a potent blood clotting agent [77]. An in vivo study was performed on a mouse model. It was observed that $\mathrm{Na}^{+}$and $\mathrm{K}^{+}$containing ORCs can achieve $594 \%$ and $220 \%$ faster blood clotting respectively compared to control (surgical gauze). $\mathrm{Na}^{+}$can activate clotting factor IX, $\mathrm{X}$ and thrombin in the blood coagulation cascade [77]. This study did not explain why $\mathrm{K}^{+}$containing ORC exhibited lower hemostatic efficacy than $\mathrm{Na}^{+}$doped ORC. The effect of $\mathrm{K}^{+}$in the blood coagulation cascade was not explained. Surface charge (zeta potential) of these materials were not measured. Inorganic oxides surface charge has prominent effect on blood coagulation cascade.

Silica xerogel (silica based sol-gel) doped with Calcium (Ca) is a potential hemostatic agent [78]. This material formed well-ordered mesoporous structure using sol-gel process. The molar 
concentration of $\mathrm{CaO}$ in the mesoporous silica xerogel was varied from 0 to 10 (wt.\%) at the expense of silica. A higher surface area was recorded for $100 \%$ silica ( $\left.489 \mathrm{~m}^{2} / \mathrm{g}\right)$. It was reported that inorganic oxides with higher surface area can accelerate intrinsic pathways for blood clotting cascades [79]. Prothrombin time (PT) and activated partial thromboplastin time (aPTT) were much shorter (16 s and $8 \mathrm{~s}$ respectively) for higher surface area mesoporous structure xerogels than nonmesoporous xerogels (19 s and $13 \mathrm{~s}$ respectively). It was also evident that aPTT and PT decreased with the increase of $\mathrm{Ca}$ concentration (10 s and $6 \mathrm{~s}$ respectively for $10 \% \mathrm{Ca}$ doped silica xerogel) [78] because calcium ions are a co-factor and catalyst for platelet reactions during blood coagulation [35]. MTT assay was performed on osteoblast cells in this study though fibroblast cells would be more effective for wound healing analysis. In-vivo studies are needed to show the effect of Ca doped silica xerogels on living organisms.

Mesoporous bioactive glass microspheres can be used as a hemostat [80]. Mesoporous microspheres were synthesized using ethanol sols of the inorganic precursors and surface directing agents. Microsphere diameter was found in the range of $100 \mathrm{~nm}$ to $1 \mu \mathrm{m}$. They were mixed with citrated sheep blood and a TEG® test was conducted [80]. TEG® (thromboelastography) is a test which measures the efficiency of blood coagulation [81]. Time for initial blood clot, maximum clot strength, rate of clot formation can be measured using TEG®. Amount of sample introduced in the TEG® test, also plays a critical role for blood coagulation. Greatest hemostatic activity was observed for $20 \mathrm{mg}$ MBG microspheres and hemostatic activity started within 3 minutes [80]. In this study it was noted that MBG microspheres play a dual role by supplying $\mathrm{Ca}$ ions and the mesoporous structure provides the physical barrier for surface dependent hemostasis [80]. It was also investigated by the same research group that surface charge density of metal oxides has a prominent effect on blood coagulation and it initiates the intrinsic pathway of the blood coagulation cascade [82]. It was noted that most negatively charged surfaces show fast onset of hemostasis time, increase rate of clot formation and clot strength. Most positively charged surfaces retard the onset of hemostasis time, decrease rate of clot formation and clot strength [82]. During the synthesis of MBG microspheres, the EISA method was not followed. The EISA method can lead to the formation of more micelles which can increase surface area, pore volume, porosity and the order of mesoporous channels. These improved physical properties could accelerate the hemostatic effect. 
Silver (Ag) containing MGBs have also been tested for hemostatic activity [83]. The MBGs provide the hemostatic effect while the Ag ions provide antibacterial properties. They used 0.02 wt.\% Ag concentration on the basis of antibacterial performance. The cell viability assay was conducted using extract of MBGs. However, cells in contact with powder samples could be more cytotoxic than extracts. In another study, $\mathrm{Ag}^{+}$doped mesoporous silica spheres achieved hemostasis within 3 minutes [84] but the precise concentration of $\mathrm{Ag}^{+}$in the silica glasses is not known. Therefore it is not possible to determine whether the concentration was in a cytotoxic range or not.

Gallium (Ga) containing MBGs can be a potential hemostatic agent [85]. It was observed that 1 (mol\%) Ga-MBG accelerated more platelet adhesion $\left(1.6 \times 10^{12}\right)$ than $2 \%$ and $3 \%$ Ga-MBGs $\left(1 \times 10^{12}\right.$ and $0.95 \times 10^{12}$ respectively) though control MBG can enhance more platelet adhesion than $2 \%$ and $3 \%$ Ga-MBGs $\left(1.1 \times 10^{12}\right)$. The antibacterial study revealed that $3 \%$ Ga-MBG achieved highest antibacterial efficacy compared to $1 \%$ and $2 \%$ Ga-MBGs [85]. The same research group synthesized hemostatic composite scaffolds using chitosan and different concentrations of $1 \% \mathrm{Ga}-$ MBG (10, 30, $50 \mathrm{wt} \%)$ [86]. During platelet adhesion studies, maximum platelets were adhered with 30 and $50 \mathrm{wt} \%$ Ga-MBG/chitosan scaffolds $\left(\sim 68 \times 10^{12}\right)$ than 10 wt $\%$ Ga-MBG/chitosan scaffold $\left(56 \times 10^{12}\right)$. The literature claimed that this was the synergistic effect of chitosan and GaMBG which can increase hemostatic activity [86]. However, the specific surface area of GaMBG/chitosan scaffolds $\left(25 \mathrm{~m}^{2} / \mathrm{g}\right)$ were greatly reduced compared to Ga-MBGs $\left(435 \mathrm{~m}^{2} / \mathrm{g}\right)$. Therefore, it is postulated that the hemostatic efficacy obtained using Ga-MBG/chitosan scaffolds was not the synergistic effect of chitosan and Ga-MBG, but only chitosan as it was liable for binding negatively charged platelets and RBCs.

Finely divided tantalum oxide powder containing 0.025 to 0.04 (wt.\%) iron $\left(\mathrm{Fe}^{3+}\right)$ can be used for burn treatment without using a skin graft [87]. [87]. Tantalum was chosen as a carrier because of its biological compatibility and $\mathrm{Fe}^{3+}$ was chosen because it was reported to accelerate hemostasis. Trivalent ions can reduce zeta potential of particles in a solution and can aggregate more platelets [88]. However, no TEG test was conducted to measure blood clot strength and no cytotoxicity study was done.

Metallic tantalum has biological inertness. The strength of metallic tantalum is similar to stainless steel and is malleable [89]. These properties were chosen to use tantalum clips as a hemostat. 
Hemostatic clips are used to recover delayed bleeding after surgery. However, these clips remain in the body after wounds are healed and may cause complications in the future. During endoscopic closure, suturing is better than clipping [90]. This is because clips can lead to abdominal pain after surgery. Table 2.1 summarizes different potential hemostatic agents working principle and plausible effects.

In summary, commercial hemostatic agents do not meet all the requirements for ideal hemostatic agents. (Table 1.1). Zeolite based hemostats can produce exothermic reactions and, gelatin and chitosan containing hemostats cause allergic reactions. In the case of Arista ${ }^{\circledR}$, swelling of particles can cause necrosis Hydrogel based hemostats are good for soft tissues, however, swelling of hydrogel could be cytotoxic to living cells. Chitosan based hemostatic agents are not suitable for excessive bleeding due to their light weight, and nanoparticles could lead to thrombosis. Inorganic hemostats tend to have fewer complications. MBGs are inorganic hemostats which can achieve hemostasis effectively using their physical properties with minimal side effects. 
Table 2.1: Commercial and potential hemostats, their working principles and shortcomings

\begin{tabular}{|c|c|c|}
\hline Name of the hemostat & Working principle & Shortcomings \\
\hline QuickClot® & $\begin{array}{l}\text { Dehydrates blood and concentrates serum } \\
\text { proteins }\end{array}$ & $\begin{array}{l}\text { Produces exothermic reaction. Can } \\
\text { lead to thrombosis. }\end{array}$ \\
\hline Woundstat ${ }^{\mathrm{TM}}$ & Absorb water from the blood & - Results thrombosis \\
\hline Gelfoam ${ }^{\circledR}$ & Initiates intrinsic pathway & - Causes allergic reactions \\
\hline Celox $^{\mathrm{TM}}$ & Aggregates RBCs and platelets & - Leads to inflammation \\
\hline $\begin{array}{l}\text { Dry fibrin sealant dressing } \\
\text { (DFSD) }\end{array}$ & Provides fibrinogen & - Transmission of diseases \\
\hline Arista ${ }^{\circledR}$ & $\begin{array}{l}\text { Dehydrates blood and acts as a molecular sieve } \\
\text { for platelets and serum proteins }\end{array}$ & - Can cause necrosis \\
\hline Hydrogel-SMP composite & $\begin{array}{l}\text { Absorb water from the blood and expand to fill } \\
\text { the wound cavity }\end{array}$ & $\begin{array}{l}\text { - Good for deep and irregular wounds. } \\
\text { - Removal can be an issue. }\end{array}$ \\
\hline $\begin{array}{l}\text { Hydrogel nanocomposite } \\
\text { (HNC) }\end{array}$ & $\begin{array}{l}\text { Swelling of particles provide physical barrier. } \\
\text { Nanoparticles stimulate intrinsic pathway. }\end{array}$ & $\begin{array}{l}\text { - Swelling can lead to compression } \\
\text { necrosis }\end{array}$ \\
\hline $\begin{array}{l}\text { Synthetic surgical glue } \\
\text { (MeTro) }\end{array}$ & $\begin{array}{l}\text { Photo crosslinking of surgical glue enables } \\
\text { adherence to soft tissues }\end{array}$ & - Applicable for soft tissues only. \\
\hline $\begin{array}{l}\text { Batroxobin (snake venom) } \\
\text { loaded in peptide hydrogel }\end{array}$ & $\begin{array}{l}\text { Converts fibrinogen to fibrin and fibrin mesh } \\
\text { can entrap RBCs. Hydrogel acts as a physical } \\
\text { barrier. }\end{array}$ & $\begin{array}{l}\text { - Could be cytotoxic and leads to } \\
\text { thrombosis }\end{array}$ \\
\hline Chitosan coated diatom silica & $\begin{array}{l}\text { Can aggregate negatively charged RBCs. Silica } \\
\text { stimulates intrinsic pathway. Porous silica } \\
\text { absorb water from the blood. }\end{array}$ & - Not suitable for excessive bleeding. \\
\hline $\begin{array}{l}\text { Mini-sponge dressing coated } \\
\text { with chitosan }\end{array}$ & $\begin{array}{l}\text { Absorb blood from the wound, provides } \\
\text { physical barrier. Chitosan aggregate RBCs and } \\
\text { platelets. }\end{array}$ & - Removal could be complicated \\
\hline $\begin{array}{l}\text { Chicken feather keratin } \\
\text { nanoparticles }\end{array}$ & $\begin{array}{l}\text { Nanoparticles initiate intrinsic pathway and } \\
\text { adsorbed to RBCs/platelets to form a barrier. }\end{array}$ & $\begin{array}{l}\text { - Could be cytotoxic. Can lead to } \\
\text { thrombosis. }\end{array}$ \\
\hline $\begin{array}{l}\text { Gauze loaded with } \mathrm{CaCO}_{3} \text {, } \\
\text { thrombin and tranexamic acid }\end{array}$ & $\begin{array}{l}\mathrm{Ca}^{2+} \text { acts as a co-factor. Thrombin cleaves } \\
\text { fibrinogen. Tranexamic acid is anti-fibrinolytic. }\end{array}$ & - Can transmit diseases. \\
\hline Phosphate coacervates & Platelets adhesion & $\begin{array}{l}\text { - Weakens the formation of stable } \\
\text { fibrin clot. }\end{array}$ \\
\hline Artificial platelets & $\begin{array}{l}\text { Can bind activated platelets. } \\
\text { Increase platelet aggregation. }\end{array}$ & $\begin{array}{l}\text { - Improper dose leads to pulmonary } \\
\text { problems. }\end{array}$ \\
\hline $\begin{array}{l}\text { Oxidized regenerated } \\
\text { cellulose doped with } \mathrm{Na}^{+} \text {and } \\
\mathrm{K}^{+}\end{array}$ & $\mathrm{Na}^{+}$activates factor IX, $\mathrm{X}$ and thrombin. & Surface charge was not measured. \\
\hline Silica xerogels & $\begin{array}{l}\text { Accelerate intrinsic pathway. } \mathrm{Ca}^{2+} \text { is a co-factor } \\
\text { for blood coagulation. }\end{array}$ & $\begin{array}{l}\text { - Cell viability was not evaluated on } \\
\text { fibroblast cells. } \\
\text { - No in-vivo study was conducted. }\end{array}$ \\
\hline MBG microsphere & $\begin{array}{l}\text { Negative surface charge initiates intrinsic } \\
\text { pathway. } \mathrm{Ca}^{2+} \text { acts as a co-factor. }\end{array}$ & $\begin{array}{l}\text { - Change in synthesis process could } \\
\text { provide better hemostatic } \\
\text { performance. }\end{array}$ \\
\hline Silver containing MBGs & $\begin{array}{l}\text { Absorb water from the blood. } \\
\text { Concentrate blood clotting factors. }\end{array}$ & $\begin{array}{l}\text { - Cell viability performed on powder } \\
\text { extracts. }\end{array}$ \\
\hline $\begin{array}{l}\text { Gallium doped MBGs and } \\
\text { Ga-MBG/chitosan scaffold }\end{array}$ & $\begin{array}{l}\text { Water absorption from the blood. } \\
\text { Concentration of clotting factors. } \\
\text { Chitosan induces RBCs and platelets. }\end{array}$ & - Surface area reduced for scaffolds \\
\hline $\begin{array}{l}\text { Tantalum oxide and iron } \\
\text { oxide powder }\end{array}$ & $\begin{array}{l}\text { Tantalum oxide provides physical barrier. } \mathrm{Fe}^{3+} \\
\text { stimulates platelet aggregation. }\end{array}$ & $\begin{array}{l}\text { - Thromboelastography and cell } \\
\text { viability were not conducted. }\end{array}$ \\
\hline Tantalum hemostatic clips & Joining of surrounding tissue. & Future complications. \\
\hline
\end{tabular}




\subsection{Rationale}

The current, pertinent, literature does not report the effect of calcination heating rate during synthesis of MBGs on their physical properties. It is hypothesized that calcination heating rate could control the porous architecture of MBGs. This processing parameter will be investigated in this study.

The reason MBGs are chosen for this study is because they have good physical properties i.e. high surface area, pore volume and ordered channel structure, and have the potential to act as a molecular sieves for platelets and other serum proteins to aggregate. The composition for the MBGs was chosen based on the properties of each elements. Silica is the main ingredient for a lot of bioactive glasses as it is a network former. Calcium is a network modifier which disrupts the continuity of the silica network. Calcium also plays an important role in the blood coagulation cascade [35]. Phosphorus addition into the sol-gel glasses increases degradation rate of silica network in the surrounding environment which leads to rapid HA crystallization [91]. To achieve enhanced bioactivity of synthesized glasses, calcium to phosphorus ratio should be maintained 2 to 3 [92]. Recently, tantalum has been incorporated into silica based bioglass systems and exhibited promising properties suitable for orthopedic applications when mixed with poly (acrylic acid) to prepare bioadhesives [93]. That is why $\mathrm{SiO}_{2}-\mathrm{CaO}-\mathrm{P}_{2} \mathrm{O}_{5}-\mathrm{Ta}_{2} \mathrm{O}_{5}$ glass network will be studied in this research. Tantalum will be incorporated into the MBG network to investigate the effect of tantalum on hemostasis. To the author's knowledge, the incorporation of tantalum into MBGs is a novel approach to treating hemorrhage. 


\section{The Effect of Calcination Heating Rate on the Structure of Mesoporous Bioactive}

Glasses.

This chapter is based on the following submitted paper:

Md. Saidur Rahman, Andrew Mendonca, Adel Alhalawani, Deanna Polintan, Owen M. Clarkin and Mark R. Towler. The effect of calcination heating rate on the structure of mesoporous bioactive glasses. The Journal of Non-Crystalline solids (manuscript number: NOC-D-18-00435).

\subsection{Introduction}

Since their invention in the 1960s, bioactive glasses (BGs) have found increasing use in the biomedical engineering field. One of the main reasons for this is their ability to form an interfacial bond with host tissue [94]. This bond is formed as a result of the formation of a hydroxycarbonated apatite (HCA) layer, which is comparable in composition to the mineral phase of bone [95]. Bone cells will proliferate at the interface, causing bone growth into the BG [3]. Silica-based BGs have an amorphous network structure which can contain dopants to disrupt the continuity of the glass network, and form non-bridging silicon-oxygen bonds (Si-NBO) [22]. The number of Si-NBOs directly influences the bioactivity of the glasses, with greater number of Si-NBO bonds leading to greater reactivity [22]. Dependent on the dopants they can also facilitate apatite deposition or accelerate BG degradation [96]. Gradual degradation and release of ionic species from the glass can have targeted effects such as inhibition of infection and angiogenesis [97].

Mesoporous materials were synthesized in 1992 using surface directing agent [7]. Mesoporous bioactive glasses (MBGs) possess channel structures resulting in high surface area [9]. This facilitates increased release of ions and results in improved bioactivity [10]. MBGs also possess higher pore volume (PV, $\sim 0.45 \mathrm{~cm}^{3} / \mathrm{g}$ ) compared to BGs $\left(\sim 0.03 \mathrm{~cm}^{3} / \mathrm{g}\right)$ [11] with pore sizes ranging from 2 to $50 \mathrm{~nm}$ [12]. These properties make MBGs candidates for drug delivery [13], implant coatings [15], tissue engineering [15], bone grafting [14], dental [16] and hemostatic applications [2]. An ideal hemostat should have the following properties: it can achieve hemostasis within two minutes of application [28], it should be biodegradable, inhibit bacterial infection, suitable for both deep and irregular wounds, and be non-inflammatory [38]. The porous morphology of MBGs can absorb water from the blood into their mesopores and can concentrate blood clotting factors, accelerating hemostasis [83]. Their high surface area gives fast degradability, and dopants can be used to inhibit bacterial infection and inflammation [85]. 
Sol-gels are stable suspensions of colloids in a porous gel network [8]. The sol-gel process is the building block for the synthesis of MBGs. Besides composition, there are two main parameters that effect the physical structure of MBGs (aside from composition): type of surfactant and calcination temperature. The effects of surfactant have been studied and reviewed, and the effects of surfactant on surface area, pore volume and pore size have been correlated [39]. CTAB (cetyltrimethylammonium bromide) produces the highest SA and PV, followed by the F-series poloxamers (F127 and F108), and lastly the P-series poloxamers (P123 and P85) [39]. The effect of calcination temperature was studied by Pereira et al. [40]. It was found that SA and PV decrease as the calcination temperature is increased from $400^{\circ} \mathrm{C}$ to $800^{\circ} \mathrm{C}$. This was done without the use of surfactant to confound the results [40]. The effect of calcination temperature, heating rate and the residence time of thermal treatment for MBG scaffolds were studied by Shih et al. [98]. They synthesized MBG scaffolds utilizing F-127 as a surfactant at various calcination temperatures $\left(400,500,600,700\right.$ and $\left.800^{\circ} \mathrm{C}\right)$, using different heating rates $\left(1,10\right.$ and $\left.20^{\circ} \mathrm{C} / \mathrm{min}\right)$ and with varying residence times (2, 4, 6 and 8 hours). In their study, there was no clear correlation between the three parameters. To the authors' knowledge, the literature is lacking insight into the relationship between heating rate and MBG's physical and chemical properties.

It is hypothesized that heating rate during calcination affects the physical and chemical structure of sol-gel glasses. In order to confirm this, two batches of MBG were synthesized using low $\left(1^{\circ} \mathrm{C} / \mathrm{min}\right)$ and high $\left(20^{\circ} \mathrm{C} / \mathrm{min}\right)$ heating rates. Physical structure and chemical composition of these two batches are compared and analyzed.

\subsection{Synthesis and characterization}

\subsubsection{Materials}

Reagent grade triblock copolymer $\mathrm{P} 123\left(\mathrm{EO}_{20} \mathrm{PO}_{70} \mathrm{EO}_{20}\right)$, calcium nitrate tetrahydrate $[\geq 99.0 \%$, $\left.\mathrm{Ca}\left(\mathrm{NO}_{3}\right)_{2} .4 \mathrm{H}_{2} \mathrm{O}\right]$, triethyl phosphate ( $\geq 99.8 \%$, TEP), tetraethyl orthosilicate $(98 \%$, TEOS), and

ethanol $(\mathrm{EtOH})$ were used. Reagent grade hydrochloric acid $(\mathrm{HCl})$ was diluted to $0.5 \mathrm{M} \mathrm{HCl}$ using deionized (DI) water. All reagents were purchased from Sigma Aldrich (Oakville, ON, Canada). For this work, P123 was chosen as a surface directing agent because it yields more ordered mesoporous structures compared to other agents such as CTAB and F127 [39]. 


\subsubsection{Synthesis}

MBG synthesis was performed following the process of Yan et al. [9]. Typically, 4g of P123 and $1.4 \mathrm{~g}$ of calcium nitrate tetrahydrate were dissolved in $76 \mathrm{~mL}$ of EtOH. In a separate graduated cylinder, $1 \mathrm{~mL}$ of $0.5 \mathrm{M}$ hydrochloric acid and $7.18 \mathrm{~mL}$ of TEOS were left to react for the acidcatalyzed hydrolysis of TEOS. $0.68 \mathrm{~mL}$ TEP was added to the EtOH solution. Lastly, the TEOSacid solution was poured into the EtOH solution. The solution was covered and stirred overnight. It was then transferred to a petri dish for 5 days to allow for the evaporation-induced self-assembly (EISA) process. The EISA-derived gel was then calcined at $650^{\circ} \mathrm{C}$ using a Hot Spot 110 furnace (Zircar Zirconia Inc., Florida, USA) for 6 hours, with $\left(20^{\circ} \mathrm{C} / \mathrm{min}\right.$ and $\left.1{ }^{\circ} \mathrm{C} / \mathrm{min}\right)$ heating rates. The glasses have identical chemical compositions (Table 3.1)

Table 3.1: Compositions for synthesized MBGs (mol\%).

\begin{tabular}{cccc}
\hline Sample code & $\mathbf{S i O}_{2}$ & $\mathbf{C a O}$ & $\boldsymbol{P}_{2} \boldsymbol{O}_{5}$ \\
\hline$H-M B G$ & 80 & 15 & 5 \\
$L-M B G$ & 80 & 15 & 5 \\
\hline
\end{tabular}

The calcined samples were ground in a PM 100 ball mill (Retsch GmbH, Germany) at 500 rounds per minute (rpm) for 45 minutes. . A $45 \mu \mathrm{m}$ sieve was used to obtain powders with particle sizes $<45 \mu \mathrm{m}$ for characterization.

\subsubsection{X-ray diffraction}

Diffraction patterns were collected using a Philips PW3710 X-ray diffractometer (Phillips, Holland) with a $\mathrm{Cu}$ source from $10^{\circ}$ to $80^{\circ}(2 \theta)$, at a step size of $0.1^{\circ}$ and count time of $2 \mathrm{~s}$ per step. A generator voltage of $45 \mathrm{kV}$ and a tube current of $20 \mathrm{~mA}$ were employed.

\subsubsection{Energy dispersive X-ray spectroscopy (EDS) and X-ray photoelectron spectroscopy} (XPS)

A JEOL 6380LV scanning electron microscope (JEOL, Massachusetts, USA) equipped with Oxford EDS was used to examine the chemical composition of each sample. The generating voltage used was $20 \mathrm{kV}$. A $1 \mathrm{~cm} \mathrm{Cu}$ sample holder with double sided carbon tape was pressed onto powder samples and placed into the SEM for analysis.

XPS was conducted on a K-Alpha XPS system (Thermo Fisher Scientific, Massachusetts, USA). Monochromated Al K-Alpha X-rays were used for analysis with a spot size of $400 \mu \mathrm{m}$. Charge compensation was achieved utilizing a low energy flood of electrons and ions under $\sim 5 \times 10^{-8} \mathrm{mbar}$ 
vacuum. Residual pressure was from argon associated with operation of a charge compensation source. The survey spectrum was acquired in a high pass energy $(200 \mathrm{eV})$, low point-density (1 point/eV) scanned mode. Regional spectra used to determine relative atomic composition, as well as for determination of chemical information, was acquired in a low pass energy (50eV), high point-density (0.1eV spacing) scanned mode.

\subsubsection{Fourier transform infrared (FT-IR) spectroscopy}

Attenuated total reflection Fourier transform infrared (ATR-FTIR) spectroscopy was carried out on the powder samples using an ATR-iS50 FTIR spectrometer (Thermo Scientific, Massachusetts, USA). Spectra were collected from $400-1500 \mathrm{~cm}^{-1}$ with spectral resolution $0.25 \mathrm{~cm}^{-1}$.

\subsubsection{Transmission electron microscopy (TEM)}

Transmission electron microscopy was carried out on a Hitachi HT-7700 (Hitachi, Japan), using $80 \mathrm{kV}$ generating voltage, to look at the structure of the nano-channels within the glass. Samples were embedded in modified Spurr's resin (Electron Microscopy Sciences, Pennsylvania, USA), ultramicrotomed and then placed onto copper grids for imaging.

\subsubsection{Brunauer-Emmett-Teller (BET) and Barrett-Joyner-Halenda (BJH) analysis}

Surface area measurements were carried out by nitrogen gas adsorption in a Micromeritics Gemini VII 2390 gas adsorption analyser (Micromeritics, Georgia, USA). The surface area was then calculated using Brunauer-Emmett-Teller (BET) theory, and pore size distribution and pore volume were estimated using the Barrett-Joyner-Halenda (BJH) schema.

\subsubsection{Ion release analysis}

Ion release was conducted in DI water and analyzed using inductively coupled plasma- optical emission spectroscopy (ICP-OES). $50 \mathrm{mg}$ of sample was placed in a micro-centrifuge tube containing $1 \mathrm{~mL}$ deionized water. After the appropriate time intervals (15, 30 and $60 \mathrm{~min})$, samples were centrifuged at $10000 \mathrm{rpm}$ for $2 \mathrm{~min}$ [99]. The supernatant was collected and diluted to conduct analyses.

Chemical compositions of the collected samples were analyzed using ICP-OES, performed on an Optima 7300 DV ICP-OES (Perkin Elmer, Massachusetts, USA). Calibration standards for silicon, calcium and phosphorus were prepared from a 1000 parts per million (ppm) stock solution. For the silicon sample 1, 5, 10 and 25 ppm were used as calibration standards. For calcium 0.5, 1, 5, 
and $10 \mathrm{ppm}$, and for phosphorous $0.1,0.5,1,5 \mathrm{ppm}$ calibration standards were used. In all cases, DI water was used as the blank.

\subsubsection{Statistical analysis}

Data were plotted using the mean \pm standard deviation of samples $(n=9)$. Statistical analysis was performed using SPSS software (IBM SPSS Statistics, version 24, New York, USA). Independent samples t-test was used to analyze the data and to find out statistical significance with $\mathrm{p}<0.05$.

\subsection{Results}

Figure 3.1 shows the XRD patterns for the H- and L-MBG samples. No peaks were present in the patterns of either sample, confirming the amorphicity of both glasses. EDS results (

Table 3.2) confirm the presence of $\mathrm{O}, \mathrm{Si}, \mathrm{Ca}$ and $\mathrm{P}$ in both glasses. Compositional data was also measured with XPS and relevant spectra for the glasses are shown in Figure 3.2 and Figure 3.3. Expected peaks for $\mathrm{O}, \mathrm{Si}, \mathrm{Ca}$ and $\mathrm{P}$ were observed in the XPS spectrum.

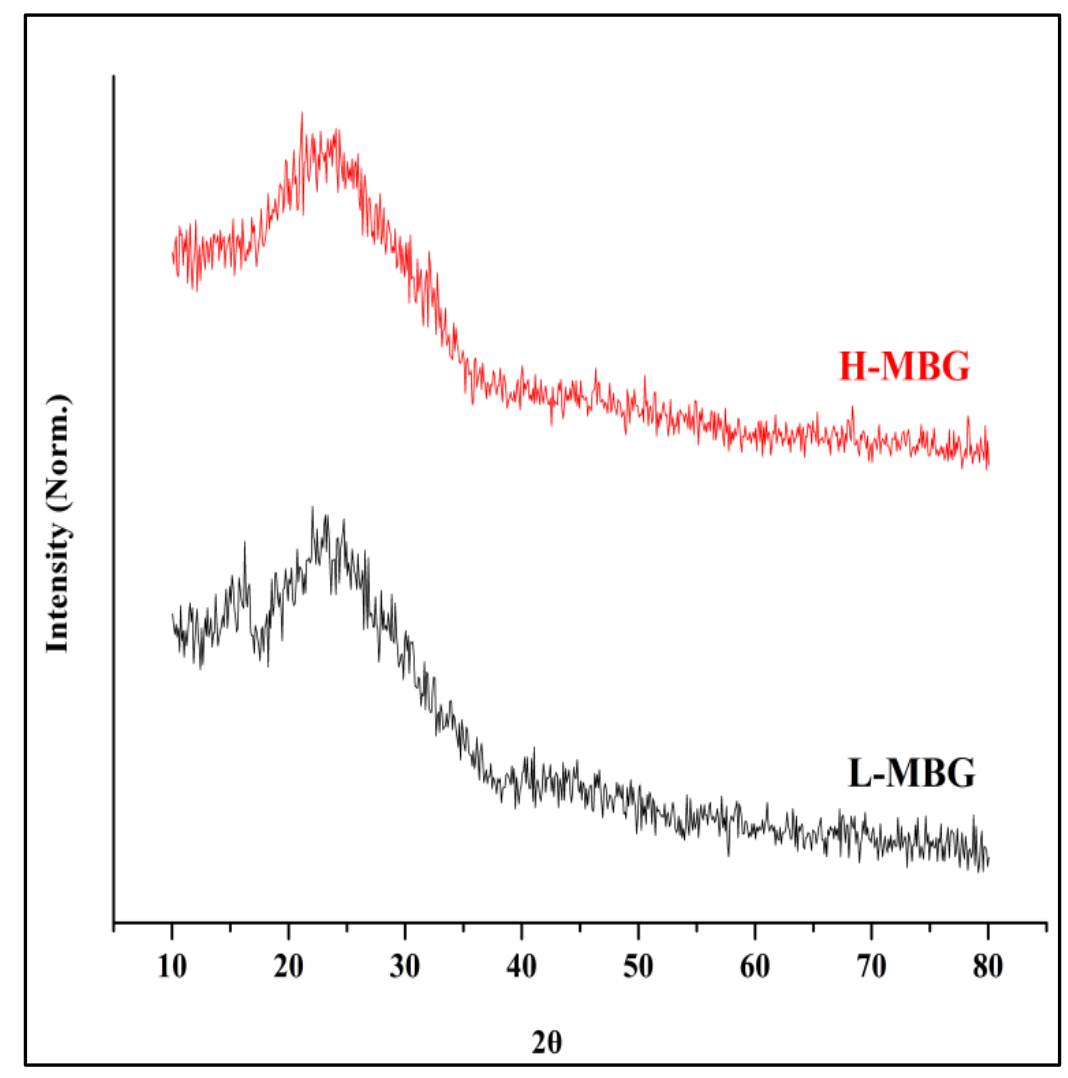

Figure 3.1: XRD traces for $H-M B G$ and $L-M B G$. 
Table 3.2: Summary of compositions (wt.\%) obtained from EDS

\begin{tabular}{ccccc}
\hline Sample & $\boldsymbol{O}$ & $\boldsymbol{S i}$ & $\boldsymbol{C a}$ & $\boldsymbol{P}$ \\
\hline$L-M B G$ & 58.60 & 31.40 & 7.23 & 2.77 \\
$H-M B G$ & 63.36 & 27.30 & 7.17 & 2.17 \\
\hline
\end{tabular}

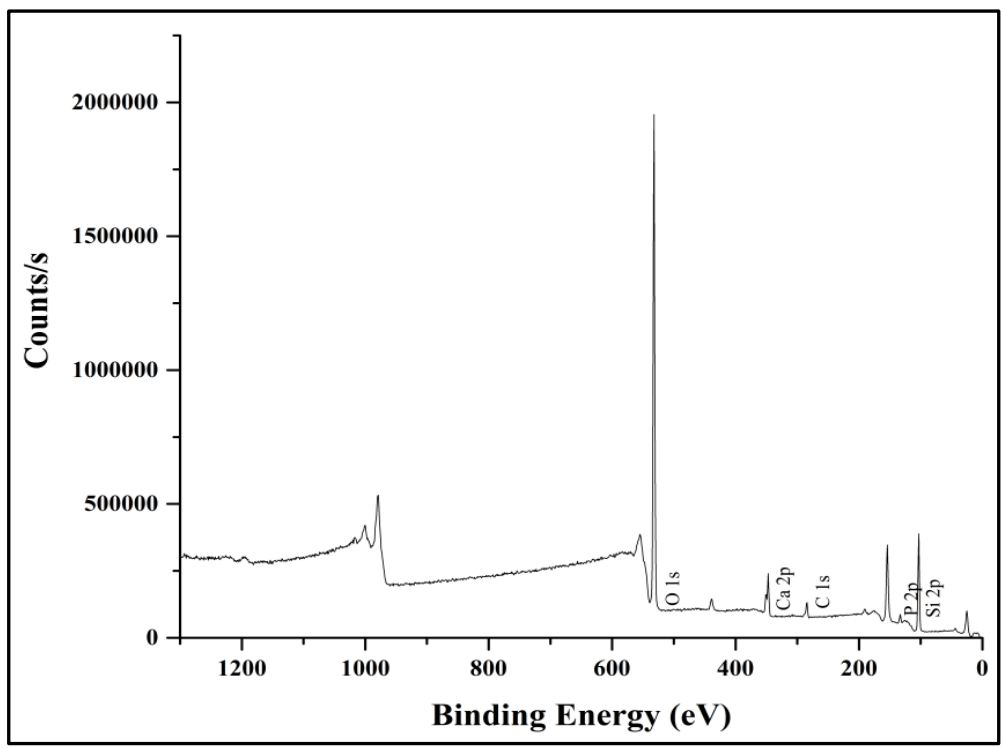

Figure 3.2: XPS spectrum for $L-M B G$.

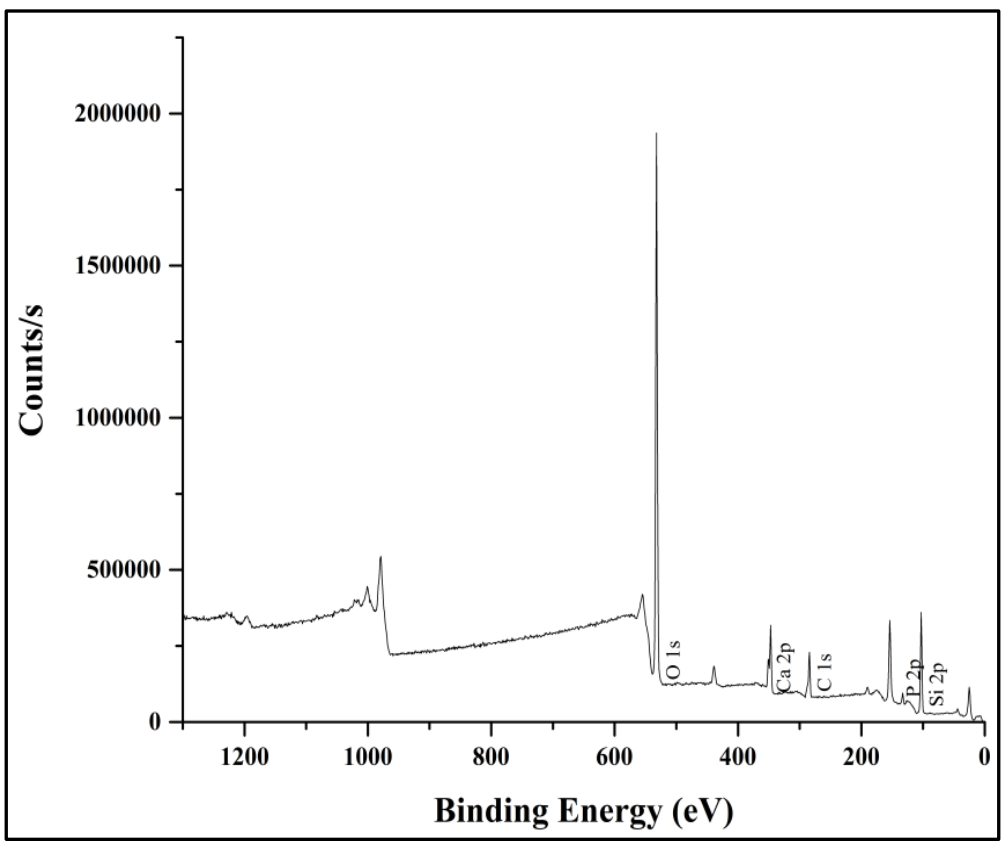

Figure 3.3: XPS spectrum for $H-M B G$. 
The carbon peak is due to the presence of adventitious carbon from adsorption of impurities during MBG handling and synthesis. Atomic percentages (normalized without carbon) are shown in Table 3.3 for $\mathrm{L}-\mathrm{MBG}$ and $\mathrm{H}-\mathrm{MBG}$.

Table 3.3: Normalized XPS data (at.\%)

\begin{tabular}{ccccc}
\hline Sample & $\boldsymbol{O}$ & $\boldsymbol{S i}$ & $\boldsymbol{C a}$ & $\boldsymbol{P}$ \\
\hline L-MBG & 60.70 & 34.42 & 2.73 & 2.15 \\
$H-M B G$ & 67.69 & 26.23 & 4.23 & 1.85 \\
\hline
\end{tabular}

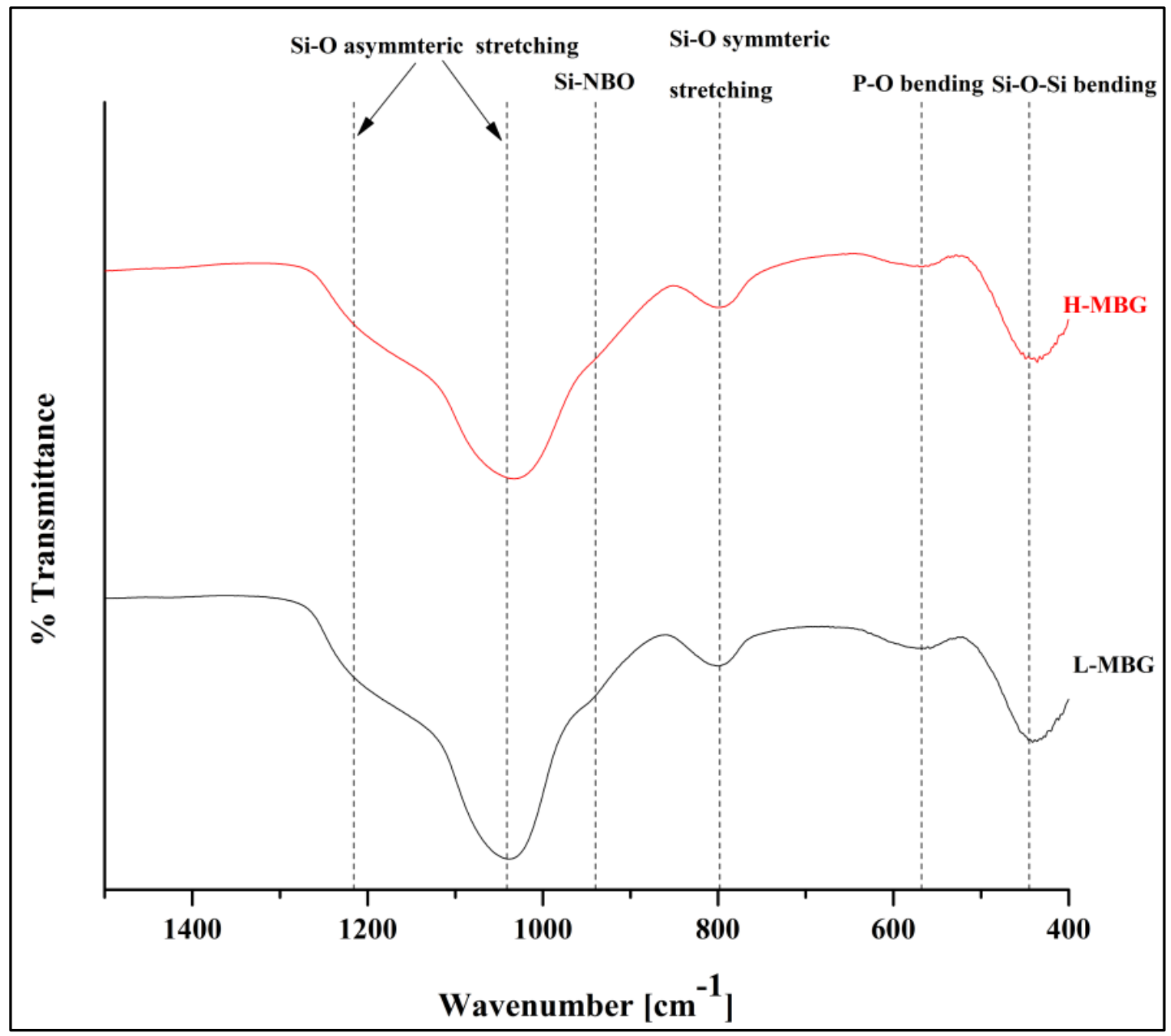

Figure 3.4: FT-IR spectra for $L-M B G$ and $H-M B G$ samples. 
FT-IR transmission spectra are shown in Figure 3.4, along with corresponding peaks. For L-MBG, the peak at $445 \mathrm{~cm}^{-1}$ represents $\mathrm{Si}-\mathrm{O}-\mathrm{Si}$ bending vibration [100], whereas the peak at $798 \mathrm{~cm}^{-1}$ indicates symmetric stretching of the Si-O bond [101]. The peak at $568 \mathrm{~cm}^{-1}$ corresponds to P-O bending mode [96]. Characteristic peaks located at $1041 \mathrm{~cm}^{-1}$ and $1216 \mathrm{~cm}^{-1}$ are attributed to asymmetric stretching of Si-O bonds [4]. Lastly, the peak observed at $940 \mathrm{~cm}^{-1}$ is identified as the Si-NBO bond [28,29]. In case of H-MBG, all the functional groups were observed in the same intensities as L-MBG.

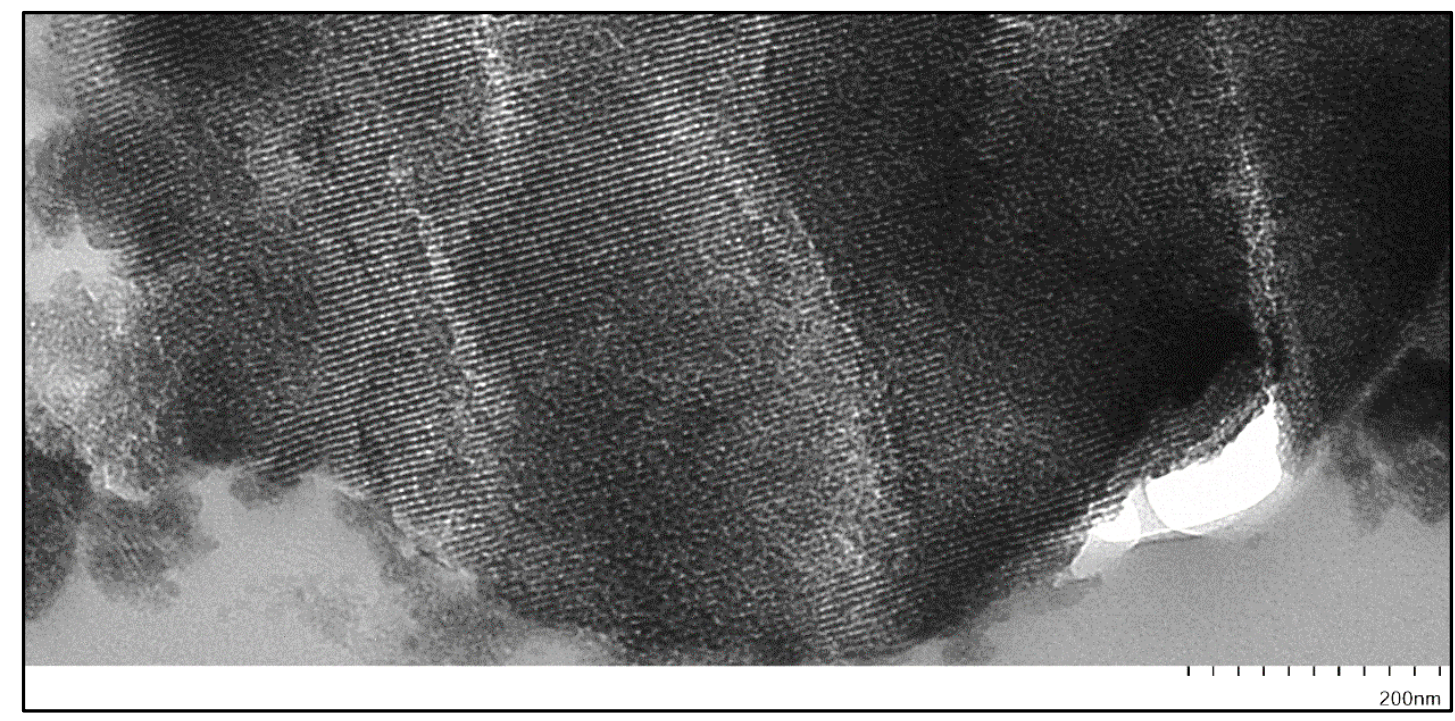

Figure 3.5: TEM image of $L-M B G$ at 30k magnification.

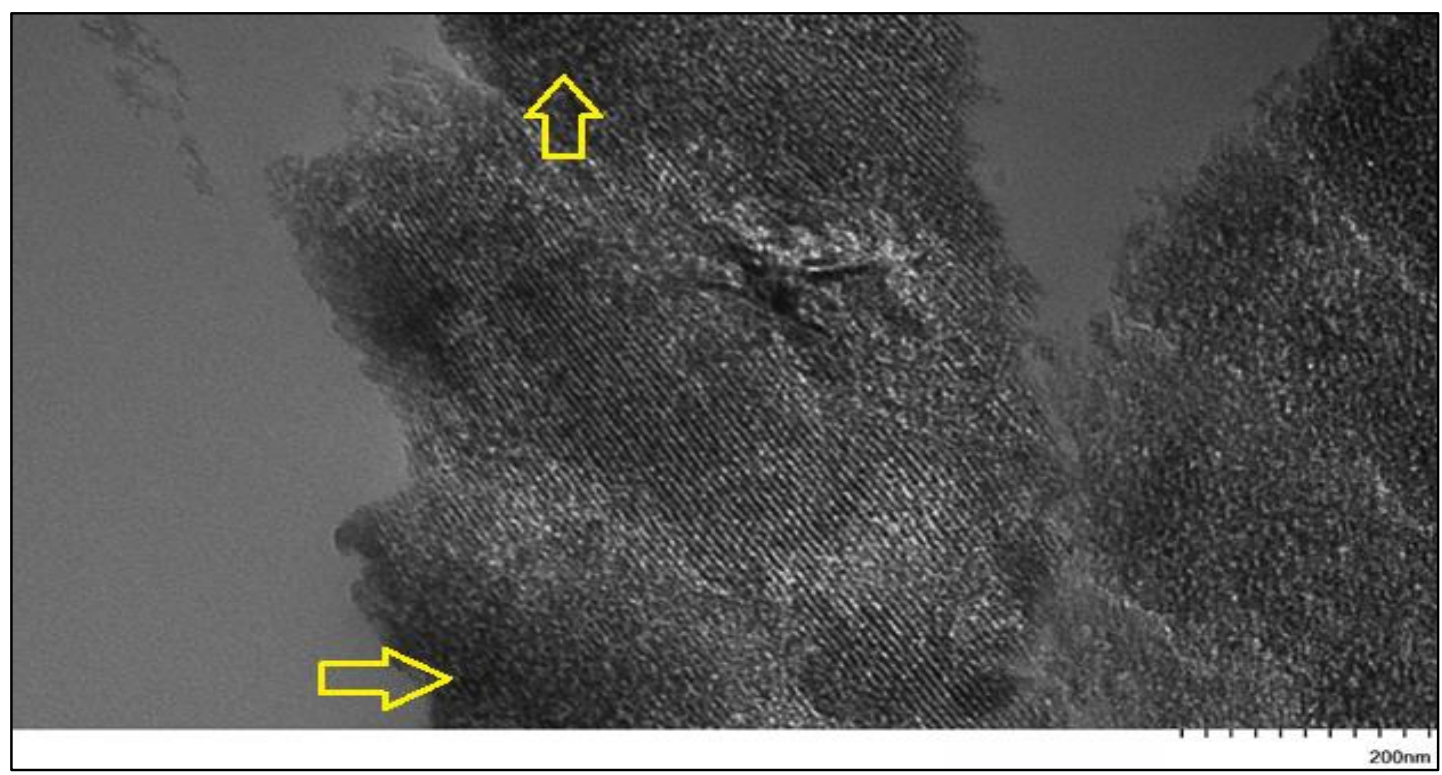

Figure 3.6: TEM image of $H-M B G$ at 30k magnification. Arrow sign in the discontinuous regions of mesoporous channels. 
TEM images of L-MBG and H-MBG samples can be seen in Figure 3.5 and Figure 3.6, respectively. In the L-MBG sample, 2D hexagonal well-ordered mesoporous channels are observed (Figure 3.5). The TEM image of H-MBG sample exhibits similar 2D hexagonal channels. However, H-MBG exhibits more discontinuities than L-MBG (Figure 3.6).

The nitrogen $\left(\mathrm{N}_{2}\right)$ adsorption isotherm was measured at $77 \mathrm{~K}$ for both glasses. BET surface area for L-MBG is $373.87 \mathrm{~m}^{2} / \mathrm{g}$ and $\mathrm{BJH}$ adsorption cumulative pore volume is $0.27 \mathrm{~cm}^{3} / \mathrm{g}$. For $\mathrm{H}-$ MBG, BET surface area and BJH pore volume are $85.91 \mathrm{~m}^{2} / \mathrm{g}$ and $0.13 \mathrm{~cm}^{3} / \mathrm{g}$, respectively. Average pore diameter is noted as $4.34 \mathrm{~nm}$ for L-MBG and $4.65 \mathrm{~nm}$ for H-MBG. Table 3.4 summarizes BET surface area, BJH pore volume and average pore diameter results.

Table 3.4: Physical properties of $L-M B G$ and $H-M B G$.

\begin{tabular}{cccc}
\hline Sample & $\begin{array}{c}\text { BET surface area } \\
\left(\mathbf{m}^{2} / \mathbf{g}\right)\end{array}$ & $\begin{array}{c}\text { BJH pore volume } \\
\left(\mathbf{c m}^{3} / \mathbf{g}\right)\end{array}$ & $\begin{array}{c}\text { BJH average pore diameter } \\
(\mathbf{n m})\end{array}$ \\
\hline$L-M B G$ & 373.87 & 0.27 & 4.34 \\
$H-M B G$ & 85.91 & 0.13 & 4.65 \\
\hline
\end{tabular}

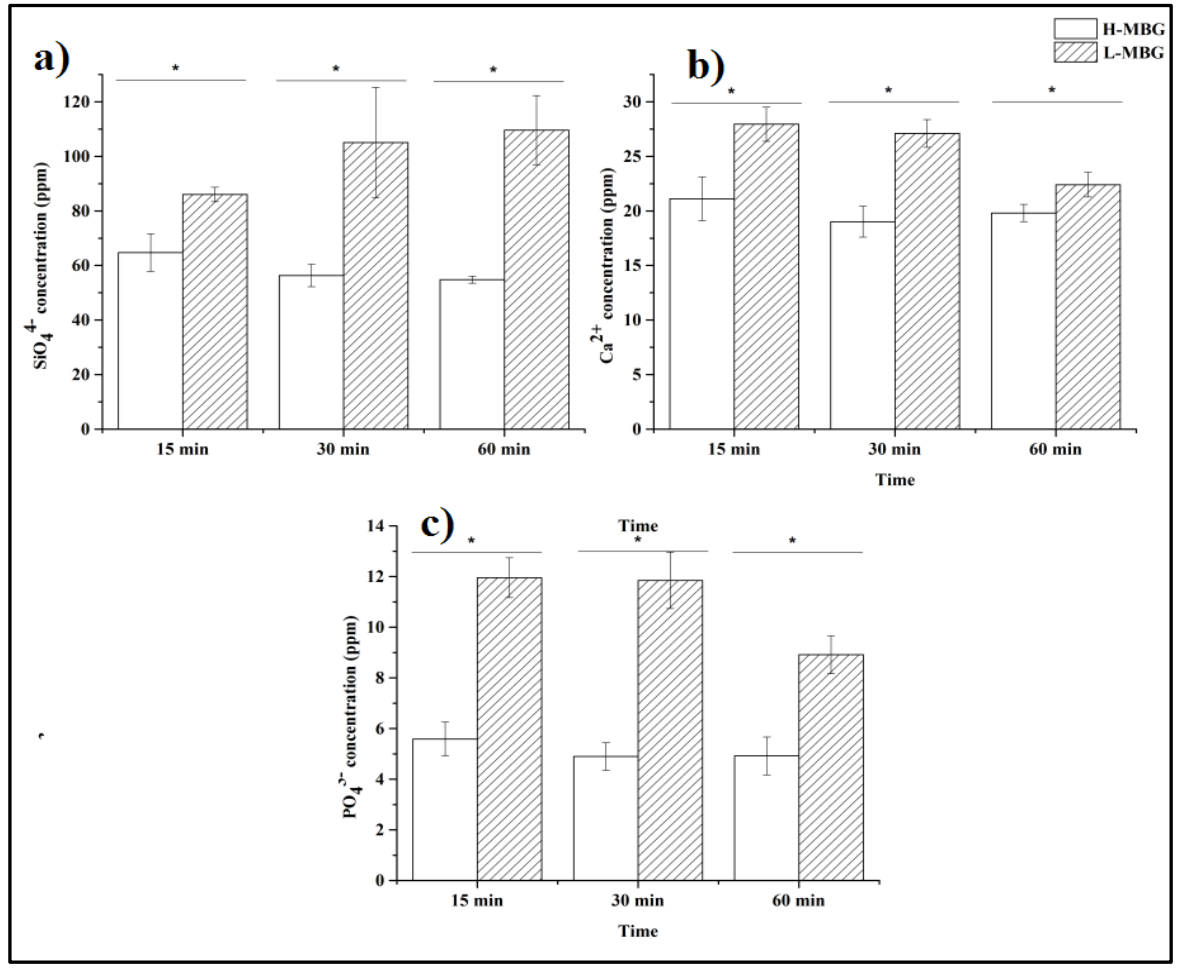

Figure 3.7: a) $\mathrm{SiO}_{4}^{4-}$, b) $\mathrm{Ca}^{2+}$ and c) $\mathrm{PO}_{4}^{3-}$ ion release from $L-M B G$ and $H-M B G$ samples. Error bar represents standard deviation from the mean $(n=9) . *$ Represents statistical significance between samples $(p<0.05)$. 
The ion release profiles for both sets of MBGs are shown in Figure 3.7. It is observed that $\mathrm{SiO}_{4}{ }^{4-}$ ion concentration increases significantly from $15 \mathrm{~min}$ to $30 \mathrm{~min}$, for $\mathrm{L}-\mathrm{MBG}$, and then begins to reach a steady state (Figure 3.7 a). The ions $\left(\mathrm{SiO}_{4}{ }^{4-}, \mathrm{Ca}^{2+}\right.$ and $\left.\mathrm{PO}_{4}{ }^{3-}\right)$ released from $\mathrm{H}-\mathrm{MBG}$ have negligible change in concentration for consecutive time intervals $(64.7,56.3$ and $54.8 \mathrm{ppm}$ for $\mathrm{SiO}_{4}{ }^{4-} ; 21.1,19$ and $19.8 \mathrm{ppm}$ for $\mathrm{Ca}^{2+} ; 5.6,4.9$ and $4.9 \mathrm{ppm}$ for $\mathrm{PO}_{4}{ }^{3-}$ ).

\subsection{Discussions}

Compositional data, measured through EDS and XPS, show that both L-MBG and H-MBG are chemically identical. The same compositional elements i.e. $\mathrm{O}, \mathrm{Si}, \mathrm{Ca}$ and $\mathrm{P}$ are detected in L-MBG and H-MBG samples. Calcium values in the XPS data (Table 3.3) are lower than expected because XPS measures the surface composition more than the bulk. It has been shown that calcium ions remain in the bulk preferentially [103]. Analyzing FT-IR transmission spectra (Figure 3.4), there are no differences between the two samples' functional groups, meaning the two glasses are chemically identical.

TEM images (Figure 3.5 and Figure 3.6) show there are differences in the mesoporous architecture of the two glasses. The H-MBG has more discontinuities in the ordered channels compared to the L-MBG; this may be attributed to the higher heating rate. P123 is a hydrophilic surfactant and produces small, ordered micelles in aqueous media [8]. During the EISA process, the micelles selfassemble to create the mesoporous channels [20]. Calcination evaporates the micelles over time, leaving behind the mesoporous architecture. It is postulated that the rapid heating causes the micelles to evaporate vigorously out of the sample. Slow heating would result in steady removal of the surfactant, retaining the integrity of the mesoporous structure (Figure 3.5). The result of these discontinuities is the decrease in surface area and pore volume of the H-MBG samples. LMBG exhibits more than four-fold higher surface area and two-fold greater pore volume than $\mathrm{H}$ MBG. Pore diameter data shows there is a minor increase $(\sim 7 \%)$ in pore diameter for $\mathrm{H}-\mathrm{MBG}$ relative to L-MBG. This may be another effect of the vigorous evaporation caused by the high heating rate. Usually, the pore diameter is determined during the EISA process by the size of the micelles, not during calcination [8]. However, rapid heating can cause expansion of the micelles thereby expanding the diameter of the channel.

The change in surface area directly affects the ion release of the samples. $\mathrm{SiO}_{4}{ }^{4-}$ ion release from H-MBG is significantly lower compared to L-MBG (Figure 3.7 a). This is due to L-MBG having 
higher surface area and a more ordered channel structure compared to $\mathrm{H}-\mathrm{MBG}$, resulting in its faster degradation. It is also noted that $\mathrm{Ca}^{2+}$ and $\mathrm{PO}_{4}{ }^{3-}$ ion concentration of L-MBG samples decreased after 30 minutes (Figure 3.7 b, c). A possible explanation for this is the development of calcium-phosphate crystals upon the glass surface. This would cause a depletion in the solution $\mathrm{Ca}^{2+}$ and $\mathrm{PO}_{4}{ }^{3-}$ concentrations, and so explains why the concentration decreased for both ions. Lower concentration of ions from H-MBG could be the result of low surface area and pore volume causing slower degradation of the $\mathrm{H}-\mathrm{MBG}$, thereby resulting in less ion release over time. There is a statistically significant $(\mathrm{p}<0.05)$ increase of ions from L-MBG after 15, 30 and 60 minutes relative to $\mathrm{H}-\mathrm{MBG}$. These time intervals were chosen based on the proposed use of these MBGs (i.e. as hemostats). Hemostats are used for short term blood coagulation because persistence of bleeding for long durations requires surgical closing. Platelet plug formation in primary hemostasis occurs within an hour [104]. The mechanism by which MBGs achieve hemostasis is thought to be a physical process (absorption of water and concentration of clotting factors). For this, high surface area and pore volume are more critical compared to the concentration of ions released. Since $\mathrm{Ca}^{2+}$ ions speed up the coagulation process, any increase in the concentration of this ion is beneficial [35]. Since L-MBGs provide a greater increase in the $\mathrm{Ca}^{2+}$ ion, their effect on hemostasis will also be greater.

\subsection{Summary}

Two batches of mesoporous bioactive glass were formulated from identical starting reagents, and the effect of calcination heating rate on composition and structure were evaluated. XRD, EDS, XPS and FT-IR results confirmed that heating rate does not influence chemical composition.

Analyzing TEM and BET results, it is evident that heating rate does influence the physical structure of the MBGs. TEM imaging gave a visual of many discontinuities in the mesoporous channels for $\mathrm{H}-\mathrm{MBG}$, and BET quantified its low specific surface area and pore volume. Relatively, L-MBGs had few discontinuities, a four-fold greater specific surface area, and a two-fold greater pore volume. This led to a greater amount of ions released from L-MBG compared to H-MBG.

L-MBGs have high potential as hemostats because the greater surface area allows for more water absorption/clotting factor concentration, and release more $\mathrm{Ca}^{2+}$ for speeding up hemostasis. 
The results presented in this study provide insight on the effects of heating rate on the physical structure of MBGs. During synthesis, low heating rate is best for getting well-structured mesoporous channels. 


\section{Tantalum Containing Mesoporous Bioactive Glasses as a Potential Hemostatic Agent.}

This chapter is based on the following paper (ready for submission):

Andrew Mendonca, Md. Saidur Rahman, Adel Alhalawani, and Mark R. Towler. Tantalum containing mesoporous bioactive glasses as a potential hemostatic agent.

\subsection{Introduction}

Bioactive glass (BGs) were first synthesized by Hench et al. and are capable of chemically bonding with host tissue [105]. Their bioactivity stems from ion release which promotes the development of a hydroxyapatite (HA) layer at the interface of the glass [2].

Mesoporous bioactive glasses (MBGs) are a subset of BGs that possess a mesoporous channel structure [9]. This gives them a high specific surface area, up to 10-20x the surface area of meltquenched BGs [10]. Bioactivity is proportionally influenced by a BG's specific surface area; therefore MBGs have high bioactivity [2]. Silica based MBGs have an amorphous structure which can accommodate various ions as network modifiers [106]. These network modifiers disrupt the continuity of the glass network and form non-bridging silicon-oxygen bonds (Si-NBO). The number of Si-NBOs affect the bioactivity of the glasses, with increased numbers of Si-NBO bonds leading to greater reactivity [106]. The network modifiers can further influence glass properties depending upon the ion used. For example, calcium ions can be used to speed up blood coagulation [107]. Mesoporous bioactive glasses containing $0.02 \mathrm{wt} \%$ silver ions have outstanding antibacterial performances and hemostatic properties [83]. The high specific surface area of the Ag doped MBGs and nanoporous structure resulted in higher water absorption rate from the blood. In addition, this water absorption concentrates the blood components and reduces clotting time [108] [109]. Gallium doped MBGs have been shown to be potential hemostatic agents and exhibit antibacterial properties [85].

Hemostatic agents help to achieve hemostasis [110]. Commercially available hemostats can be either organic or inorganic depending upon their composition. Organic hemostats are usually based on gelatin, cellulose and chitosan. Animal gelatin containing hemostats (e.g. Gelfoam®, Pfizer, Inc.) can cause serious allergic reactions and lead to anaphylaxis [47]. HemCon (Tricol Biomedical, Inc.), a chitosan based hemostat, is synthesized from shrimp shells and is unsuitable for deep wounds or irregular wound surfaces [44]. A starch-based hemostat, Arista® (CR Bard, Inc.), can notably reduce the hemostasis time through absorption of water and concentration of 
coagulation factors and platelets [51]. However, swelling of the starch particles can lead to necrosis (cell death) of surrounding tissue. Inorganic hemostats are typically clay or zeolite based [34]. Zeolites possess a microporous structure, usually with a pore diameter less than $2 \mathrm{~nm}$, and can absorb high amounts of water which reduces clotting time by concentrating clotting factors [83]. However, zeolite based hemostats can cause an exothermic reaction at the wound site with tissue temperatures capable of rising to $90^{\circ} \mathrm{C}$ [38]. The Combat Gauze (Z-Medica, LLC) hemostat, gauze implanted with kaolin, initiates the intrinsic pathway of the blood coagulation cascade [43]. However, it is slow acting and so does not provide immediate hemostasis [38].

This manuscript presents tantalum doped MBGs (Ta-MBGs) for the first time. Tantalum was chosen because of its biological inertness and previous use in hemostatic clips [89]. Tantalum oxide powder, containing low amounts of iron, have been developed as a hemostat to accelerate blood clotting and prevent bacterial infection [87]. Tantalum containing glass polyalkenoate cements are very promising for sternal closure and repair [93].

The aims of this study are to synthesize MBGs with varying amounts of tantalum, characterize the MBGs structure, and evaluate the effect of the morphology and tantalum content on the ion release and hemostasis.

\subsection{Materials and methods}

Five batches of glasses $\left[(80-\mathrm{x}) \mathrm{SiO}_{2}-15 \mathrm{CaO}-5 \mathrm{P}_{2} \mathrm{O}_{5}-\mathrm{x} \mathrm{Ta}_{2} \mathrm{O}_{5}(\mathrm{~mol} \%)\right]$ were synthesized doped with varying amounts of $\mathrm{Ta}_{2} \mathrm{O}_{5}$ in the expense of $\mathrm{SiO}_{2} .4 \mathrm{~g}$ of $\mathrm{P} 123$ and $1.42 \mathrm{~g}$ of calcium nitrate tetrahydrate $\left(\mathrm{Ca}\left(\mathrm{NO}_{3}\right)_{2} .4 \mathrm{H}_{2} \mathrm{O}\right)$ were dissolved in $76 \mathrm{~mL}$ of ethanol. In a separate graduated cylinder, $1 \mathrm{~mL}$ of $0.5 \mathrm{M}$ hydrochloric acid and appropriate amount of TEOS $\left(\mathrm{Si}\left(\mathrm{OC}_{2} \mathrm{H}_{5}\right)_{4}\right)$ was allowed to react for hydrolysis of TEOS. Then $0.68 \mathrm{~mL}$ TEP $\left(\left(\mathrm{C}_{2} \mathrm{H}_{5} \mathrm{O}\right)_{3} \mathrm{PO}\right)$ was added to the ethanol solution. For $\mathrm{Ta}_{2} \mathrm{O}_{5}$ containing glasses, appropriate amount of tantalum (V) ethoxide $\left(\left(\mathrm{CH}_{3} \mathrm{CH}_{2} \mathrm{O}\right)_{5} \mathrm{Ta}\right)$ was added to the ethanol solution. Lastly, the TEOS-acid solution was poured into the ethanol solution. The solution was covered and stirred overnight. It was then transferred to a petri dish for 5 days to allow for the evaporation-induced self-assembly (EISA) process. The EISA-derived gel was then calcined at $650^{\circ} \mathrm{C}$ using a box furnace (Hot Spot 110, Zircar Zirconia Inc., Florida, USA) for 6 hours. Then calcined samples were ground in a ball mill (PM 100, Retsch $\mathrm{GmbH}$, Haan, Germany) at $500 \mathrm{rpm}$ for 45 minutes. A $45 \mu \mathrm{m}$ sieve was used to get powders with particle sizes less than $45 \mu \mathrm{m}$ for characterization. The glasses have identical chemical 
compositions which are listed in Table 4.1. $\mathrm{Ta}_{2} \mathrm{O}_{5}$ free glasses are labelled as MTa-0. Glasses doped with $0.5,1,5$ and 10 (mol\%) $\mathrm{Ta}_{2} \mathrm{O}_{5}$ are labelled as MTa-0.5, MTa-1, MTa-5 and MTa-10 respectively. The amount of precursors used are also listed in Table 4.2.

Table 4.1: Compositions of synthesized MBGs (mol\%)

\begin{tabular}{ccccc}
\hline Sample code & $\mathbf{S i O}_{2}$ & $\mathbf{C a O}$ & $\boldsymbol{P}_{2} \boldsymbol{O}_{5}$ & $\mathbf{T a}_{2} \boldsymbol{O}_{5}$ \\
\hline MTa-0 & 80 & 15 & 5 & 0 \\
MTa-0.5 & 79.5 & 15 & 5 & 0.5 \\
MTa-1 & 79 & 15 & 5 & 1 \\
MTa-5 & 75 & 15 & 5 & 5 \\
MTa-10 & 70 & 15 & 5 & 10 \\
\hline
\end{tabular}

Table 4.2: Amounts of precursors used to synthesize MBGs

\begin{tabular}{ccccc}
\hline Sample code & $\begin{array}{c}\mathrm{Si}\left(\mathrm{OC}_{2} \mathrm{H}_{5}\right)_{4} \\
(\mathbf{m L})\end{array}$ & $\begin{array}{c}\left.\mathrm{Ca}_{4} \mathrm{NO}_{3}\right)_{2 .} .4 \mathrm{H}_{2} \mathrm{O} \\
(\mathbf{g})\end{array}$ & $\begin{array}{c}\left(\mathrm{C}_{2} \mathrm{H}_{5} \mathrm{O}\right)_{3} \mathrm{PO} \\
(\mathbf{m L})\end{array}$ & $\begin{array}{c}\left(\mathrm{CH}_{3} \mathrm{CH}\right. \\
(\mathbf{m L})\end{array}$ \\
\hline MTa-0 & 7.18 & 1.42 & 0.68 & 0 \\
MTa-0.5 & 7.14 & 1.42 & 0.68 & 0.10 \\
MTa-1 & 7.09 & 1.42 & 0.68 & 0.21 \\
MTa-5 & 6.70 & 1.42 & 0.68 & 1.11 \\
MTa-10 & 6.20 & 1.42 & 0.68 & 2.38 \\
\hline
\end{tabular}

\subsection{Glass characterization}

\subsubsection{X-ray diffraction}

Refer to section 3.2.3.

\subsubsection{Scanning electron microscopy (SEM) and Energy dispersive X-ray spectroscopy} (EDS)

Refer to section 3.2.4.

\subsubsection{X-ray photoelectron spectroscopy (XPS)}

Refer to section 3.2.4.

\subsubsection{Fourier transform infrared (FT-IR) spectroscopy}

Refer to section 3.2.5. 


\subsubsection{Transmission electron microscopy (TEM)}

Refer to section 3.2.6.

\subsubsection{Brunauer-Emmett-Teller (BET) and Barrett-Joyner-Halenda (BJH) analysis}

Refer to section 3.2.7.

\subsubsection{Zeta potential analysis}

Zeta potential of the glasses were measured using a zeta potential analyzer (Zetasizer-Nano Series, Malvern Instruments Ltd., U.K). Polystyrene latex solution was used as a calibration material and dispersant medium was DI water. Disposable folded capillary cells were used during the measurement.

\subsubsection{Ion release analysis}

Refer to section 3.2.8. Calibration standard for tantalum was prepared from a 1000 parts per million (ppm) stock solution. For tantalum 0.5, 1, 5, and $10 \mathrm{ppm}$ calibration standards were used. Wavelength of elements used during the experiment are listed in Table 4.3.

Table 4.3: Wavelength of expected elements

\begin{tabular}{ccccc}
\hline Element & $\boldsymbol{S i}$ & $\boldsymbol{C a}$ & $\boldsymbol{P}$ & $\boldsymbol{T a}$ \\
\hline $\begin{array}{c}\text { Wavelength } \\
(\mathrm{nm})\end{array}$ & 288.158 & 317.933 & 213.617 & 240.063 \\
\hline
\end{tabular}

\subsubsection{Whole blood hemostatic assay}

Thromboelastography is a laboratory test which measures the viscoelastic properties of a blood clot. TEG® 5000 Thrombelastograph® (Haemonetics Corporation, Massachusetts, USA) analyzer was used to conduct thromboelastography. Figure 4.1 shows simplified mechanism of this machine. There are two independent measuring channels in a TEG® 5000 analyzer. Cups containing blood samples are attached to each of the channels - one containing no powder sample and one containing powder sample. The cup is rotated at $4^{\circ} 45^{\prime}$ forward and backward (each every $5 \mathrm{sec}$ ) to imitate venous flow. A pin immersed in the blood is connected to a transducer, which is connected to a torsion wire. When there is any clot formation the pin starts rotating. As the clot strength increases, so does the pin rotation. TEG analytical software (version 4.2.3) is used to measure the clot properties and correlate them to 5 different values, shown in Figure 4.2 where,

$$
\mathrm{R}=\text { initial clot formation time (min) }
$$


$\mathrm{K}=$ time taken by the clot to reach $20 \mathrm{~mm}$ clot strength (min)

$\alpha=$ rate of clot formation $\left(^{\circ}\right)$

$\mathrm{MA}=$ maximum clot strength $(\mathrm{mm})$

LY30 = lysis (disintegration of cells) after 30 min i.e. percentage decrease of clot strength after $30 \mathrm{~min}$.

$\mathrm{R}, \mathrm{K}, \alpha$ and MA represent blood coagulation and LY30 represents fibrinolysis (breakdown of fibrin clot) [111].

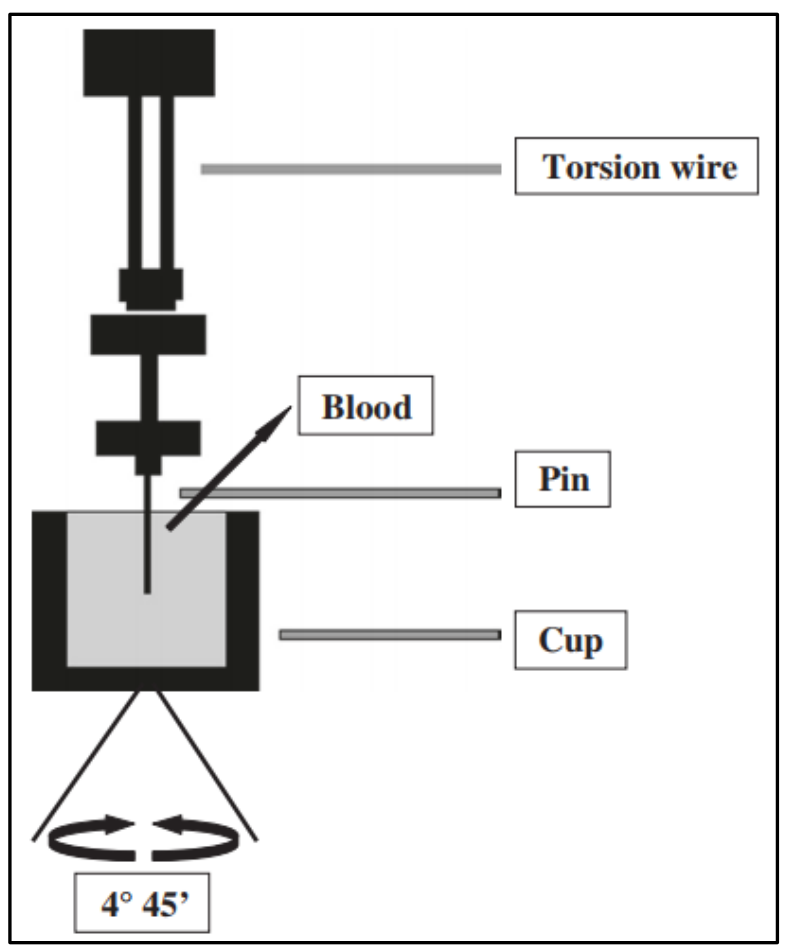

Figure 4.1: Schematic representation of thromboelastography [81]. 


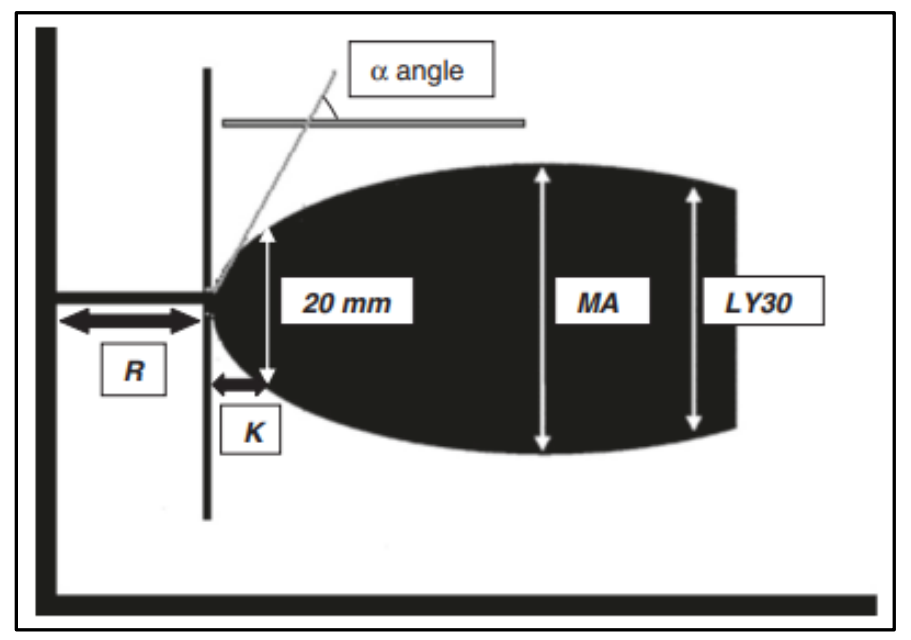

Figure 4.2: Values of thromboelastograph that represent clot formation [81].

Animal studies was performed with approval from research ethics board of St. Michael's Hospital, Toronto, Ontario, Canada (reference number: ACC 739). In this study, sample blood was taken from mice. After proper anesthetization (Figure 4.3 a), an incision was made in the mouse abdominal skin (Figure 4.3 b). The abdominal cavity was opened, the organs shifted to the side and the inferior vena cava (IVC) was isolated. The IVC was chosen because it is the largest vein in mice and maximum blood can be drawn. The blood was drawn directly from IVC using a syringe containing $3.2 \%$ sodium citrate (sodium citrate prevents platelet activation) and a $25 \mathrm{G} \mathrm{x} 1 / 2$ needle; citrated blood was then transferred to a centrifuge tube. 2 × $340 \mu \mathrm{L}$ citrated blood was put into two TEG® cups. After that $20 \mu \mathrm{L} 0.2 \mathrm{M} \mathrm{CaCl}_{2}$ was added to each cup to activate platelets. Then, 20 mg of powder samples (Arista® and MTa glasses) were added to one of the cups. The sample cup was connected to channel 1 and the blank cup (with only blood and $\mathrm{CaCl}_{2}$ ) was connected to channel 2. The TEG® 5000 Thrombelastograph ${ }^{\circledR}$ analyzer was run while maintaining $37^{\circ} \mathrm{C}$ temperature during experiments. The whole blood clotting assay is depicted in Figure 4.4 [112]. Each glass sample was repeated 5 times $(n=5)$. 


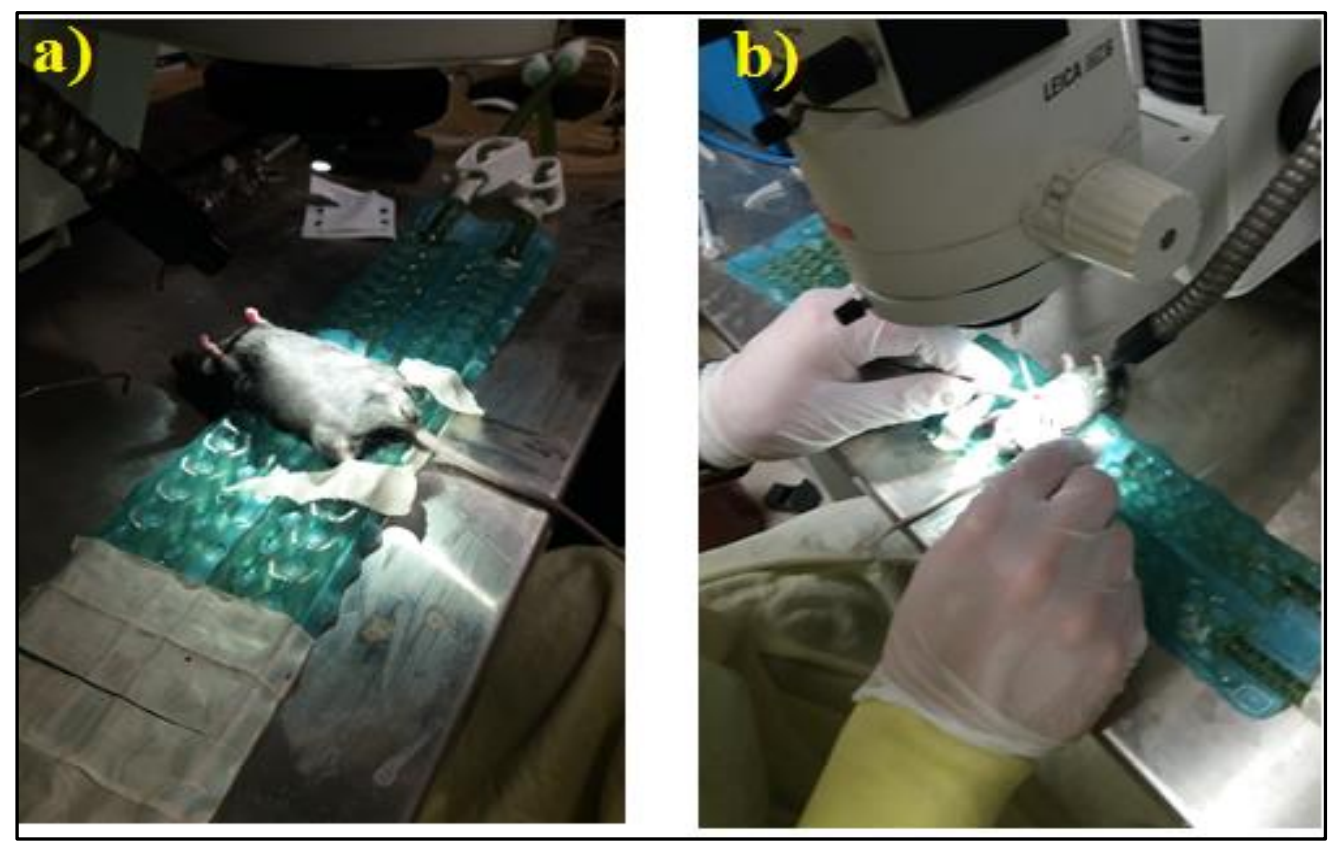

Figure 4.3: a) Anesthetized mouse, b) mouse dissection to lift abdominal skin.

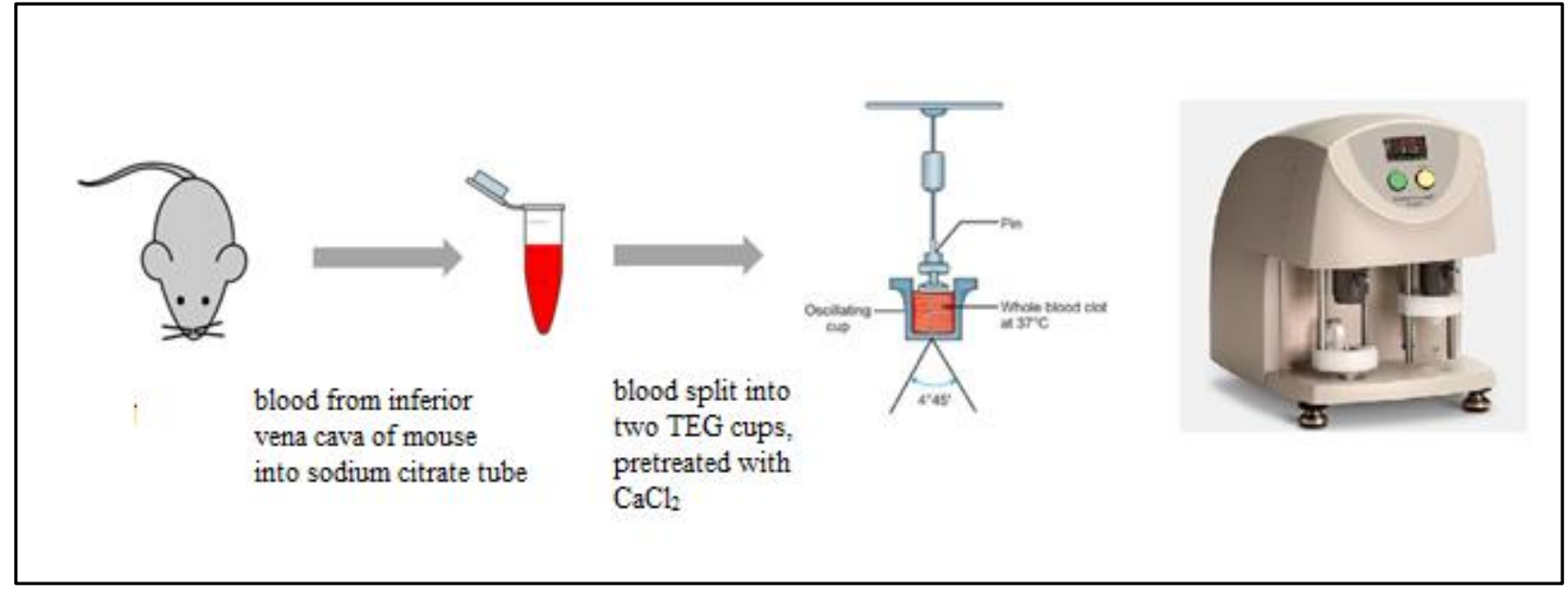

Figure 4.4: Sequence of thromboelastography experiment [112].

\subsubsection{Statistical analysis}

For ICP, data were plotted using the mean \pm standard deviation of 9 data points. Parametric one way ANOVA was used to compare the means of independent samples and independent samples ttest was used as a post-hoc analysis to find out statistical significance between groups with $\mathrm{p}<$ 0.05. Statistical analysis was performed using SPSS software (IBM SPSS Statistics, version 24, IBM corp., Armonk, NY, USA). 


\subsection{Results and discussions}

Figure 4.5 shows XRD patterns for MTa series glasses. It is observed that all glasses are amorphous and $\mathrm{Ta}_{2} \mathrm{O}_{5}$ incorporation in the glass structure did not change the phase of the glasses.

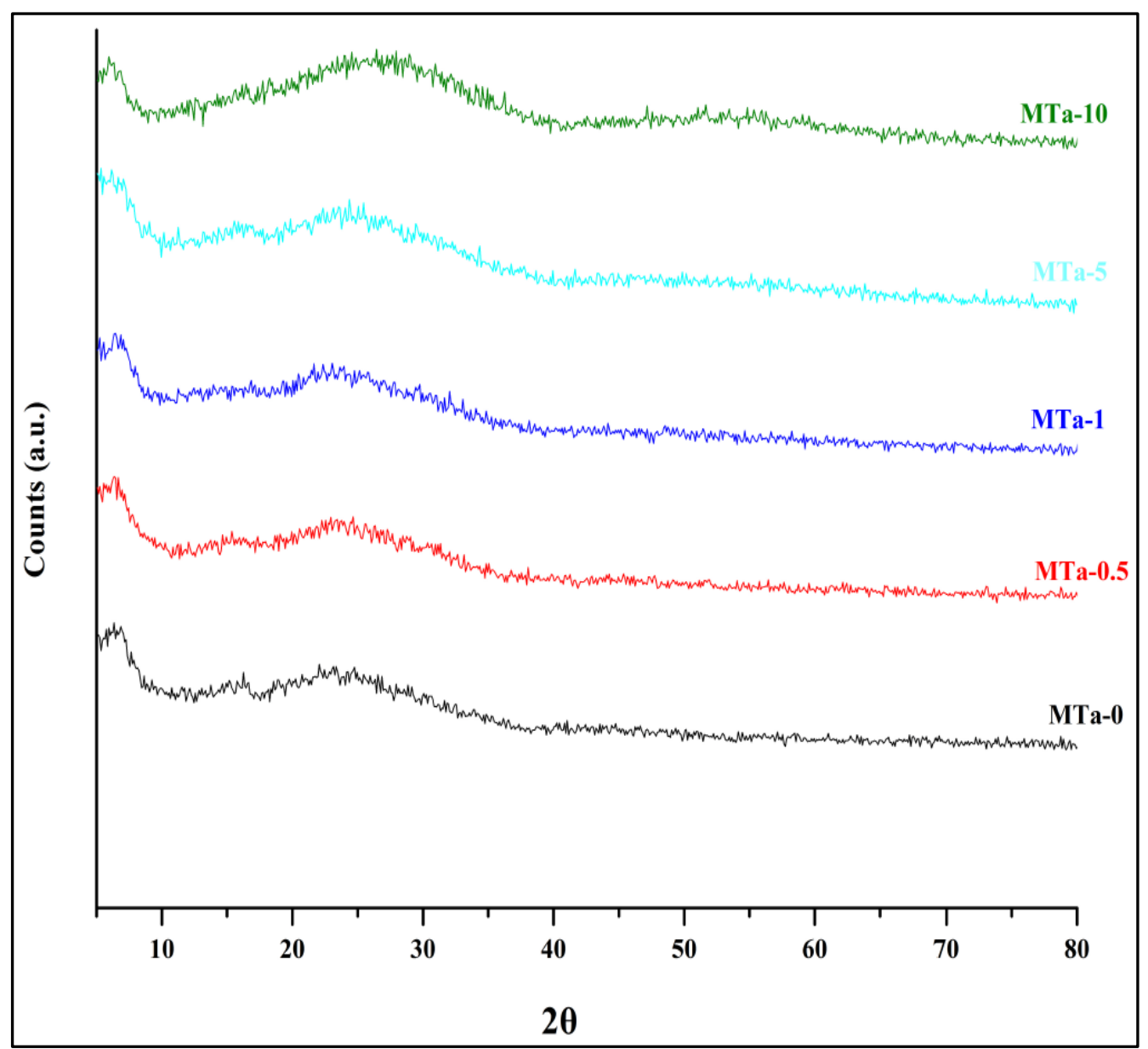

Figure 4.5: XRD patterns for $\mathrm{Ta}_{2} \mathrm{O}_{5}$ doped MBGs.

SEM images reveal that all the glasses have a similar particle size. EDS result shows the presence of $\mathrm{O}, \mathrm{Si}, \mathrm{Ca}, \mathrm{P}$ elements in MTa-0 glass (Figure 4.6 a). In tantalum containing glasses, EDS spectrum shows the existence of $\mathrm{O}, \mathrm{Si}, \mathrm{Ca}, \mathrm{P}$ and $\mathrm{Ta}$ (Figure $4.6 \mathrm{~b}$ to e). EDS provided bulk compositional data which are listed in Table 4.4. 

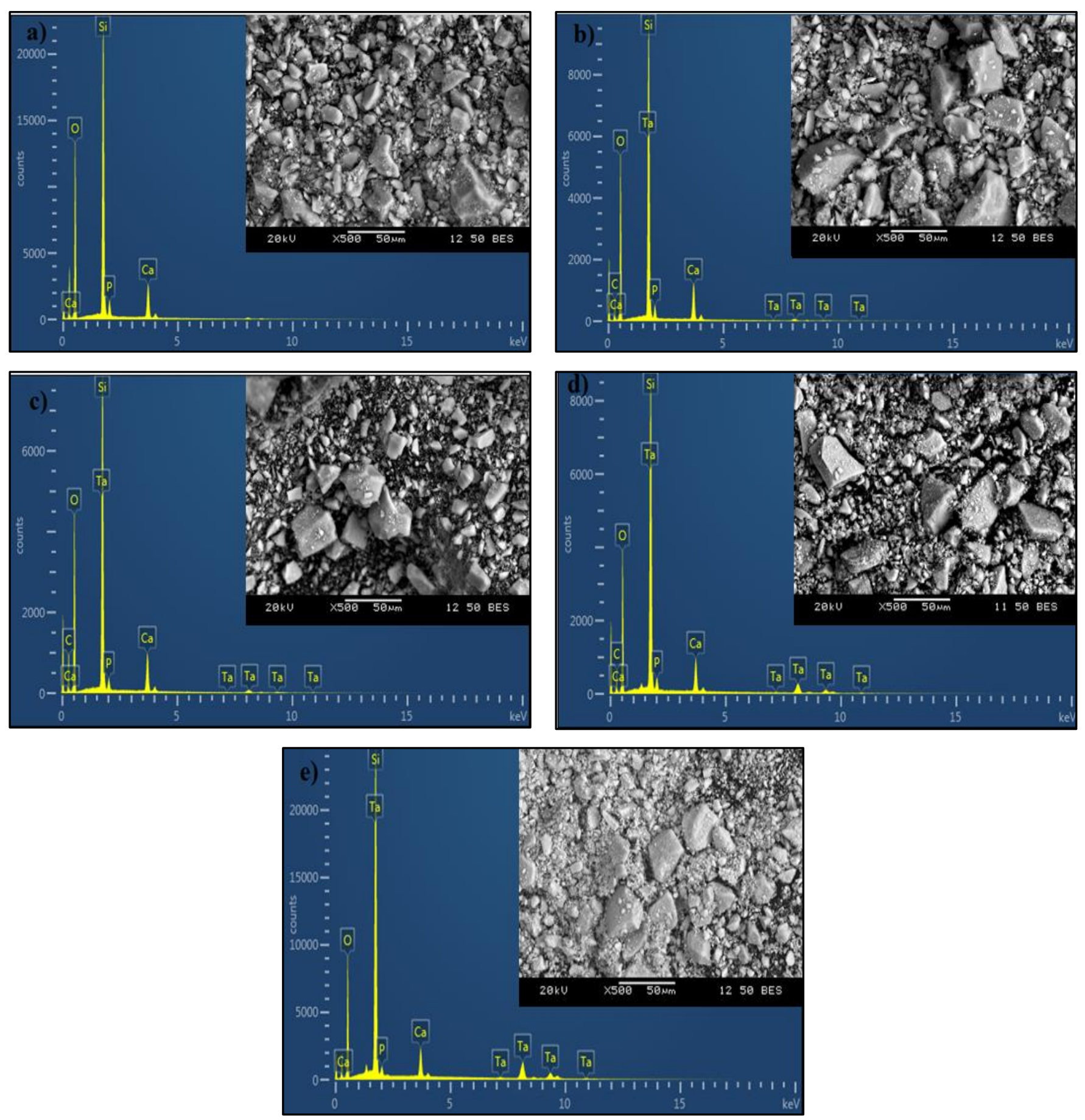

Figure 4.6: EDS spectra and SEM images for a) MTa-0, b) MTa-0.5, c) MTa-1, d) MTa-5 and e) MTa-10 glasses. 
Table 4.4: Summary of compositions (wt.\%) obtained from EDS

\begin{tabular}{cccccc}
\hline Sample & $\boldsymbol{O}$ & $\boldsymbol{S i}$ & $\boldsymbol{C a}$ & $\boldsymbol{P}$ & $\boldsymbol{T a}$ \\
\hline MTa-0 & 58.6 & 31.4 & 7.2 & 2.8 & 0 \\
MTa-0.5 & 55.5 & 31.2 & 8.0 & 2.5 & 2.8 \\
MTa-1 & 58.2 & 27.9 & 6.7 & 2.1 & 5.1 \\
MTa-5 & 47.6 & 23.6 & 6.0 & 1.8 & 21 \\
MTa-10 & 37.7 & 20.2 & 5.3 & 1.2 & 35.6 \\
\hline
\end{tabular}

EDS graphs show that when $\mathrm{Ta}_{2} \mathrm{O}_{5}$ is incorporated into the glass structure, there is an overlap of $\mathrm{Si}$ and Ta peaks (Figure $4.6 \mathrm{~b}$ to e). The effect of this overlap is more pronounced when additional $\mathrm{Ta}_{2} \mathrm{O}_{5}$ is added into the glass structure. MTa-10 glass shows $35.6 \mathrm{wt} . \%$ of Ta which is more than silicon concentration (20.2 wt.\%). This peak overlap of silicon and tantalum affects local compositional measurement. The compositional data obtained by analyzing EDS peaks, do not exhibit exact composition of elements. X-ray photoelectron spectroscopy is conducted to find out quantitative compositional data.

Compositional data are quantitatively measured with XPS. XPS is a surface sensitive spectroscopic technique and can provide elemental composition of samples. Wide scan XPS spectrum for the glasses are shown in Figure 4.7. Expected peaks for $\mathrm{O}, \mathrm{Si}, \mathrm{Ca}$ and $\mathrm{P}$ are observed in the XPS spectrum of MTa-0 glass. In the Ta containing glasses, Ta peaks are observed including O, Si, Ca and $\mathrm{P}$ peaks. However, a carbon $\mathrm{C} 1 \mathrm{~s}$ peak was also noticed in all glass samples. This is referred to as adventitious carbon due to adsorption of impurities during sample handling and transportation. For Ta, three peaks are noted: Ta4p, Ta4d, and Ta4f. The control glass shows a small peak around $26 \mathrm{eV}$ where the Ta4f peak is located. However, this is not a Ta4f peak; it is an O2s peak. The O2s peak can be found around $26 \mathrm{eV}$ [113]. As the tantalum peaks increase in intensity, the silicon peaks decrease in intensity, as would be expected. Binding energy of photoelectrons for related elements are listed in Table 4.5 (according to National Institute of Standards and Technology, NIST). Atomic percentage (normalized without carbon) are shown in Table 4.6. 
Table 4.5: Binding energy of elements

\begin{tabular}{cc}
\hline Element & $\begin{array}{c}\text { Peak binding energy } \\
(\boldsymbol{e V})\end{array}$ \\
\hline O1s & 532.20 \\
$\mathrm{C} 1 s$ & 284.54 \\
$\mathrm{Ca} 2 p$ & 347.21 \\
P2p & 133.24 \\
$\mathrm{Si} 2 p$ & 103.59 \\
$\mathrm{Ta} 4 d$ & 228.08 \\
$\mathrm{Ta} 4 f$ & 25.25 \\
$\mathrm{Ta} 4 p 3$ & 398.22 \\
\hline
\end{tabular}

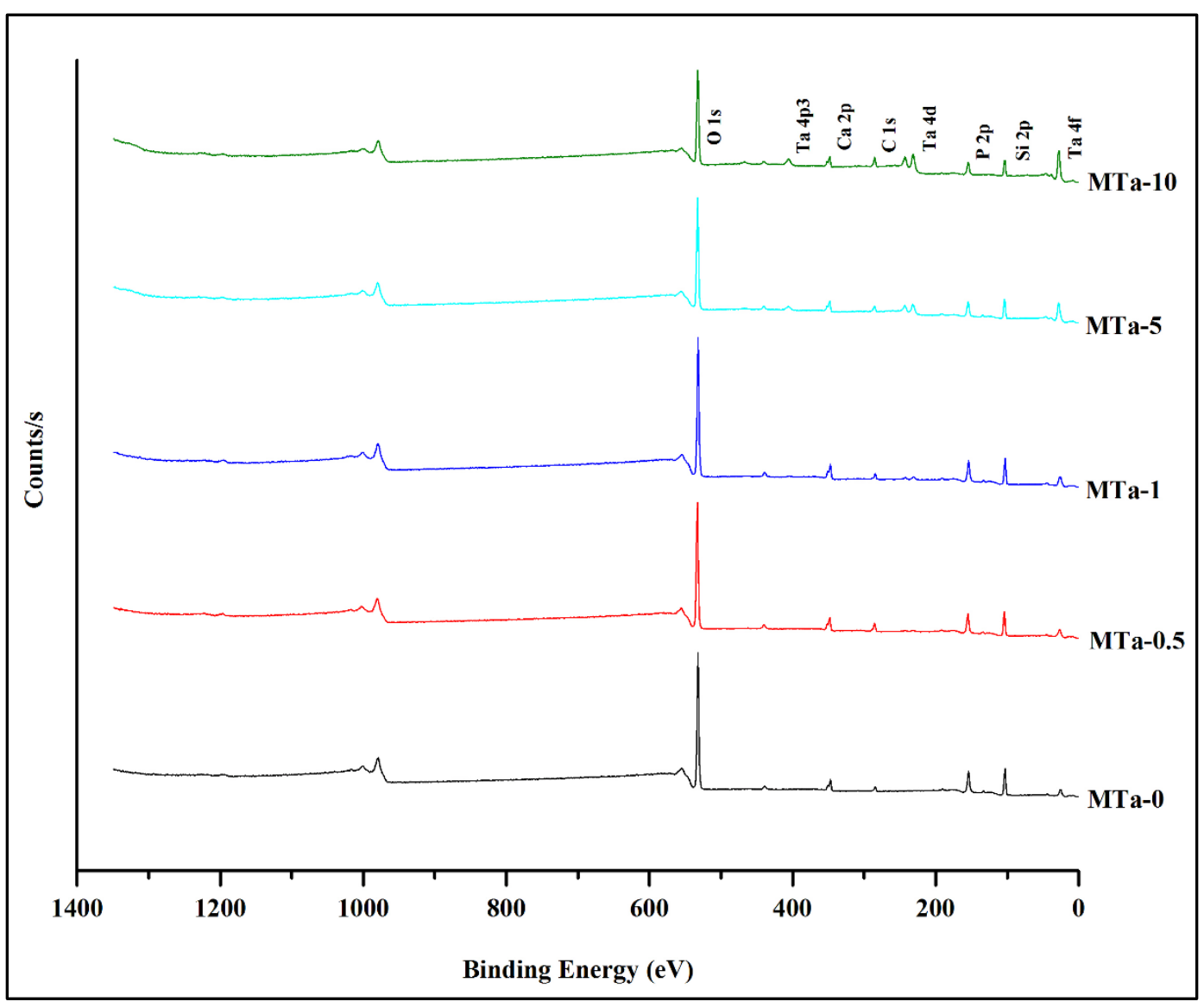

Figure 4.7: XPS spectra for $\mathrm{Ta}_{2} \mathrm{O}_{5}$ doped MBGs. 
Table 4.6: Normalized XPS data (at.\%)

\begin{tabular}{cccccc}
\hline Sample & O1s & Si2p & Ca2p & $P 2 p$ & Ta4d \\
\hline MTa-0 & 60.70 & 34.42 & 2.73 & 2.15 & 0 \\
MTa-0.5 & 61.00 & 33.59 & 3.41 & 1.79 & 0.21 \\
MTa-1 & 61.02 & 32.97 & 3.47 & 1.88 & 0.66 \\
MTa-5 & 60.76 & 30.15 & 3.09 & 2.08 & 3.92 \\
MTa-10 & 59.26 & 27.33 & 3.41 & 1.05 & 8.95 \\
\hline
\end{tabular}

It is observed that $\mathrm{Si} 2 \mathrm{p}$ at. $\%$ decreases and Ta4d at.\% increases which is expected because $\mathrm{Ta}_{2} \mathrm{O}_{5}$ was incorporated in the expense of $\mathrm{SiO}_{2}$. Ca concentrations in XPS data are lower compared to EDS data because XPS measures the surface composition data and Ca concentration in the surface is lower than the bulk composition [103].

Table 4.7: Binding energy and concentration (at.\%) of oxygen in silica and Ca-P-Ta environment

\begin{tabular}{ccccc}
\hline Sample & \multicolumn{2}{c}{$\begin{array}{c}\text { Oxygen in Si environment } \\
\text { Binding energy } \\
(\mathbf{e V})\end{array}$} & $\begin{array}{c}\text { Oxygen in Ca-P-Ta environment } \\
\text { Binding energy } \\
(\boldsymbol{e V})\end{array}$ & at.\% \\
\hline MTa-0 & 530.98 & 96.46 & 528.88 & 3.54 \\
MTa-0.5 & 530.98 & 93.09 & 529.08 & 6.91 \\
MTa-1 & 530.88 & 94.95 & 528.88 & 5.05 \\
MTa-5 & 530.68 & 92.94 & 529.08 & 7.06 \\
MTa-10 & 530.58 & 81.85 & 529.18 & 18.15 \\
\hline
\end{tabular}

High resolution O1s spectra for MBGs are shown in Figure 4.8 (a to e). Each spectrum is deconvoluted into two components. In Figure 4.8 a, (for MTa-0), the higher binding energy peak centered at $530.98 \mathrm{eV}$ can be denoted as oxygen in silica environment ( $\mathrm{Si}-\mathrm{O})$ whereas the lower binding energy peak centered at $528.88 \mathrm{eV}$ corresponds to oxygen in a non-silica environment (i.e. $\mathrm{Ca}-\mathrm{O}$ or $\mathrm{P}-\mathrm{O}$ or $\mathrm{Ta}-\mathrm{O}$ ) [103]. For MTa- 0 , the amount (at.\%) of oxygen in silica environment is measured $96.46 \%$ and in calcium-phosphorus environment is $3.54 \%$. 

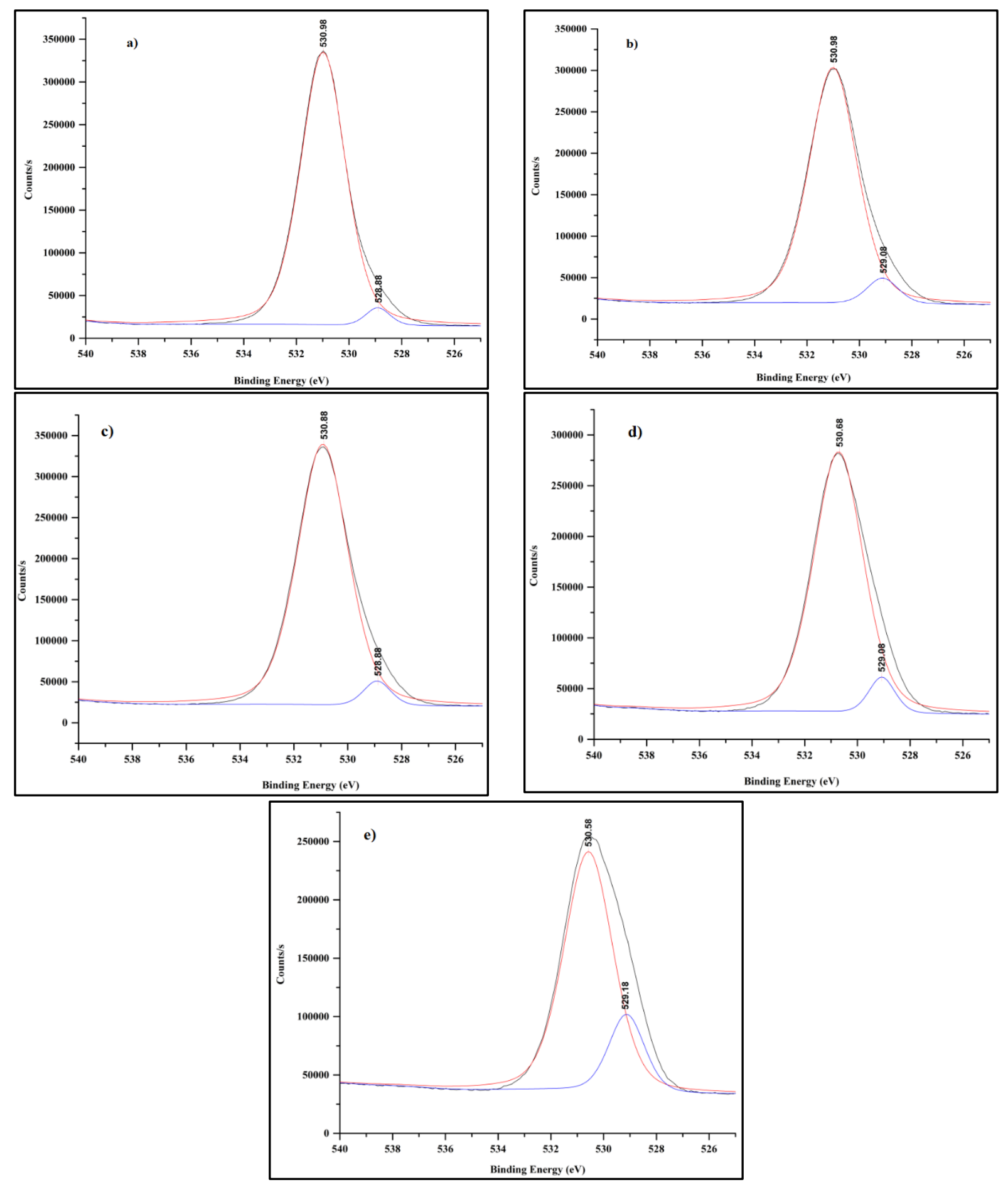

Figure 4.8: High resolution O1s spectra for a) MTa-0, b) MTa-0.5, c) MTa-1, d) MTa-5 and e) MTa-10 glasses.

Addition of more $\mathrm{Ta}_{2} \mathrm{O}_{5}$ in the glass network results in an increase of peak concentration for oxygen in calcium-phosphorus-tantalum environment (Ca-O, P-O, Ta-O) (Figure $4.8 \mathrm{~b}$ to e). In 
Table 4.7, amount (at.\%) of oxygen in silica and Ca-P-Ta environment are listed. Maximum oxygen content (at.\%) in Ca-P-Ta environment is recorded $18.15 \%$ for MTa-10 glass. These results are coherent because $\mathrm{Si}$ content is decreasing and Ta bonds to more oxygens is increasing.

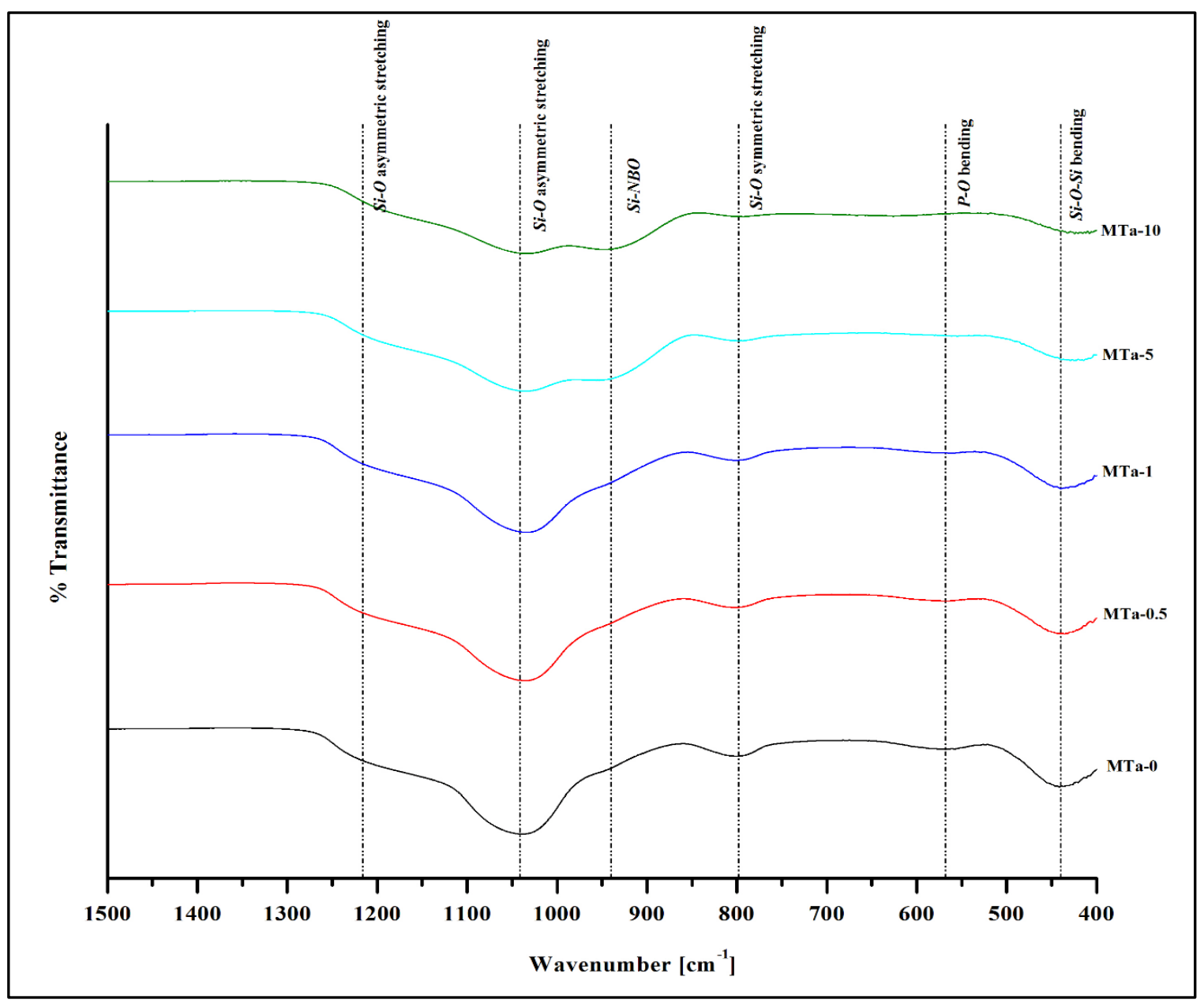

Figure 4.9: FT-IR spectra for all mesoporous glasses.

FT-IR spectra for MTa series glasses are shown in Figure 4.9. Similar peaks are observed as Figure 3.4 and explained in section 3.3. It is observed that Si-O peaks' (bending, symmetric and asymmetric stretching) intensities are decreased with addition of more $\mathrm{Ta}_{2} \mathrm{O}_{5}$ in the $\mathrm{MBG}$ structure, since $\mathrm{Ta}_{2} \mathrm{O}_{5}$ was incorporated in the expense of $\mathrm{SiO}_{2}$ in the glass structure. It is also noticed that the intensity of $\mathrm{Si}$-NBO peak increases with the addition of $\mathrm{Ta}_{2} \mathrm{O}_{5}$ in the glass network i.e. $\mathrm{Ta}_{2} \mathrm{O}_{5}$ acts as a network modifier in the glass structure which is also supported by XPS results. The presence of NBO functional group in the glass network is very important for effective ion exchange and the formation of calcium phosphate layer [114]. NBO also promotes leaching of $\mathrm{Ca}$ ions from the glass structure to form bioactive layer on the glass surface [92]. 

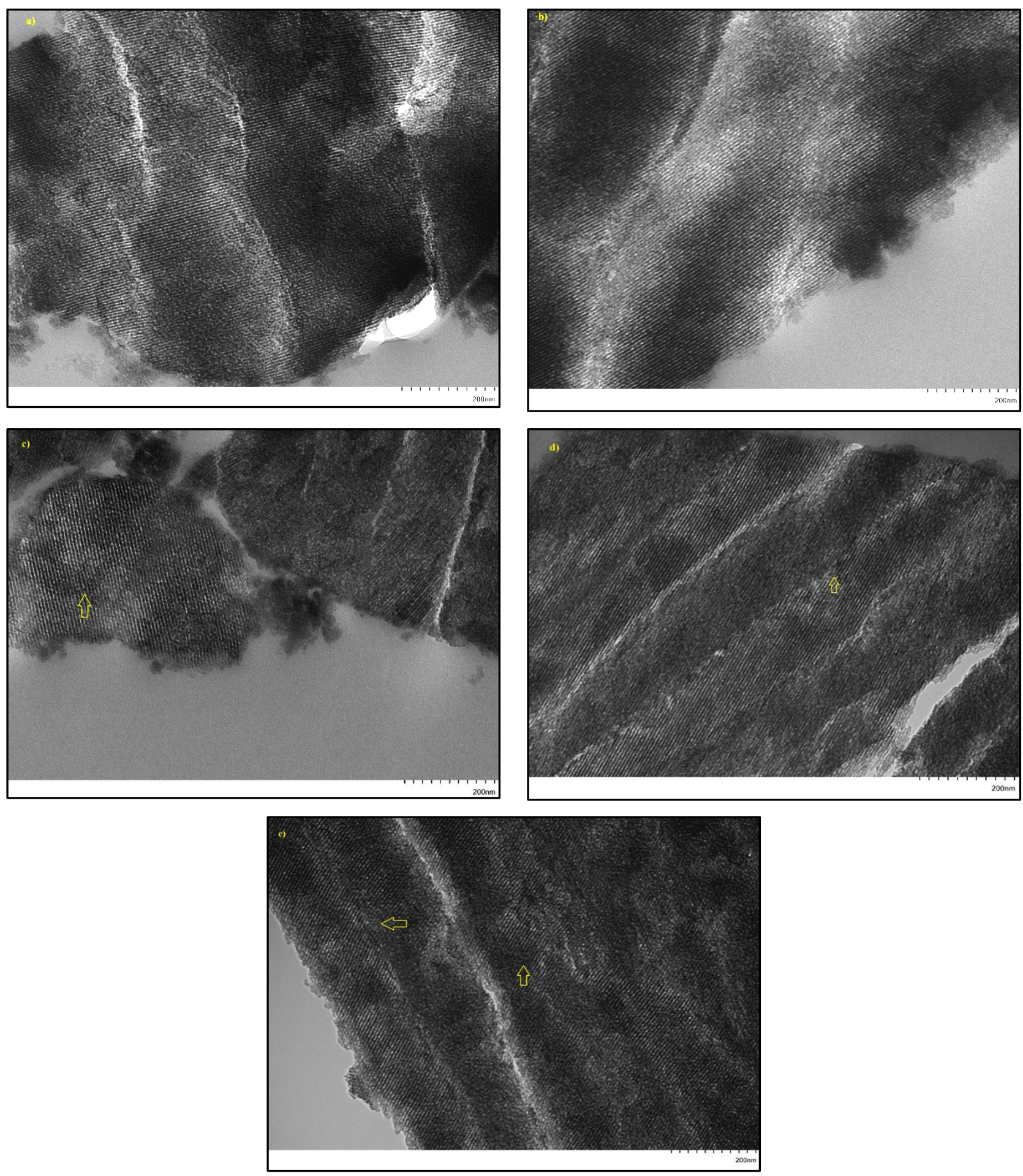

Figure 4.10: TEM images of a) MTa-0, b) MTa-0.5, c) MTa-1, d) MTa-5 and e) MTa-10 glasses. Arrow sign indicates discontinuity in the channel.

TEM imaging provides visual confirmation of the nano-channels for MBGs. TEM images for all glasses are shown in Figure 4.10 a to e. 2D hexagonal well-ordered mesoporous channels are 
observed for MTa-0, MTa-0.5, MTa-1 and MTa-5 glasses. For MTa-1, MTa-5 and MTa-10 glasses, some breakage of nano-channels is observed (Figure $4.10 \mathrm{c}, \mathrm{d}$ and e). As surface directing agents produce small micelles. During calcination, these micelles evaporated and form mesoporous structure. Addition of $\mathrm{Ta}_{2} \mathrm{O}_{5}$ breaks the connectivity of silicon-oxygen atoms i.e. acts as a network modifier (supported by XPS and FT-IR results). This results in discontinuity of nanochannels in the MBGs which is more pronounced in MTa-1, 5 and 10 glasses. For MTa- 0.5 glass less discontinuity of channels are observed (Figure $4.10 \mathrm{~b}$ ). This discontinuity of channels can reduce surface area of MBGs (investigated by BET analysis) and make the pores disconnected. This reason is supported by BET surface area results. It is hypothesized that the mesoporous channel structure could absorb water molecules from the blood into the mesopores for hemostasis. More water molecules could be absorbed into these nano-channels if the structure is continuous. A simplified physical chemistry of MBG is shown in Figure 4.11.

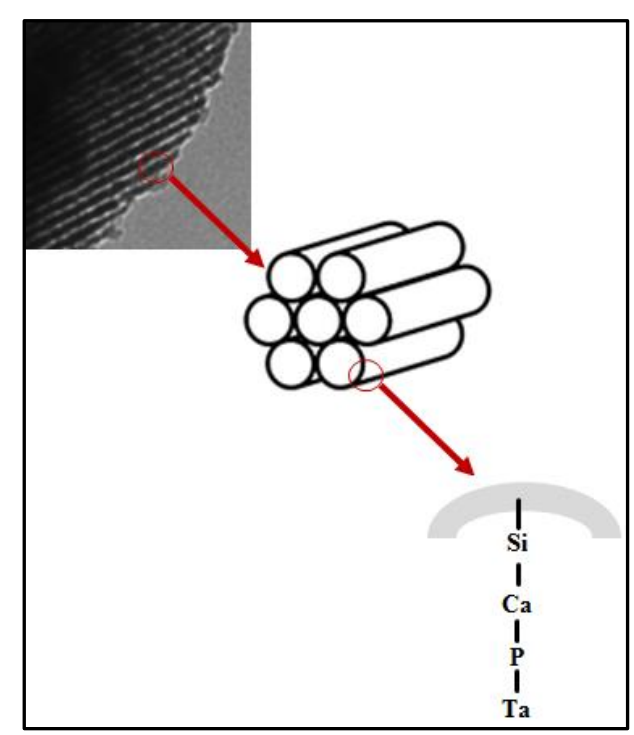

Figure 4.11: Simplified representation of physical chemistry of MBGs.

TEM results visually confirm continuity and discontinuity of nano-channels whereas BrunauerEmmett-Teller (BET) equation and Barrett- Joyner-Halenda (BJH) method quantifies surface area and pore volume respectively. $\left(\mathrm{N}_{2}\right)$ adsorption isotherm is measured at $77 \mathrm{~K}$ for all glasses. $\mathrm{N}_{2}$ is used as adsorbate because it is inert, highly pure and has strong interaction with most solids. According to ISO 9277, gas molecules will physically adsorb to the external and accessible internal pores of solid surface (Figure 4.12) [115]. When $\mathrm{N}_{2}$ is dosed into MBGs, gas molecules adsorb in the isolated regions of porous MBGs (stage 1 in Figure 4.13) at lower pressure. When pressure is 
increased, number of adsorbed molecules increase and a complete monolayer is formed (stage 2 in Figure 4.13). Further increasing of gas pressure results in multilayers of gas molecules forming and then the BET equation is used to calculate surface area (stage 3 in Figure 4.13). BET equation can be written as:

$$
\frac{p / p_{o}}{n_{a}\left(1-p / p_{o}\right)}=\frac{1}{n_{m} C}+\frac{C-1}{n_{m} C} \frac{p}{p_{o}} \quad \text { Equation (1) [115] }
$$

Where, $\mathrm{p}$ is pressure of the adsorptive in equilibrium with the adsorbate $(\mathrm{Pa}), \mathrm{p}_{\mathrm{o}}$ is saturation vapor pressure of the adsorptive $(\mathrm{Pa}), \mathrm{n}_{\mathrm{a}}$ is specific amount adsorbed $\left(\mathrm{mol} \mathrm{g}^{-1}\right), \mathrm{C}$ is BET parameter which depends on the number of layers on the surface, $n_{m}$ is specific monolayer amount of adsorbate $\left(\mathrm{mol} \mathrm{g}^{-1}\right)$.

In the third stage BET surface area and specific surface area are measured using following equations:

$$
\begin{array}{ll}
\boldsymbol{A}_{\boldsymbol{S}}(\boldsymbol{B E T})=\boldsymbol{n}_{\boldsymbol{m}} \times \boldsymbol{L} \times \boldsymbol{a}_{\boldsymbol{m}} & \text { Equation (2) [12] } \\
\boldsymbol{a}_{\boldsymbol{s}}(\boldsymbol{B E T})=\boldsymbol{A}_{\boldsymbol{S}}(\boldsymbol{B E T}) / \boldsymbol{m} & \text { Equation (3) [12]. }
\end{array}
$$

Where, $A_{s}$ is BET surface area, $a_{s}$ is BET specific surface area, $m$ is mass of solid sample, $L$ is Avogadro constant $\left(6.023 \times 10^{23}\right)$ and $\mathrm{a}_{\mathrm{m}}$ is adsorbate molecular cross-sectional area (e.g. 0.162 $\mathrm{nm}^{2}$ for $\mathrm{N}_{2}$ at $\left.77 \mathrm{~K}\right)$.

Further increase in gas pressure results complete coverage of MBG samples and fill all the porosity (stage 4 in Figure 4.13). In this case capillary condensation (multilayer adsorption in porous medium and pores are filled with condensed liquid) occurs. BJH method is applied to measure pore volume and pore diameter when capillary condensation develops. BJH equation can be written as:

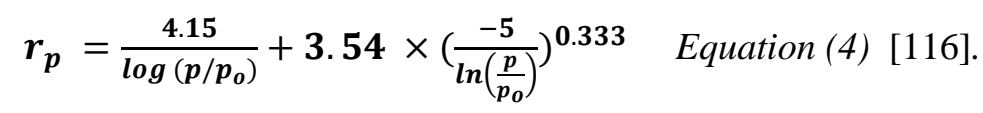

Where, $r_{p}$ is pore radius (Angstrom).

BET surface area, BJH pore volume and average pore diameter for all glasses are listed in Table 4.8. From the table it can be said that $0.5 \mathrm{~mol} \%$ addition of $\mathrm{Ta}_{2} \mathrm{O}_{5}$ in the $\mathrm{MBG}$ network does not reduce surface area. TEM image does not exhibit breakage of nano-channels for MTa-0.5 glass 
(Figure $4.10 \mathrm{~b}$ ) either. Addition of $\mathrm{Ta}_{2} \mathrm{O}_{5}$ more than $0.5 \mathrm{~mol} \%$ in the glass network, reduces BET surface area. For MTa-1 glass, surface area recorded $353.14 \mathrm{~m}^{2} / \mathrm{g}$. TEM image also shows that there are some discontinuity in the nano-channel structure (Figure $4.10 \mathrm{c}$ ) which causes decrease of surface area (from $373.98 \mathrm{~m}^{2} / \mathrm{g}$ to $353.14 \mathrm{~m}^{2} / \mathrm{g}$ ). Any kind of discontinuity affects porous morphology of MBGs and less gas molecules adsorbed which results lower surface area. For pore volume measurements, the amount of $\mathrm{N}_{2}$ gas adsorbed were recorded $\sim 161,155,151,148$ and $129\left(\mathrm{~cm}^{3} / \mathrm{g} \mathrm{STP}\right)$ at 0.5 relative pressure $\left(\mathrm{p} / \mathrm{p}_{\mathrm{o}}\right)$ for MTa-0, 0.5, 1, 5 and MTa-10 glass samples respectively (Figure 4.14). It could be hypothesized that addition of more $\mathrm{Ta}_{2} \mathrm{O}_{5}$ in the glass structure increases pore wall thickness. $\mathrm{Ta}_{2} \mathrm{O}_{5}$ also acts as a network modifier and disrupts the interconnected channel structures. The introduction of this larger element into the glass network could result in slight expansion of the walls of the MBGs, thereby reducing the pore volume. The increase of pore wall thickness reduces average pore diameter which is supported by the pore diameter results (Table 4.8). For MTa-0 glass, average pore diameter recorded 4.3nm whereas for MTa-10 glass average pore diameter found $3.9 \mathrm{~nm} . \mathrm{N}_{2}$ gas molecules are adsorbed in MTa-10 glass sample and resulted surface area $297.55 \mathrm{~m}^{2} / \mathrm{g}$ which is lowest compared to other glasses. However, this surface area is higher than melt quench bioactive glasses $\left(2 \mathrm{~m}^{2} / \mathrm{g}\right)$ [117].

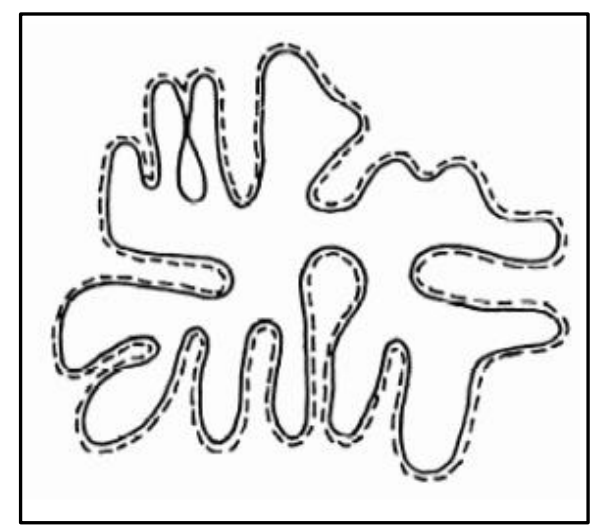

Figure 4.12: Schematic representation of surface detected by gas adsorption method for mesoporous materials [115]. 


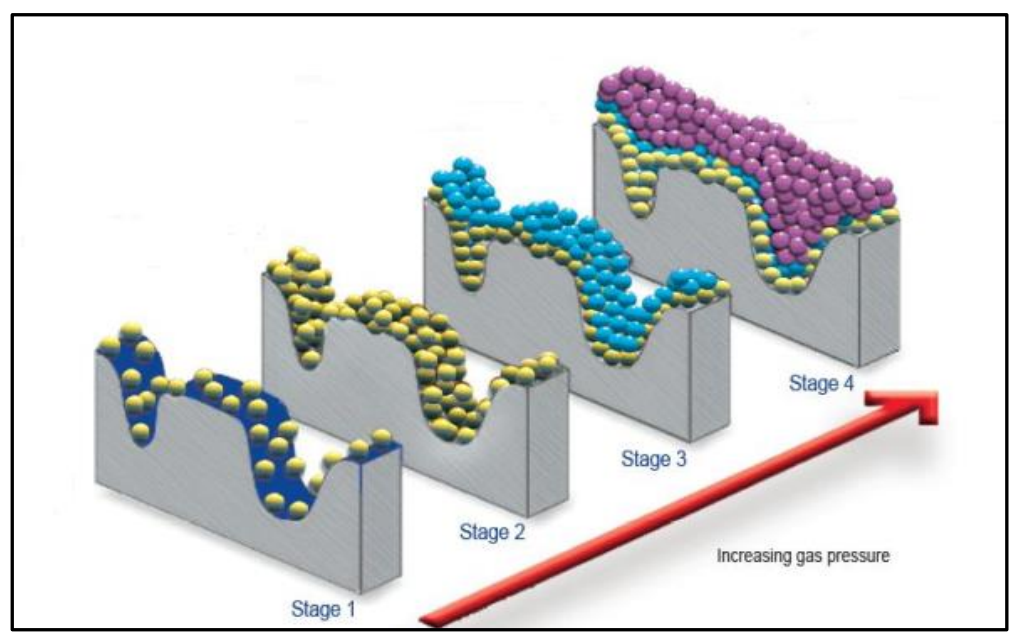

Figure 4.13: $N_{2}$ gas molecules adsorption in the porous structure during different stages to measure surface area and pore volume [118].
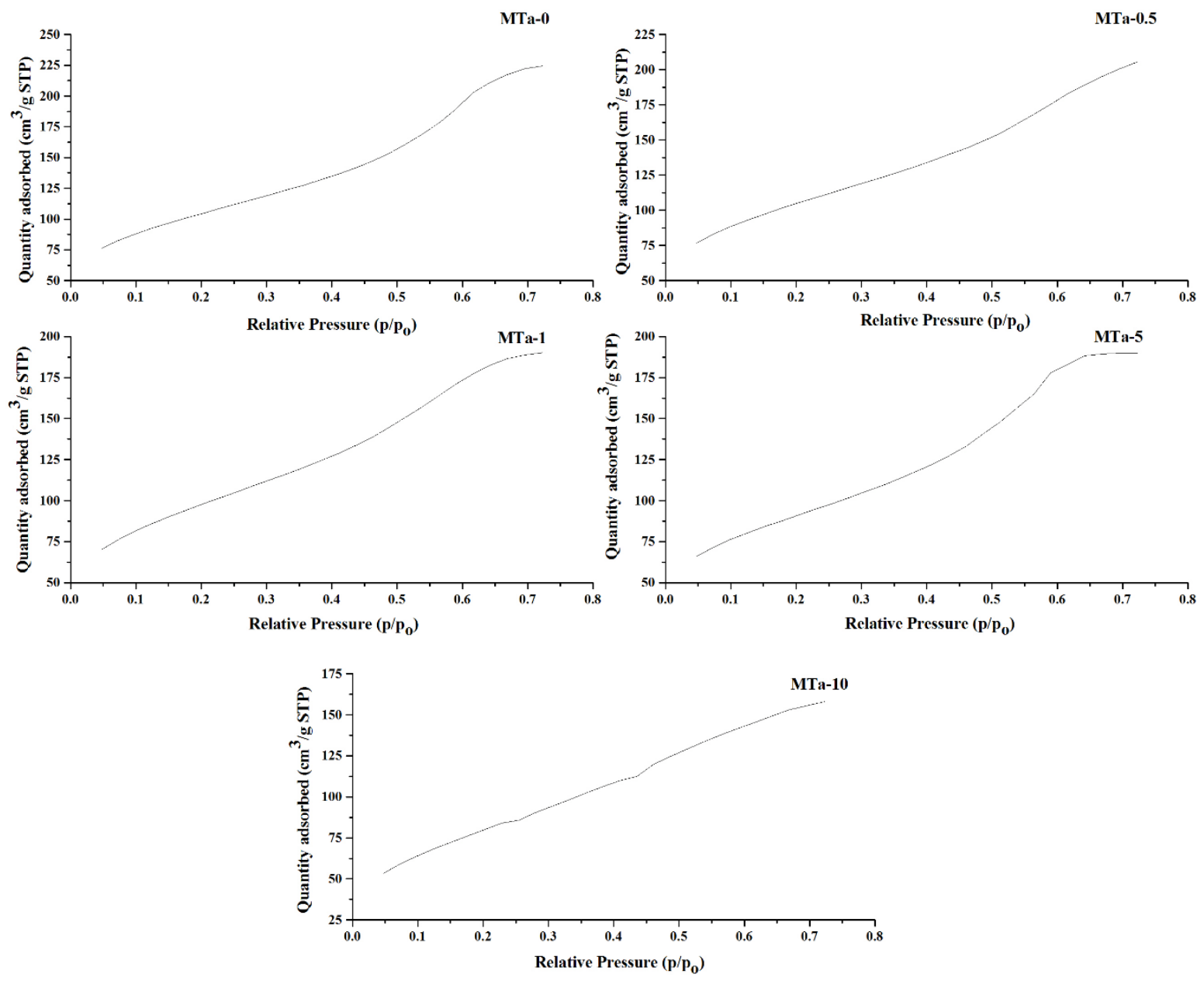

Figure 4.14: BET adsorption isotherm for MBGs. 
Table 4.8: Physical properties for MTa series glasses

\begin{tabular}{cccc}
\hline Sample & $\begin{array}{c}\text { BET surface area } \\
\left(\mathbf{m}^{2} / \mathbf{g}\right)\end{array}$ & $\begin{array}{c}\text { BJH pore volume } \\
\left(\mathbf{c m}^{3} / \mathbf{g}\right)\end{array}$ & $\begin{array}{c}\text { BJH average pore } \\
\text { diameter } \\
(\mathbf{n m})\end{array}$ \\
\hline MTa-0 & 373.87 & 0.27 & 4.3 \\
MTa-0.5 & 373.98 & 0.22 & 4.2 \\
MTa-1 & 353.14 & 0.21 & 4.1 \\
MTa-5 & 328.44 & 0.23 & 4.0 \\
$M T a-10$ & 297.55 & 0.17 & 3.9 \\
\hline
\end{tabular}

Zeta potential is measured to check the electrostatic attraction or repulsion between particles and the stability of particles suspension in a liquid. High value of zeta potential (positive or negative) indicates particles stability and low value of zeta potential means particles are more prone to agglomerate [119]. Particles with zeta potential ranges from $\pm 10 \mathrm{mV}$ to $\pm 30 \mathrm{mV}$ indicates incipient stability and $\pm 30 \mathrm{mV}$ to $\pm 40 \mathrm{mV}$ implies moderate stability [120]. Zeta potential results are listed in Table 4.9 .

Table 4.9: Zeta potential of $M B G s$

\begin{tabular}{cc}
\hline Sample & $\begin{array}{c}\text { Zeta potential } \\
(\boldsymbol{m} \boldsymbol{V})\end{array}$ \\
\hline$M T a-0$ & -22.7 \\
$M T a-0.5$ & -20.4 \\
$M T a-1$ & -24.8 \\
$M T a-5$ & -24.8 \\
$M T a-10$ & -31.1 \\
\hline
\end{tabular}

Mesoporous bioactive glasses show negative zeta potential because of the presence of negatively charged silanol $(\mathrm{Si}-\mathrm{OH})$ groups on the glass surface. We are interested on the magnitude of zeta potential. It is observed that zeta potential decreased to $-20.4 \mathrm{mV}$ for MTa- 0.5 glass. This could be the result of reducing amount of $\mathrm{SiO}_{2}$ and the addition of $\mathrm{Ta}_{2} \mathrm{O}_{5}$ into the glass structure. However, zeta potential increased for MTa-1, remained same for MTa-5. Zeta potential $-31.1 \mathrm{mV}$ reading is recorded for $\mathrm{MTa}-10$ glass. It could be said that $\mathrm{Ta}_{2} \mathrm{O}_{5}$ concentration more than 0.5 
mol\% acts as a network modifier in the glass structure (confirmed by XPS and FT-IR). Network modifier leads to formation of NBO in the glass network [4] which increases net electron charge density. As a result, zeta potential increases for adding excess amount of $\mathrm{Ta}_{2} \mathrm{O}_{5}$ in the glass structure. $\mathrm{Ta}_{2} \mathrm{O}_{5}$ concentration up to $0.5 \mathrm{~mol} \%$ acts as a network former.

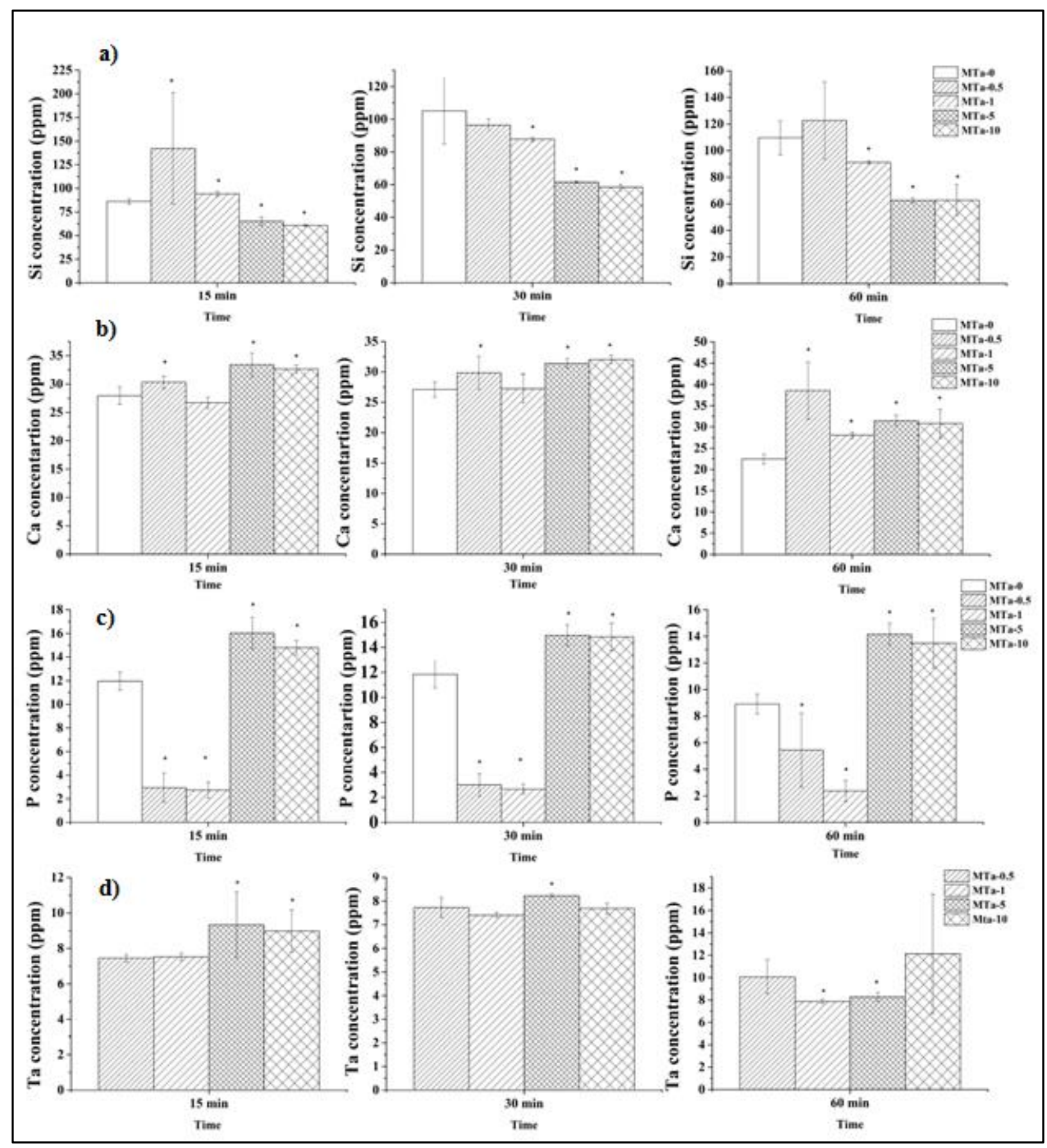

Figure 4.15: Ion release profiles for $\mathrm{Ta}_{2} \mathrm{O}_{5}$ doped MBGs: a) Silicon, b) Calcium, c) Phosphorus and d) Tantalum ions. 
Ion release profiles are shown in Figure 4.15 for $\mathrm{Si}, \mathrm{Ca}, \mathrm{P}$ and $\mathrm{Ta}$ ions respectively. After 15 minutes, maximum silicon ion is released from MTa-0.5 glass (142 ppm) which is statistically significant with respect to MTa-0 (86 ppm) (p < 0.05). MTa-1, MTa-5 and MTa-10 glasses release significantly less silicon ions, compared to MTa- 0 , for all time intervals. MTa-0 glass can release more silicon ions compared to MTa-1, MTa-5 and MTa-10 glasses because it contains more silicon than other glasses. MTa-0 glass and MTa- 0.5 glass could release almost similar amount of silicon ion (as 58 and 29 ppm standard deviation are observed for MTa-0.5 glass after 15 and 60 mins respectively). Surface area of MTa-0 and MTa- 0.5 glasses play a vital role in this case for releasing more silicon ions compared to other glasses.

Calcium and phosphate ions concentration from different MBGs reduce after 15, 30 and 60 mins which was not expected (Figure 4.15 b). It is very likely that there is a development of calcium phosphate compounds on the surface of the glasses [41]. These compounds impede the further dissolution of ions, which also explains why other ions do not increase in concentration greatly between $15 \mathrm{mins}$ and 60mins. Tantalum ion release from MTa-0.5, MTa-1, MTa-5 and MTa-10 glasses are shown in Figure 4.15 d. MTa-10 glass can release more tantalum ion after 15, 30 and 60 mins compared to MTa-0.5, MTa-1 and MTa-5 glasses. MTa-10 glass contains more tantalum than other glasses which helps to release more tantalum ions. After analyzing the ion release profiles it can be summarized that ions released from MBGs containing increasing amounts of tantalum show decreasing trends for silicon ion release and increasing trend for tantalum ion release. Ion release profiles for calcium and phosphorus do not show any trend after 15, 30 and 60 min time intervals. The reasons for selecting these time intervals are explained in section 3.4.

Values of thromboelastographs for all samples are listed in Appendix I. R time efficiency is measured as the ratio of the $\mathrm{R}$ time of a sample in blood and $\mathrm{R}$ time of untreated blood. Table 4.10 shows R time efficiency of all samples. The result shows that Arista® is $91 \%$ more effective compared to no powder added in the TEG® cup. MTa- 0 glass is $58 \%$ more effective which is the highest among MTa series glasses. MTa-10 glass is $10 \%$ less effective compared to no powder added. The trend in the results are supported by BET surface area results (Table 4.8) as they both decrease as the tantalum content in samples is increased. The morphology of MBGs act as a molecular sieve for platelets and other blood clotting factors to combine. As surface area and continuous channel structure (Figure $4.10 \mathrm{a}$ and b) of MTa-0 and MTa-0.5 glasses are higher 
compared to MTa-5 and MTa-10 glasses, they are expected to perform better. MTa-10 glass possess low surface area and discontinuities in the channel structure which make this glass less effective than other MTa series glasses.

Table 4.10: $R$ time performance of different powder samples with respect to no powder added

\begin{tabular}{cc}
\hline Sample & $\boldsymbol{R}_{\text {Efficiency }}(\%)$ \\
\hline Arista ${ }^{\circledR}$ & $91 \%$ \\
MTa-0 & $58 \%$ \\
MTa-0.5 & $46 \%$ \\
MTa-1 & $26 \%$ \\
MTa-5 & $16 \%$ \\
MTa-10 & $-10 \%$ \\
\hline
\end{tabular}

The reason why $\mathrm{K}, \alpha$, and MA values are not discussed is due to the limitations in this method. $\mathrm{K}$ time had missing values for different trials i.e. the clot amplitude of some samples did not reach $20 \mathrm{~mm}$ to detect $\mathrm{K}$ time. Also, it was found that there was too much variation for $\alpha$ (standard deviation $\sim 16^{\circ}$ ) and MA (standard deviation $\sim 15 \mathrm{~mm}$ ) data values.

\subsection{Limitations of thromboelastography}

There are limitations of thromboelastography: when citrated mice blood was taken to a centrifuge tube, clots were detected on the syringes in most of the trials. After removing the clots, blood was transferred to the TEG® cup prior to the start of the experiment. Platelets are one of the main contributors for blood clotting as mentioned in section 1.6. Removing the blood clots before the experiment resulted a lot of the platelets being removed from the blood. This could be the reason of getting slower clot initiation time $(\mathrm{R})$ for some samples compared to others. K time would also be affected as lack of platelets would prevent the clot from reaching the $20 \mathrm{~mm}$ amplitude.

Another limitation of thromboelastography is in regards to the blood samples used. There was a lot of variation in the mice regarding gender, age, and body composition (fat\%) of mice, all of which affect the results [81]. This also sometimes made it difficult to get sufficient amount of blood (at least $720 \mu \mathrm{L}$ ) from each mouse to run the tests. 


\subsection{Summary}

A series of mesoporous bioactive glasses (MBGs) were successfully synthesized and characterized in terms of composition, structure and porosity. Preliminary work on hemostatic effects was also conducted. XRD shows that all glasses are amorphous, and do not produce any crystalline structure with the addition of tantalum. EDS and XPS data confirms the incorporation of tantalum into the glass structure. FTIR peaks, corresponding to the $\mathrm{Si}-\mathrm{O}$ bonds present in the glass matrices, have expected trends i.e. increasing $\mathrm{Ta}_{2} \mathrm{O}_{5}$ content reduces the intensity of $\mathrm{Si}-\mathrm{O}$ bending, symmetric and asymmetric stretching peaks. Conversely, increasing $\mathrm{Ta}_{2} \mathrm{O}_{5}$ concentration increases the intensity of the Si-NBO bonding peak. $\mathrm{Ta}_{2} \mathrm{O}_{5}$ acts as a network modifier in the glass structure. This result is also confirmed by the XPS high resolution O1s spectra.

Characterization of the mesostructure and porosity of the MBGs was performed using TEM and BET theory. TEM imaging supplied visual confirmation of the inner structure whereas BET quantified specific surface area and pore volume. The assumption being made here is that a higher surface area would be achievable if the mesoporous structure was more continuous within the sample. Any discontinuities in the architecture would lower the pore volume and surface area. Comparing TEM images of each set of glasses, the MBGs retain an ordered hexagonal structure. MTa-5 and MTa-10 glasses have more discontinuities in the structure. These discontinuities decrease surface area of MBGs. Lowest surface area is recorded for MTa-10 glass.

No steady state point was identified in the ion release analysis. A likely explanation is because the time interval chosen based on relevance to hemostat application was too short for high releasing of ions.

Preliminary blood coagulation study was investigated. Commercial hemostat Arista ${ }^{\circledR}$ performed better to achieve hemostasis. MTa- 0 and MTa- 0.5 glasses exhibited promising efficiency. However, thromboelastography has some limitations such as clot formation in the citrated blood prior to the start of the experiment, variations in the mice blood composition. Other lab tests (PT, aPTT, platelet aggregation) need to be completed to find out $\mathrm{Ta}_{2} \mathrm{O}_{5}$ doped MBGs positive or negative effect for hemostasis. 


\section{Conclusions and future work}

\subsection{Conclusions}

The effect of calcination heating rate on chemical and physical structure of MBGs was evaluated. Glass characterization techniques (XRD, EDS, XPS, FT-IR) revealed that calcination heating rate does not influence chemical composition of the MBGs. TEM and BET results confirmed that calcination heating rate influences the physical structure of MBGs. TEM provides visual confirmation of discontinuities and BET quantifies lower surface area of H-MBG compared to LMBG. $1^{\circ} \mathrm{C} / \mathrm{min}$ heating rate is best to get well ordered MBGs.

A low heating rate $\left(1^{\circ} \mathrm{C} / \mathrm{min}\right)$ was utilized to synthesize a series of $\mathrm{Ta}_{2} \mathrm{O}_{5}$ doped $\mathrm{MBGs}$. It was observed that MBGs containing $\mathrm{Ta}_{2} \mathrm{O}_{5}$ up to $0.5 \mathrm{~mol} \%$ (i.e. MTa-0, and 0.5) possess excellent surface area and pore volume compared to MTa-1, 5 and 10 glasses. $\mathrm{Ta}_{2} \mathrm{O}_{5}$ concentration more than $0.5 \mathrm{~mol} \%$ acts as a network modifier which reduces surface area of MBGs. Whole blood hemostatic assay showed that commercial hemostat Arista® can start immediate blot clot formation. After that MTa-0 and MTa-0.5 exhibited promising results, as these glasses surface area was high (373.87 and $373.98 \mathrm{~m}^{2} / \mathrm{g}$ respectively) compared to MTa-1, 5 and 10 glasses. The porous structure and less discontinuity of MTa-0 and MTa-0.5 MBGs can facilitate water absorption from the blood and can concentrate platelets by acting as a molecular sieve for the platelets to aggregate [85]. These physical properties of MBGs leads to the extrinsic pathway of blood coagulation cascade. Negative zeta potential and the presence of Si-OH group on the MBGs surface can initiate the intrinsic pathway of blood coagulation cascade [80]. MTa-1, 5 and 10 glasses also possess negative zeta potential and contain Si-OH group in their surfaces. However, glasses having lower surface area and discontinuity in the channel structure cannot be as effective as MTa-0 and MTa-0.5 glasses. Because of these discontinuities, MBGs will not be able to act as a molecular sieve to combine more platelets. Thromboelastography revealed that low concentration of $\mathrm{Ta}_{2} \mathrm{O}_{5}$ doped MBGs i.e. MTa- 0 and MTa- 0.5 could be a potential hemostatic agent.

\subsection{Recommendations for future work}

The whole blood coagulation study using mice blood was not satisfactory. There were several variables noted during that study which could affect thromboelastography results. The following are the recommendations for blood coagulation study and additional biological testing: 
a) Human blood can be used to run thromboelastography. It will be more convenient to get appropriate amounts of human blood to conduct a whole blood coagulation study. Ethical approval is in process to initiate blood coagulation study at St. Michael's Hospital, Toronto, Ontario, Canada, M5B 1W8.

b) There are other conventional tests such as PT, aPTT and platelet aggregation can be investigated to find out extrinsic and intrinsic pathway of blood coagulation process. The efficiency of $\mathrm{Ta}_{2} \mathrm{O}_{5}$ containing MBGs on hemostasis can be tested. It should be noted that thromboelastography is not the substitute for PT and aPTT test [81].

c) Cell viability study will be evaluated on fibroblast and osteoblast cells. Glass powder and extract samples will be assessed in cell viability study.

d) Infection of wounds can lead to serious complications. It can delay wound healing and antibacterial function is a property of an ideal hemostats. Antimicrobial analysis will be conducted for all MBG samples. 


\section{Appendix I}

Amount of precursor calculation for MTa-0 glass:

Molar composition for MTa-0 glass, $\mathrm{SiO}_{2}: \mathrm{CaO}: \mathrm{P}_{2} \mathrm{O}_{5}=80: 15: 5$

Let, $6.7 \mathrm{gm}$ of TEOS is equivalent to $80(\mathrm{~mol} \%) \mathrm{SiO}_{2}$. Density of TEOS is $0.933 \mathrm{~g} / \mathrm{mL}$ (Sigma Aldrich). So, the amount of TEOS =6.7/0.933 (i.e. $7.18 \mathrm{~mL}$ ).

Molar mass of TEOS is $208.33 \mathrm{~g} / \mathrm{mol}$.

The number of $\mathrm{SiO}_{2}$ moles $=6.7 / 208.33$ moles

The molar ratio of $\mathrm{CaO}$ to $\mathrm{SiO}_{2}=15 / 80$

Number of moles of $\mathrm{CaO}=15 / 80 \times 6.7 / 208.33$ moles

Molar mass of $\mathrm{Ca}\left(\mathrm{NO}_{3}\right)_{2} .4 \mathrm{H}_{2} \mathrm{O}=236.15 \mathrm{~g} / \mathrm{mol}$ (Sigma Aldrich)

So, the amount of $\mathrm{Ca}\left(\mathrm{NO}_{3}\right)_{2} .4 \mathrm{H}_{2} \mathrm{O}=236.15 \times 15 / 80 \times 6.7 / 208.33=1.42 \mathrm{~g}$

The molar ratio of $\mathrm{P}_{2} \mathrm{O}_{5}$ to $\mathrm{SiO}_{2}=5 / 80 \times 2$ (for 2 atoms of $\mathrm{P}$ )

Number of moles of $\mathrm{P}_{2} \mathrm{O}_{5}=5 / 80 \times 2 \times 6.7 / 208.33$ moles

Molar mass of $\left(\mathrm{C}_{2} \mathrm{H}_{5}\right)_{3} \mathrm{PO}_{4}=182.15 \mathrm{~g} / \mathrm{mol}$ (Sigma Aldrich)

The mass of $\left(\mathrm{C}_{2} \mathrm{H}_{5}\right)_{3} \mathrm{PO}_{4}=182.15 \times 5 / 80 \times 2 \times 6.7 / 208.33=0.73 \mathrm{~g}$

Density of $\left(\mathrm{C}_{2} \mathrm{H}_{5}\right)_{3} \mathrm{PO}_{4}=1.072 \mathrm{~g} / \mathrm{mL}$ (Sigma Aldrich)

So, the amount of $\left(\mathrm{C}_{2} \mathrm{H}_{5}\right)_{3} \mathrm{PO}_{4}=0.72 / 1.072=0.68 \mathrm{~mL}$

Example: amount of Tantalum precursor calculation for MTa- 0.5 glass

Number of moles of Tantalum $=0.5 / 79.5 \times 6.7 / 208.33 \times 2$ moles

Molar mass of $\mathrm{Ta}\left(\mathrm{OC}_{2} \mathrm{H}_{5}\right)_{5}=406.25 \mathrm{~g} / \mathrm{mol}$ (Sigma Aldrich) 
The mass of $\mathrm{Ta}\left(\mathrm{OC}_{2} \mathrm{H}_{5}\right)_{5}=0.5 / 79.5 \times 6.7 / 208.33 \times 2 \times 406.25 \mathrm{~g}$

Density of $\mathrm{Ta}\left(\mathrm{OC}_{2} \mathrm{H}_{5}\right)_{5}=1.566 \mathrm{~g} / \mathrm{mL}$ (Sigma Aldrich)

So, the amount of $\mathrm{Ta}\left(\mathrm{OC}_{2} \mathrm{H}_{5}\right)_{5}=0.10 \mathrm{Ml}$

\section{Thromboelastography data values}

\section{R time}

\begin{tabular}{|c|c|c|c|c|c|c|c|}
\hline Sample & & & $(\min )$ & & & Mean & STD. \\
\hline Arista ${ }^{\circledR}$ & 0.2 & 0.1 & 0.2 & 0.2 & 0.2 & 0.2 & 0.04 \\
\hline nothing & 1.5 & 1.9 & 1.8 & 4.1 & 2.2 & 2.3 & 1.04 \\
\hline MTa-0 & 0.4 & 0.3 & 0.9 & 1.8 & 1.3 & 0.9 & 0.63 \\
\hline nothing & 1.2 & 1.5 & 2.4 & 3.2 & 2 & 2.1 & 0.79 \\
\hline$M T a-0.5$ & 0.6 & 1.8 & 0.8 & 1.2 & 1.5 & 1.2 & 0.49 \\
\hline nothing & 2.2 & 2 & 3.3 & 2.3 & 2 & 2.4 & 0.54 \\
\hline$M T a-1$ & 2.7 & 2 & 0.2 & 0.8 & 1.3 & 1.4 & 0.98 \\
\hline nothing & 3 & 2.3 & 0.8 & 1.3 & 1.2 & 1.7 & 0.90 \\
\hline MTa-5 & 0.6 & 1.5 & 0.9 & 0.8 & 1.2 & 1.0 & 0.35 \\
\hline nothing & 1.3 & 1.8 & 1.1 & 2.2 & 0.7 & 1.4 & 0.59 \\
\hline MTa-10 & 1.6 & 0.8 & 3.5 & 1.2 & 1 & 1.6 & 1.09 \\
\hline nothing & 1.9 & 1.7 & 1.6 & 1.6 & 0.8 & 1.5 & 0.42 \\
\hline
\end{tabular}

K time

\begin{tabular}{cccccc}
\hline Sample & \multicolumn{5}{c}{$\boldsymbol{K}(\mathbf{m i n})$} \\
\hline Arista ${ }^{\circledR}$ & 2 & 0.8 & 1.2 & 1.6 & 1.1 \\
nothing & - & 19.1 & 2.1 & - & 12.8 \\
MTa-0 & 8.2 & 16.2 & - & 1.8 & 3.6 \\
nothing & 13.2 & 8.6 & - & 5.7 & 3.8 \\
MTa-0.5 & 4.8 & - & - & 2.1 & 3.3 \\
nothing & 6.2 & - & - & 4.6 & 3 \\
MTa-1 & 2.4 & - & 8.5 & 2.8 & 2.3 \\
nothing & 3.6 & 16.6 & 14.7 & 2.9 & 1.5 \\
MTa-5 & 2.7 & 9.9 & 6.4 & - & 5.7 \\
nothing & 3.8 & 8.8 & 1.8 & - & 4.2 \\
MTa-10 & 4.8 & - & 26.1 & 2.4 & 5.8 \\
nothing & 9.4 & 18.8 & 18.5 & 2.2 & 5.3 \\
\hline
\end{tabular}




\section{$\boldsymbol{\alpha}$}

\begin{tabular}{|c|c|c|c|c|c|c|c|}
\hline Sample & & & $\alpha\left({ }^{\circ}\right)$ & & & Mean & STD. \\
\hline Arista ${ }^{\circledR}$ & 76.8 & 82.9 & 77 & 78.1 & 78.8 & 78.72 & 2.48 \\
\hline nothing & 24 & 30.3 & 65.7 & 8.5 & 30.6 & 31.82 & 20.96 \\
\hline$M T a-0$ & 43.4 & 39.8 & 28.3 & 62.7 & 46.8 & 44.2 & 12.47 \\
\hline nothing & 43.7 & 41.6 & 20 & 40 & 52.9 & 39.64 & 12.06 \\
\hline$M T a-0.5$ & 43.2 & 15 & 33.9 & 58.5 & 48.7 & 39.86 & 16.51 \\
\hline nothing & 36 & 28.6 & 13 & 46.3 & 57.4 & 36.26 & 16.94 \\
\hline$M T a-1$ & 58.7 & 14.9 & 58 & 59.6 & 58.7 & 50.0 & 19.62 \\
\hline nothing & 52.2 & 25.1 & 45.5 & 57.8 & 70.3 & 50.18 & 16.72 \\
\hline MTa-5 & 60.1 & 30.3 & 38.3 & 41.2 & 38.5 & 41.68 & 11.07 \\
\hline nothing & 59.5 & 46.3 & 72.6 & 20.3 & 52.3 & 50.2 & 19.38 \\
\hline MTa-10 & 49.2 & 33.2 & 13 & 61 & 39.1 & 39.1 & 18.01 \\
\hline nothing & 40.9 & 30.6 & 37 & 64.5 & 42.6 & 43.12 & 12.81 \\
\hline
\end{tabular}

MA

\begin{tabular}{|c|c|c|c|c|c|c|c|}
\hline Sample & & & $A(\mathrm{~mm}$ & & & Mean & STD. \\
\hline Arista ${ }^{\circledR}$ & 22.9 & 37.1 & 53.8 & 30.5 & 39.6 & 36.8 & 11.51 \\
\hline nothing & 5.7 & 21.9 & 57.8 & 7.3 & 27.2 & 23.98 & 21.04 \\
\hline MTa-0 & 28.6 & 21.1 & 14.1 & 52.6 & 46.6 & 32.6 & 16.48 \\
\hline nothing & 23.5 & 26.1 & 15.1 & 47.1 & 50.6 & 32.48 & 15.54 \\
\hline MTa-0.5 & 45.5 & 16.7 & 9.9 & 41.5 & 43.4 & 31.4 & 16.76 \\
\hline nothing & 45.1 & 19.5 & 11.5 & 46.2 & 50.6 & 34.58 & 17.77 \\
\hline MTa-1 & 48.9 & 16.8 & 27 & 47.1 & 52.4 & 38.44 & 15.64 \\
\hline nothing & 51 & 23.1 & 25.3 & 53.6 & 58 & 42.2 & 16.64 \\
\hline$M T a-5$ & 52.2 & 26.4 & 40.2 & 16.9 & 41.4 & 35.42 & 13.83 \\
\hline nothing & 49.8 & 28 & 52.8 & 9.6 & 44 & 36.84 & 17.99 \\
\hline MTa-10 & 42.8 & 19.2 & 22 & 45.2 & 43.6 & 34.56 & 12.81 \\
\hline nothing & 35 & 23.7 & 21.5 & 56.9 & 43.8 & 36.18 & 14.66 \\
\hline
\end{tabular}




\section{References}

[1] Z. Abbasi, M.E. Bahroloolum, M.H. Shariat, R. Bagheri, Bioactive Glasses in Dentistry : A Review, J. Glas. Dent. A Rev. 2 (2015) 1-9.

[2] C. Vichery, J.-M. Nedelec, Bioactive Glass Nanoparticles: From Synthesis to Materials Design for Biomedical Applications, Materials (Basel). 9 (2016) 288. doi:10.3390/ma9040288.

[3] L.L. Hench, An Introduction to Bioceramics, 2nd ed., Imperial College Press, 2013.

[4] J. Serra, P. González, S. Liste, C. Serra, S. Chiussi, B. León, M. Pérez-Amor, H.O. Ylänen, M. Hupa, FTIR and XPS studies of bioactive silica based glasses, J. Non. Cryst. Solids. 332 (2003) 2027. doi:10.1016/j.jnoncrysol.2003.09.013.

[5] G. Kaur, O.P. Pandey, K. Singh, D. Homa, B. Scott, G. Pickrell, A review of bioactive glasses: Their structure, properties, fabrication and apatite formation, J. Biomed. Mater. Res. - Part A. 102 (2014) 254-274. doi:10.1002/jbm.a.34690.

[6] D.S. Brauer, Bioactive Glasses-Structure and Properties, Angew. Chemie Int. Ed. 54 (2015) 41604181. doi:10.1002/anie.201405310.

[7] C.T. Kresge, M.E. Leonowicz, W.J. Roth, J.C. Vartuli, J.S. Beck, Ordered mesoporous molecular sieves synthesized by a liquid-crystal template mechanism, Nature. 359 (1992) 710-712. doi:10.1038/359710a0.

[8] M.Z. David Levy, The Sol-Gel Handbook, 1st ed., Wiley-VCH Verlag GmbH \& Co. KGaA, Boschstr., 2015. doi:10.1002/9783527670819.

[9] X. Yan, C. Yu, X. Zhou, J. Tang, D. Zhao, Highly ordered mesoporous bioactive glasses with superior in vitro bone-forming bioactivities, Angew. Chemie - Int. Ed. 43 (2004) 5980-5984. doi:10.1002/anie.200460598.

[10] C. Wu, J. Chang, Multifunctional mesoporous bioactive glasses for effective delivery of therapeutic ions and drug/growth factors, J. Control. Release. $193 \quad$ (2014) 282-295. doi:10.1016/j.jconrel.2014.04.026.

[11] L.L. Sepulveda, P., Jones, J. R., \& Hench, Characterization of Melt-Derived 45S5 and sol-gelderived 58S Bioactive Glasses, J. Biomed. Mater. Res. (2001) 734-740. doi:10.1002/jbm.0000.

[12] T.S. K. S. W. Sing, D. H. Everett, R. A. W. Haul, L. Moscou, R. A. Pierotti, J. Rouquerol, IUPAC. Gas/solid systems with special reference to the determination of surface area and porosity, Pure 
Appl. Chem. 57 (1985) 603-619. doi:10.1351/pac198557040603.

[13] Y. Li, Y.Z. Liu, T. Long, X. Bin Yu, T.T. Tang, K.R. Dai, B. Tian, Y.P. Guo, Z.A. Zhu, Mesoporous bioactive glass as a drug delivery system: Fabrication, bactericidal properties and biocompatibility, J. Mater. Sci. Mater. Med. 24 (2013) 1951-1961. doi:10.1007/s10856-013-4960-z.

[14] M. Alcaide, P. Portolés, A. López-Noriega, D. Arcos, M. Vallet-Regí, M.T. Portolés, Interaction of an ordered mesoporous bioactive glass with osteoblasts, fibroblasts and lymphocytes, demonstrating its biocompatibility as a potential bone graft material, Acta Biomater. 6 (2010) 892-899. doi:10.1016/j.actbio.2009.09.008.

[15] J. Ye, J. He, C. Wang, K. Yao, Z. Gou, Copper-containing mesoporous bioactive glass coatings on orbital implants for improving drug delivery capacity and antibacterial activity, Biotechnol. Lett. 36 (2014) 961-968. doi:10.1007/s10529-014-1465-x.

[16] Y. Zhang, L. Chen, M. Shi, D. Zhai, H. Zhu, J. Chang, C. Wu, X. Zheng, J. Yin, Mesoporous Bioactive Glass Nanolayer-Modified Zirconia Coatings on Ti-6Al-4V with Improved In Vitro Bioactivity, Int. J. Appl. Glas. Sci. 7 (2016) 216-228. doi:10.1111/ijag.12210.

[17] M. Manzano, M. Vallet-Regí, New developments in ordered mesoporous materials for drug delivery, J. Mater. Chem. 20 (2010) 5593. doi:10.1039/b922651f.

[18] G. Kaur, G. Pickrell, N. Sriranganathan, V. Kumar, D. Homa, Review and the state of the art: Solgel and melt quenched bioactive glasses for tissue engineering, J. Biomed. Mater. Res. - Part B Appl. Biomater. 104 (2016) 1248-1275. doi:10.1002/jbm.b.33443.

[19] L.L. Hench, J.K. West, The sol-gel process, Chem. Rev. 90 (1990) 33-72. doi:10.1021/cr00099a003.

[20] A.S. and H.F. C. Jeffrey Brinker, Yunfeng Lu, Evaporation-Induced Self-Assembly: Nanostructures Made Easy, Adv. Mater. 11 (1999) 579-585. doi:10.1002/(SICI)15214095(199905)11:7<579::AID-ADMA579>3.0.CO;2-R.

[21] L.M. Mukundan, R. Nirmal, D. Vaikkath, P.D. Nair, A new synthesis route to high surface area sol gel bioactive glass through alcohol washing: a preliminary study, Biomatter. 3 (2013) 1-10. doi:10.4161/biom.24288.

[22] P. González, J. Serra, S. Liste, S. Chiussi, B. León, M. Pérez-Amor, Raman spectroscopic study of bioactive silica based glasses, J. Non. Cryst. Solids. 320 (2003) 92-99. doi:10.1016/S00223093(03)00013-9. 
[23] K.M. Van De Graaff, R. Ward Rhees, Schaum's Easy Outlines: Human Anatomy and Physiology, (2011) 104. doi:10.1036/0071406069.

[24] D.C. Rizzo, Fundamentals of Anatomy Physiology, Third, 2010.

[25] P. Ian, N. Muralitharan, Fundamentals of Anatomy and Physiology - For Nursing and Healthcare Students, Second, Wiley Blackwell, 2017.

[26] J.H. Levy, Hemostatic agents, Transfusion. 44 (2004) 58S-62S. doi:10.1111/j.00411132.2004.04173.x.

[27] J.F. Kragh, D.G. Baer, T.J. Walters, Extended (16-hour) tourniquet application after combat wounds: A case report and review of the current literature, J. Orthop. Trauma. 21 (2007) 274-278. doi:10.1097/BOT.0b013e3180437dd9.

[28] H. Khoshmohabat, S. Paydar, H.M. Kazemi, B. Dalfardi, Overview of agents used for emergency hemostasis, Trauma Mon. 21 (2016). doi:10.5812/traumamon.26023.

[29] H.R. Champion, R.F. Bellamy, C.P. Roberts, A. Leppaniemi, A profile of combat injury., J. Trauma. 54 (2003) S13-S19. doi:10.1097/01.TA.0000057151.02906.27.

[30] J.A. Evans, K.J.P. Van Wessem, D. McDougall, K.A. Lee, T. Lyons, Z.J. Balogh, Epidemiology of traumatic deaths: Comprehensive population-based assessment, World J. Surg. 34 (2010) 158-163. doi:10.1007/s00268-009-0266-1.

[31] B.S. Kheirabadi, M.R. Scherer, J.S. Estep, M.A. Dubick, J.B. Holcomb, Determination of efficacy of new hemostatic dressings in a model of extremity arterial hemorrhage in swine, J. Trauma - Inj. Infect. Crit. Care. 67 (2009) 450-459. doi:10.1097/TA.0b013e3181ac0c99.

[32] A. Mehrabadi, S. Liu, S. Bartholomew, J.A. Hutcheon, M.S. Kramer, R.M. Liston, K.S. Joseph, Temporal Trends in Postpartum Hemorrhage and Severe Postpartum Hemorrhage in Canada From 2003 to 2010, J. Obstet. Gynaecol. Canada. 36 (2014) 21-33. doi:10.1016/S1701-2163(15)306800.

[33] K.J.P. David J. Perry, Hemostasis and Thrombosis Protocols, Springer Sci. Bus. Media. 31 (1999) $3,15-16$.

[34] S. Pourshahrestani, E. Zeimaran, I. Djordjevic, N.A. Kadri, M.R. Towler, Inorganic hemostats: The state-of-the-art and recent advances, Mater. Sci. Eng. C. 58 (2016) 1255-1268. doi:10.1016/j.msec.2015.09.008. 
[35] P.C.D. and P.M.M. C.Th. Smit Sibinga, Coagulation and Blood Transfusion, 1992. doi:10.1097/00001721-199206000-00015.

[36] B. Furie, B.C. Furie, Mechanisms of Thrombus Formation, N. Engl. J. Med. 359 (2008) 938-949. doi:10.1056/NEJMra0801082.

[37] D.S. Kauvar, C.E. Wade, The epidemiology and modern management of traumatic hemorrhage: US and international perspectives, Crit. Care. 9 (2005) 1-9. doi:10.1186/cc3779.

[38] B. Kheirabadi, Evaluation of topical hemostatic agents for combat wound treatment, US Army Med. Dep. J. (2011).

[39] C. Wu, J. Chang, Mesoporous bioactive glasses: structure characteristics, drug/growth factor delivery and bone regeneration application., Interface Focus. 2 (2012) 292-306. doi:10.1098/rsfs.2011.0121.

[40] M.M. Pereira, A.E. Clark, L.L. Hench, Effect of Texture on the Rate of Hydroxyapatite Formation on Gel-Silica Surface, J. Am. Ceram. Soc. 78 (1995) 2463-2468. doi:10.1111/j.11512916.1995.tb08686.x.

[41] I. Izquierdo-Barba, A.J. Salinas, M. Vallet-Regí, Bioactive Glasses: From Macro to Nano, Int. J. Appl. Glas. Sci. 4 (2013) 149-161. doi:10.1111/ijag.12028.

[42] A. Mahajna, M. Hirsh, M.M. Krausz, Use of the hemostatic agent QuikClot ${ }^{\circledR}$ for the treatment of massive splenic injury in a rat model, Eur. Surg. Res. 39 (2007) 251-257. doi:10.1159/000102590.

[43] A.T. Don Johnson, Brian Gegel, James Burgert, John Gasko, Carrie Cromwell, Monika Jaskowska, Rachel Steward, The Efficacy of QuikClot Combat Gauze, Fluid Resuscitation and Movement on Hemorrhage Control in a Porcine Model, Ann. Med. Surg. 3 (2014) 21-5. doi:10.1016/j.amsu.2014.03.001.

[44] M.A. Schreiber, D.J. Neveleff, Achieving hemostasis with topical hemostats: Making clinically and economically appropriate decisions in the surgical and trauma settings, AORN J. 94 (2011) S1-S20. doi:10.1016/j.aorn.2011.09.018.

[45] Y.J. Zhang, B. Gao, X.W. Liu, Topical and effective hemostatic medicines in the battlefield, Int. J. Clin. Exp. Med. 8 (2015) 10-19.

[46] W.D. Spotnitz, S. Burks, Surgical Toolbox, Transfusion. 48 (2008) 1502-1516. doi:10.1111/j.15372995.2008.01703.x. 
[47] H.T. Spencer, J.T. Hsu, D.R. McDonald, L.I. Karlin, Intraoperative anaphylaxis to gelatin in topical hemostatic agents during anterior spinal fusion: a case report., Spine J. 12 (2012) e1-6. doi:10.1016/j.spinee.2012.08.425.

[48] R.W.J. Millner, A.S. Lockhart, H. Bird, C. Alexiou, A New Hemostatic Agent: Initial Life-Saving Experience With Celox (Chitosan) in Cardiothoracic Surgery, Ann. Thorac. Surg. 87 (2009) e13e14. doi:10.1016/j.athoracsur.2008.09.046.

[49] T. M. Ways, W. Lau, V. Khutoryanskiy, Chitosan and Its Derivatives for Application in Mucoadhesive Drug Delivery Systems, Polymers $\quad$ (Basel). $10 \quad$ (2018) 267. doi:10.3390/polym10030267.

[50] J.H. John Holcomb, Martin MacPhee, Stephen Hetz, Richard Harris, Anthony Pusateri, Efficacy of a Dry Fibrin Sealant Dressing for Hemorrhage Control After Ballistic Injury, 133 (1998) 32-35.

[51] B.A. Bruckner, L.N. Blau, L. Rodriguez, E.E. Suarez, U.Q. Ngo, M.J. Reardon, M. Loebe, Microporous polysaccharide hemosphere absorbable hemostat use in cardiothoracic surgical procedures, J. Cardiothorac. Surg. 9 (2014) 134. doi:10.1186/s13019-014-0134-4.

[52] M.R. Humphreys, E.P. Castle, P.E. Andrews, M.T. Gettman, M.H. Ereth, Microporous polysaccharide hemospheres for management of laparoscopic trocar injury to the spleen, Am. J. Surg. 195 (2008) 99-103. doi:10.1016/j.amjsurg.2007.03.006.

[53] T.L. Landsman, T. Touchet, S.M. Hasan, C. Smith, B. Russell, J. Rivera, D.J. Maitland, E. CosgriffHernandez, A shape memory foam composite with enhanced fluid uptake and bactericidal properties as a hemostatic agent, Acta Biomater. 47 (2017) 91-99. doi:10.1016/j.actbio.2016.10.008.

[54] Q. Chai, Y. Jiao, X. Yu, Hydrogels for Biomedical Applications: Their Characteristics and the Mechanisms behind Them, Gels. 3 (2017) 6. doi:10.3390/gels3010006.

[55] M.B.B. Monroe, A.D. Easley, K. Grant, G.K. Fletcher, C. Boyer, D.J. Maitland, Multifunctional Shape-Memory Polymer Foams with Bio-inspired Antimicrobials, ChemPhysChem. (2017) 1-11. doi:10.1002/cphc.201701015.

[56] D.G. Ahearn, D.T. Grace, M.J. Jennings, R.N. Borazjani, K.J. Boles, L.J. Rose, R.B. Simmons, E.N. Ahanotu, Effects of hydrogel/silver coatings on in vitro adhesion to catheters of bacteria associated with urinary tract infections, Curr. Microbiol. 41 (2000) 120-125. doi:10.1007/s002840010105.

[57] J.N. Rodriguez, F.J. Clubb, T.S. Wilson, M.W. Miller, T.W. Fossum, J. Hartman, E. Tuzun, P. Singhal, D.J. Maitland, In vivo response to an implanted shape memory polyurethane foam in a 
porcine aneurysm model, J. Biomed. Mater. Res. - Part A. 102 (2014) 1231-1242. doi:10.1002/jbm.a.34782.

[58] Z. Mirzakhanian, K. Faghihi, A. Barati, H.R. Momeni, Synthesis of superabsorbent hydrogel nanocomposites for use as hemostatic agent, Int. J. Polym. Mater. Polym. Biomater. 65 (2016) 779788. doi:10.1080/00914037.2016.1171218.

[59] S.E. Gautier, M. Oudega, M. Fragoso, P. Chapon, G.W. Plant, M.B. Bunge, J. Parel -M., Poly(ahydroxyacids) for Application in the Spinal Cord: Resorbability and Biocompatability with Adult Rat Schwann Cells and Spinal Cord, J. Biomed. Mater. Res. 42 (1998) 642-654. http://onlinelibrary.wiley.com/store/10.1002/(SICI)1097-4636(19981215)42:4\%3C642::AIDJBM22\%3E3.0.CO;2K/asset/22_ftp.pdf?v=1\&t=hsqcukoj\&s=15a00ef962c6980b2e0bde5d90c76dd773d058f0.

[60] N. Annabi, Y.N. Zhang, A. Assmann, E.S. Sani, G. Cheng, A.D. Lassaletta, A. Vegh, B. Dehghani, G.U. Ruiz-Esparza, X. Wang, S. Gangadharan, A.S. Weiss, A. Khademhosseini, Engineering a highly elastic human protein-based sealant for surgical applications, Sci. Transl. Med. 9 (2017). doi:10.1126/scitranslmed.aai7466.

[61] N. Annabi, S.M. Mithieux, P. Zorlutuna, G. Camci-Unal, A.S. Weiss, A. Khademhosseini, Engineered cell-laden human protein-based elastomer, Biomaterials. 34 (2013) 5496-5505. doi:10.1016/j.biomaterials.2013.03.076.

[62] K.E. You, M.A. Koo, D.H. Lee, B.J. Kwon, M.H. Lee, S.H. Hyon, Y. Seomun, J.T. Kim, J.C. Park, The effective control of a bleeding injury using a medical adhesive containing batroxobin, Biomed. Mater. 9 (2014). doi:10.1088/1748-6041/9/2/025002.

[63] V.A. Kumar, N.C. Wickremasinghe, S. Shi, J.D. Hartgerink, Nanofibrous Snake Venom Hemostat, ACS Biomater. Sci. Eng. 1 (2015) 1300-1305. doi:10.1021/acsbiomaterials.5b00356.

[64] S. Leonardo, B. Prieto-Simón, M. Campàs, Past, present and future of diatoms in biosensing, TrAC - Trends Anal. Chem. 79 (2016) 276-285. doi:10.1016/j.trac.2015.11.022.

[65] C. Feng, J. Li, G.S. Wu, Y.Z. Mu, M. Kong, C.Q. Jiang, X.J. Cheng, Y. Liu, X.G. Chen, ChitosanCoated Diatom Silica as Hemostatic Agent for Hemorrhage Control, ACS Appl. Mater. Interfaces. 8 (2016) 34234-34243. doi:10.1021/acsami.6b12317.

[66] E.D. Cox, M.A. Schreiber, J. McManus, C.E. Wade, J.B. Holcomb, New hemostatic agents in the combat setting, Transfusion. 49 (2009). doi:10.1111/j.1537-2995.2008.01988.x. 
[67] G.R. Mueller, T.J. Pineda, H.X. Xie, J.S. Teach, A.D. Barofsky, J.R. Schmid, K.W. Gregory, A novel sponge-based wound stasis dressing to treat lethal noncompressible hemorrhage, J. Trauma Acute Care Surg. 73 (2012). doi:10.1097/TA.0b013e3182617c3c.

[68] J. Wang, S. Hao, T. Luo, Q. Yang, B. Wang, Development of feather keratin nanoparticles and investigation of their hemostatic efficacy, Mater. Sci. Eng. C. 68 (2016) 768-773. doi:10.1016/j.msec.2016.07.035.

[69] V. Saucedo-Rivalcoba, A.L. Martínez-Hernández, G. Martínez-Barrera, C. Velasco-Santos, V.M. Castaño, (Chicken feathers keratin)/polyurethane membranes, Appl. Phys. A Mater. Sci. Process. 104 (2011) 219-228. doi:10.1007/s00339-010-6111-4.

[70] E. Fröhlich, Action of Nanoparticles on Platelet Activation and Plasmatic Coagulation., Curr. Med. Chem. 23 (2016) 408-30. http://www.ncbi.nlm.nih.gov/pubmed/26063498.

[71] J. R. Baylis, A. Finkelstein-Kulka, L. Macias-Valle, J. Manji, M. Lee, E. Levchenko, C. Okpaleke, S. Al-Salihi, A. Javer, C. J. Kastrup, Rapid hemostasis in a sheep model using particles that propel thrombin and tranexamic acid, Laryngoscope. 127 (2017) 787-793. doi:10.1002/lary.26408.

[72] A. Momeni, M.J. Filiaggi, Degradation and hemostatic properties of polyphosphate coacervates, Acta Biomater. 41 (2016) 328-341. doi:10.1016/j.actbio.2016.06.002.

[73] J. Bertram, C. Williams, Synthetic Platelets: Nanotechnology to Halt Bleeding, Sci. Transl. Med. 1 (2009) 1-17. doi:10.1126/scitranslmed.3000397.Synthetic.

[74] H. Mohri, T. Ohkubo, The role of the RGD peptides and the $\gamma$ chain peptide of fibrinogen on fibrinogen binding to activated platelets, Peptides. 14 (1993) 353-357. doi:10.1016/01969781(93)90052-I.

[75] J. Bertram, C. Williams, Synthetic Platelets: Nanotechnology to Halt Bleeding, Sci. Transl. ... 1 (2009) 1-17. doi:10.1126/scitranslmed.3000397.Synthetic.

[76] https://pubchem.ncbi.nlm.nih.gov/compound/Arg-gly-asp\#section=Top, (n.d.).

[77] Z.B. Demirekin, U.A. Sezer, D.U. Karatopuk, S. Sezer, Development of Metal Ion Binded Oxidized Regenerated Cellulose Powder as Hemostatic Agent: A Comparative Study with in Vivo Performance, Ind. Eng. Chem. Res. 54 (2015) 4906-4914. doi:10.1021/ie504985b.

[78] X. Wu, J. Wei, X. Lu, Y. Lv, F. Chen, Y. Zhang, C. Liu, Chemical characteristics and hemostatic performances of ordered mesoporous calcium-doped silica xerogels, Biomed. Mater. 5 (2010). 
doi:10.1088/1748-6041/5/3/035006.

[79] T.A. Ostomel, Q. Shi, G.D. Stucky, Oxide hemostatic activity, J. Am. Chem. Soc. 128 (2006) 83848385. doi:10.1021/ja061717a.

[80] T.A. Ostomel, Q. Shi, C.K. Tsung, H. Liang, G.D. Stucky, Spherical bioactive glass with enhanced rates of hydroxyapatite deposition and hemostatic activity, Small. 2 (2006) 1261-1265. doi:10.1002/smll.200600177.

[81] L.T. da Luz, B. Nascimento, S. Rizoli, Thrombelastography (TEG): practical considerations on its clinical use in trauma resuscitation, Scand. J. Trauma, Resusc. Emerg. Med. 21 (2013) 29. doi:http://dx.doi.org/10.1186/1757-7241-21-29.

[82] T.A. Ostomel, Q. Shi, P.K. Stoimenov, G.D. Stucky, Metal oxide surface charge mediated hemostasis, Langmuir. 23 (2007) 11233-11238. doi:10.1021/la701281t.

[83] G. Hu, L. Xiao, P. Tong, D. Bi, H. Wang, H. Ma, G. Zhu, H. Liu, Antibacterial hemostatic dressings with nanoporous bioglass containing silver, Int. J. Nanomedicine. 7 (2012) 2613-2620. doi:10.2147/IJN.S31081.

[84] C. Dai, Y. Yuan, C. Liu, J. Wei, H. Hong, X. Li, X. Pan, Degradable, antibacterial silver exchanged mesoporous silica spheres for hemorrhage control, Biomaterials. 30 (2009) 5364-5375. doi:10.1016/j.biomaterials.2009.06.052.

[85] S. Pourshahrestani, E. Zeimaran, N. Adib Kadri, N. Gargiulo, S. Samuel, S.V. Naveen, T. Kamarul, M.R. Towler, Gallium-containing mesoporous bioactive glass with potent hemostatic activity and antibacterial efficacy, J. Mater. Chem. B. 4 (2016) 71-86. doi:10.1039/C5TB02062J.

[86] S. Pourshahrestani, E. Zeimaran, N.A. Kadri, N. Gargiulo, H.M. Jindal, S.V. Naveen, S.D. Sekaran, T. Kamarul, M.R. Towler, Potency and Cytotoxicity of a Novel Gallium-Containing Mesoporous Bioactive Glass/Chitosan Composite Scaffold as Hemostatic Agents, ACS Appl. Mater. Interfaces. 9 (2017) 31381-31392. doi:10.1021/acsami.7b07769.

[87] O.C.T. Hoffmann Roger W, Tantalum oxide composition, US2491416 A, 1949.

[88] James A. Patterson, Method for applying a blood clotting agent, US6521265 B1, 2013.

[89] J.J.C. PETER B. SAMUELS, HERBERT ROEDLING, ROBERT KATZ, A New Hemostatic Clip : 2-Year Review of 1007 Cases, (1966) 427-431.

[90] S. V. Kantsevoy, M. Bitner, G. Hajiyeva, P.M. Mirovski, M.E. Cox, T. Swope, K. Alexander, N. 
Meenaghan, J.L. Fitzpatrick, V. Gushchin, Endoscopic management of colonic perforations: clips versus suturing closure (with videos), Gastrointest. Endosc. 84 (2016) 487-493. doi:10.1016/j.gie.2015.08.074.

[91] A. Tilocca, A.N. Cormack, Structural effects of phosphorus inclusion in bioactive silicate glasses, J. Phys. Chem. B. 111 (2007) 14256-14264. doi:10.1021/jp075677o.

[92] M. Araújo, M. Miola, G. Baldi, J. Perez, E. Verné, Bioactive glasses with low Ca/P ratio and enhanced bioactivity, Materials (Basel). 9 (2016). doi:10.3390/ma9040226.

[93] A.M. Alhalawani, C. Mehrvar, W. Stone, S.D. Waldman, M.R. Towler, A novel tantalumcontaining bioglass. Part II. Development of a bioadhesive for sternal fixation and repair, Mater. Sci. Eng. C. 71 (2017) 401-411. doi:10.1016/j.msec.2016.10.024.

[94] H.O. Ylänen, Bioactive glasses Materials, properties and applications, 1st ed., Woodhead Publishing Limited, 2011.

[95] I. Farooq, Z. Imran, U. Farooq, A. Leghari, H. Ali, Bioactive Glass: A Material for the Future, World J. Dent. 3 (2012) 199-201. doi:10.5005/jp-journals-10015-1156.

[96] M.D. O’Donnell, S.J. Watts, R.G. Hill, R. V. Law, The effect of phosphate content on the bioactivity of soda-lime- phosphosilicate glasses, J. Mater. Sci. Mater. Med. 20 (2009) 1611-1618. doi:10.1007/s10856-009-3732-2.

[97] A.P.T. Mohamed N. Rahaman, Delbert E. Day, B. Sonny Bal, Qiang Fu, Steven B. Jung, Lynda F. Bonewald, Bioactive glass in tissue engineering, J. Mater. Sci. Mater. Med. 24 (2013) 669-676. doi:10.1016/j.actbio.2011.03.016.Bioactive.

[98] C.J. Shih, H.T. Chen, L.F. Huang, P.S. Lu, H.F. Chang, I.L. Chang, Synthesis and in vitro bioactivity of mesoporous bioactive glass scaffolds, Mater. Sci. Eng. C. 30 (2010) 657-663. doi:10.1016/j.msec.2010.02.006.

[99] S.O. Majekodunmi, A Review on Centrifugation in the Pharmaceutical Industry, Am. J. Biomed. Eng. 5 (2015) 67-78. doi:10.5923/j.ajbe.20150502.03.

[100] A.M. El-Kady, A.F. Ali, Fabrication and characterization of $\mathrm{ZnO}$ modified bioactive glass nanoparticles, Ceram. Int. 38 (2012) 1195-1204. doi:10.1016/j.ceramint.2011.07.069.

[101] A. Philippart, E. Boccardi, L. Pontiroli, A.M. Beltrán, A. Inayat, C. Vitale-Brovarone, W. Schwieger, E. Spiecker, A.R. Boccaccini, Development of Novel Mesoporous Silica-Based 
Bioactive Glass Scaffolds with Drug Delivery Capabilities, Adv. Sci. Technol. 96 (2014) 54-60. doi:10.4028/www.scientific.net/AST.96.54.

[102] A.T. Shah, Q. Ain, A.A. Chaudhry, A.F. Khan, B. Iqbal, S. Ahmad, S.A. Siddiqi, I. ur Rehman, A study of the effect of precursors on physical and biological properties of mesoporous bioactive glass, J. Mater. Sci. 50 (2015) 1794-1804. doi:10.1007/s10853-014-8742-x.

[103] J. Perez-Pariente, F. Balas, M. Vallet-Regi, Surface and chemical study of SiO2 $\cdot \mathrm{P} 2 \mathrm{O} 5 \cdot \mathrm{CaO} \cdot(\mathrm{MgO})$ bioactive glasses, Chem. Mater. 12 (2000) 750-755. doi:10.1021/cm9911114.

[104] G.D. Boon, An overview of hemostasis, Toxicol. Pathol. 21 (1993) 170-179. doi:10.1177/019262339302100209.

[105] L.L. Hench, R.J. Splinter, W.C. Allen, T.K. Greenlee, Bonding mechanisms at the interface of ceramic prosthetic materials, J. Biomed. Mater. Res. 5 (1971) 117-141. doi:10.1002/jbm.820050611.

[106] P. González, J. Serra, S. Liste, S. Chiussi, B. León, M. Pérez-Amor, Raman spectroscopic study of bioactive silica based glasses, J. Non. Cryst. Solids. 320 (2003) 92-99. doi:10.1016/S00223093(03)00013-9.

[107] J.E. Lovelock, B.M. Porterfield, Blood clotting: the function of electrolytes and of calcium, Biochem. J. 50 (1952) 415-420.

[108] R. Phetnin, S.T. Rattanachan, Preparation and antibacterial property on silver incorporated mesoporous bioactive glass microspheres, J. Sol-Gel Sci. Technol. 75 (2015) 279-290. doi:10.1007/s10971-015-3697-1.

[109] N. Gargiulo, A.M. Cusano, F. Causa, D. Caputo, P.A. Netti, Silver-containing mesoporous bioactive glass with improved antibacterial properties, J. Mater. Sci. Mater. Med. 24 (2013) 2129-2135. doi:10.1007/s10856-013-4968-4.

[110] M.M. Levi, R. Vink, E. de Jonge, Management of bleeding disorders by prohemostatic therapy., Int. J. Hematol. 76 Suppl 2 (2002) 139-144. doi:10.1007/BF03165104.

[111] Haemonetics Corporation, TEG 5000 Hemostasis analyzer system, (2011) 3-5. http://www.haemonetics.com/ /media/sharepoint/devices/teg/marketing/brochures/teg5000_broch ure/col-pp-000078-us_teg_brochure.pdf.ashx.

[112] J.F. and H.N. Tyler W. Stratton, Guangheng Zhu, Yiming Wang, Pingguo Chen, Miguel A.D. 
Neves, Reid C. Gallant, Peter A.A. Norris, Novel mechanism of thrombosis : Role of the $\beta 3$ integrin PSI domain in blood coagulation, in: 4th Bienn. Summit Thromb. Hemost. Soc. North Am., San Diego, California, 2018: p. 3.

[113] NIST X-ray Photoelectron Spectroscopy Database, (2012). doi:10.18434/T4T88K.

[114] J. Serra, P. González, S. Liste, S. Chiussi, B. León, M. Pérez-Amor, H.O. Ylänen, M. Hupa, Influence of the non-bridging oxygen groups on the bioactivity of silicate glasses, J. Mater. Sci. Mater. Med. 13 (2002) 1221-1225. doi:10.1023/A:1021174912802.

[115] I. Standard, Determination of the specific surface area of solids by gas adsorption-BET method (ISO 9277), 2010 (2010).

[116] X. Huang, N.P. Young, H.E. Townley, Characterization and Comparison of Mesoporous Silica Particles for Optimized Drug Delivery, Nanomater. Nanotechnol. 4 (2014) 2. doi:10.5772/58290.

[117] L.L. Hench, An Introduction to Bioceramics, 2nd Editio, Imperial College Press, 2013. doi:10.1017/CBO9780511623806.

[118] Micromeritics Instrument Corporation, Gas Adsorption Theory, http://www.micromeritics.com/Repository/Files/Gas_Adsorption_Theory_poster.pdf. (1AD) 1.

[119] A. Doostmohammadi, A. Monshi, R. Salehi, M.H. Fathi, Z. Golniya, A.U. Daniels, Bioactive glass nanoparticles with negative zeta potential, Ceram. Int. 37 (2011) 2311-2316. doi:10.1016/j.ceramint.2011.03.026.

[120] Zeta Potential of Colloids in Water and Waste Water, Am. Soc. Test. Mater. ASTM Stand. D. 418782 (1985). 